US Army Corps of Engineers ${ }_{\circledast}$ Engineer Research and Development Center

\title{
Hydroacoustic Evaluation of Juvenile
} Salmonid Passage Through Experimental Routes at Bonneville Dam in 1998

Gene R. Ploskey, William T. Nagy, Larry R. Lawrence, January 2001

Deborah S. Patterson, Carl R. Schilt, Peter N. Johnson, and John R. Skalski 
The contents of this report are not to be used for advertising, publication, or promotional purposes. Citation of trade names does not constitute an official endorsement or approval of the use of such commercial products.

The findings of this report are not to be construed as an official Department of the Army position, unless so designated by other authorized documents. 


\title{
Hydroacoustic Evaluation of Juvenile Salmonid Passage Through Experimental Routes at Bonneville Dam in 1998
}

\author{
by Gene R. Ploskey, William T. Nagy, Larry R. Lawrence \\ Environmental Laboratory \\ U.S. Army Engineer Research and Development Center \\ 3909 Halls Ferry Road \\ Vicksburg, MS 39180-6199 \\ Deborah S. Patterson \\ DynTel Corporation \\ 3530 Manor Drive, Suite 4 \\ Vicksburg, MS 39180 \\ Carl R. Schilt, Peter N. Johnson \\ AScl Corporation \\ 1365 Beverly Road \\ McLean, VA 22101 \\ John R. Skalski \\ University of Washington \\ Columbia Basin Branch, School of Fisheries \\ 1325 Fourth Avenue, Suite 1820 \\ Seattle, WA 98101-2509
}

Final report

Approved for public release; distribution is unlimited 


\section{Contents}

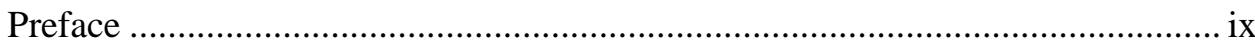

Conversion Factors, Non-SI to SI Units of Measurement ................................... xi

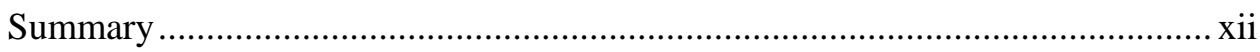

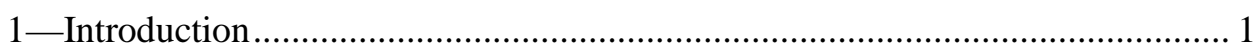

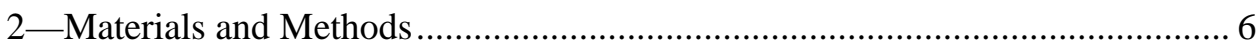

Prototype Surface Collector and Units 1-2 f.............................................. 6

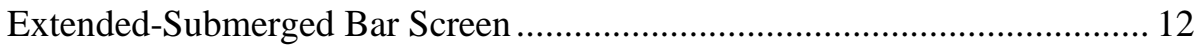

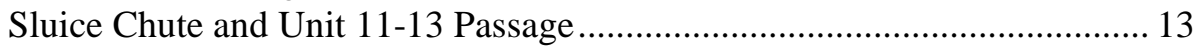

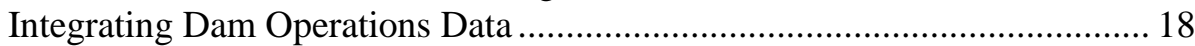

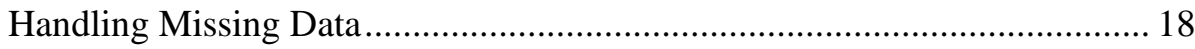

Fish Selection Criteria and Intertracker Bias .............................................. 19

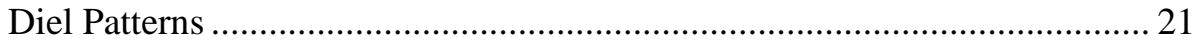

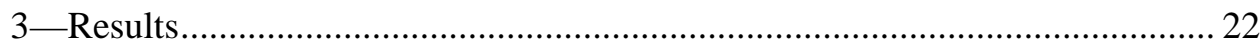

Prototype Surface Collector and Adjacent Units ........................................ 22

Extended-Submerged Bar Screen at Intake 8b ........................................ 31

Sluice Chute at Powerhouse 2 .................................................................. 35

Diel Trends in Efficiency and Passage ....................................................... 42

Prototype collector and adjacent units ................................................... 42

Extended-submerged bar screen ....................................................... 45

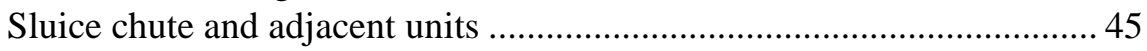

Intertracker Differences and Potential Bias ................................................... 49

Comparing Sluice-Chute and Deep-Slot Passage and Effectiveness ............. 53

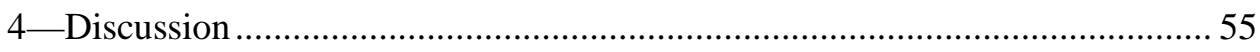

Prototype Surface Collector and Adjacent Turbine Units.............................. 55

Extended-Submerged Bar Screen at Intake 8b ...........................................5 58

Sluice Chute and Adjacent Units at Powerhouse 2...................................... 59

Comparing Sluice-Chute and In-turbine Estimates of PSC Passage

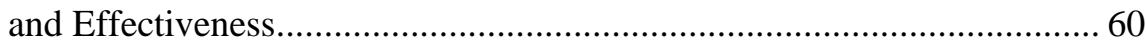


Appendix A: Detectability Modeling Results for All Deployed Transducers at Bonneville Dam in 1998.

Appendix B: Statistical Synopsis for Calculating Metrics and Testing

\section{List of Figures}

Figure 1. Front views of transducer deployments at 20- and 5-ft-wide slot openings in the PSC and a side view of a typical up- and downlooking pair of transducers

Figure 2. Cross section of one of six intakes at Units 3 and 5 showing the PSC, the in-turbine, downlooking hydroacoustic beam, and the STS.

Figure 3. Cross-sectional view through a Powerhouse 1 turbine intake showing an STS and hydroacoustic beams for sampling fish passing above and below the screen.

Figure 4. Cross section of Intake 8b showing an ESBS and up- and downlooking hydroacoustic beam for sampling fish passing above and below the ESBS

Figure 5. Diagram showing front and side views of hydroacoustic sample volumes of split-beam transducers on a span mount at the Powerhouse 2 sluice chute

Figure 6. Cross section through a Powerhouse 2 turbine intake showing an STS and hydroacoustic beams for sampling fish passing above and below the STS.

Figure 7. Lateral and vertical distribution of fish passing through 20 -ft-wide slots in the PSC at Intakes $3 \mathrm{~b}$ and $5 \mathrm{~b}$

Figure 8. Estimated number of fish counted passing through 5- and 20-ft slot entrances in the PSC based upon slot-entrance sampling.

Figure 9. Efficiency of the 5- and 20-ft slot based upon slot-entrance counts and in-turbine estimates of numbers passing under the PSC . ..... 
Figure 10. Estimated numbers of juvenile salmon passing under the PSC during 5- and 20-ft-wide slot treatments in spring and summer 1998 as estimated by sampling with a downlooking transducer in the turbine downstream of the PSC

Figure 11. Effectiveness of 5- and 20-ft-wide slots in the PSC based upon slot-entrance counts

Figure 12. Downward displacements and their 95-percent confidence intervals for fish passing through a downlooking hydroacoustic beam in the turbine intakes downstream of the PSC.

Figure 13. Sensitivity of PSC efficiency estimates from in-turbine transducer beams to the cutoff range for classifying fish traces as passing through or under the PSC

Figure 14. Efficiency of 5- and 20-ft-wide slots estimated from in-turbine counts of fish passing through and under the PSC

Figure 15. Estimated number of fish collected by the PSC during 2-day, 5- and 20-ft-wide slot treatments based upon in-turbine counts 28

Figure 16. Correlation of numbers of fish collected at Unit 3 with numbers collected at Unit 5 under 2-day, 5- and 20-ft-wide slot treatments ..... 28

Figure 17. Correlation of two measures of slot effectiveness at the PSC 29

Figure 18. Seasonal trends in the density of fish passing through 5- and 20-ft-wide slots in the PSC

Figure 19. FGE of STS in Intakes $1 \mathrm{~b}$ and $2 \mathrm{~b}$ as a function of Julian date in 1998

Figure 20. Estimated numbers of fish passing above and below STS in Intakes $1 b$ and $2 b$

Figure 21. Seasonal trends in estimated numbers of fish passing through Units 1 and 2 by slot-width treatment at the PSC 32

Figure 22. Total fish passage rate at all intakes of Units 1 and 2 relative to rates at two 5-ft- or two 20-ft-wide, 40-ft-deep slots at the PSC

Figure 23. Fish passage rate per foot of slot width at six slots of Units 1 and 2 and two slots at the PSC during 2-day treatments 33 
Figure 24. Efficiency of the PSC slots calculated as passage per foot of slot width divided by passage per foot of width through slots and Units 1 and 2 .

Figure 25. FGE of an extended-length bar screen at Intake $8 \mathrm{~b}$ estimated by fixed-aspect hydroacoustics and netting. 34

Figure 26. Correlation of netting estimates of FGE provided by the NMFS with hydroacoustic estimates made in this study.

Figure 27. Seasonal decline in numbers of fish guided by an ESBS at Intake $8 \mathrm{~b}$, as estimated by fixed-aspect hydroacoustics (this study) and netting (NMFS)

Figure 28. Correlation of estimates of numbers of juvenile salmon guided by an ESBS at Intake 8b, as determined by fixed-aspect hydroacoustic sampling (this study) and netting (NMFS)

Figure 29. Hydroacoustic and netting estimates of numbers of unguided fish in spring and summer

Figure 30. Combined FPE of the sluice and STS in Units 11-13 when the sluice was opened and the FGE of STS alone when the sluice chute was closed 37

Figure 31. Sluice-chute efficiency relative to total passage at the sluice chute plus Units 11-13 fish passage in spring and summer 1998 38

Figure 32. Effectiveness of the sluice chute in terms of the proportion of fish passing through the sluiceway (relative to sluice and Unit 11-13 passage) divided by the proportion of water flowing through the sluiceway (relative to flow through the sluiceway and Units 11-13).

Figure 33. FGE of STS in Units 11-13 in spring and summer as a function of sluice-chute treatment

Figure 34. Daily rate of fish passage through the sluice chute and Units 11-13

Figure 35. Estimated daily rate of passage of juvenile salmon through the sluice chute and the JBS at Powerhouse 2 in 1998 40

Figure 36. Correlation of FPE through the JBS by the NMFS with hydroacoustic estimates for the sluice chute 
Figure 37. Efficiency of the sluice chute for passing juvenile salmon relative to passage through the sluice chute and the entire Powerhouse 2 JBS

Figure 38. Hourly fish passage through PSC slots in spring and summer 1998 , as estimated from in-turbine counts

Figure 39. Diel pattern in fish passage under 5- and 20-ft-wide, 40-ft-deep slots in the PSC in spring and summer 1998

Figure 40. Diel pattern in mean efficiency of the PSC at Powerhouse 1 in spring and summer 1998.

Figure 41. Diel pattern in the effectiveness of the 5- and 20-ft-wide slots in the PSC for passing fish relative to water

Figure 42. Diel pattern in fish passage at Units 1 and 2 and the adjacent PSC slots in spring and summer 1998

Figure 43. Correlation of hourly passage at PSC slots with hourly passage at adjacent Units 1 and 2 45

Figure 44. Diel trends in the FGE of an ESBS at Intake $8 b$ of Powerhouse 1 in spring and summer 1998. 46

Figure 45. Diel trends in the passage of fish above (guided) and below (unguided) an ESBS at Intake 8b of Powerhouse 1 in spring and summer 1998

Figure 46. Diel trends in the combined efficiency of the sluice chute and STS in Units 11-13 in spring and summer 1998

Figure 47. Diel trend in the efficiency of the sluice chute in terms of fish passage at the chute relative to fish passage through the chute and Units 11-13 in spring and summer 1998

Figure 48. Diel trend in mean effectiveness of the sluice chute, where effectiveness is the proportion of fish passing at the sluice chute relative to the total passing at the sluice chute and Units 11-13 divided by the proportion of water moving through the same routes 48

Figure 49. Diel trends in hourly passage of fish through the sluice chute at Powerhouse 2 in spring and summer 1998. 48

Figure 50. Diel trends in the density of fish passing through the sluice chute in spring and summer 1998 . 
Figure 51. Diel trends in the FPE of STS in Intakes 11b, 12b, and $13 \mathrm{~b}$ at Powerhouse 2 in spring and summer 1998

Figure 52. Diel trends in the hourly passage of fish below STS (unguided fish) in Intakes $11 \mathrm{~b}, 12 \mathrm{~b}$, and $13 \mathrm{~b}$ adjacent to the sluice chute 51

Figure 53. Diel trends in hourly passage of fish above STS in Intakes 11b, $12 \mathrm{~b}$, and $13 \mathrm{~b}$ adjacent to the sluice chute, which was either opened or closed (see line references) on a daily basis 52

Figure 54. Fish counts made by trackers on 30, 12-min files collected at select locations where transducers were deployed at Bonneville Dam 53

Figure 55. Fish counts from six sets of data files by trackers who processed data in summer 1998

Figure 56. Efficiency of the PSC based upon unadjusted counts (means with 95-percent confidence intervals) and bias-corrected counts (means with connecting lines) of fish at PSC slot entrances

\section{List of Tables}

Table 1. Experimental Design for the 1998 Evaluation of the Bonneville First Powerhouse Prototype Surface Collector.

Table 2. Experimental Design for the 1998 Test of the Effect of the Bonneville Second Powerhouse Sluice Chute on Fish Passage Metrics at Units 11-13 and the Whole Powerhouse

Table 3. Acceptance Criteria for Fish Traces Formed by Successive Echoes Passing Through Hydroacoustic Beams and Displayed on a Computer Generated Echogram

Table 4. Distribution of Passage of Fish Through PSC Slot Entrances at Intakes $3 b$ and $5 b$ in Spring and Summer

Table 5. Comparison of Mean Fish Passage per Day and Effectiveness Among the Two PSC Deep-Slot Treatments at Powerhouse 1 Based Upon In-Turbine Hydroacoustic Sampling and the Sluice Chute at Powerhouse 2 Based upon Split-Beam Hydroacoustic Sampling 


\section{Preface}

This report was prepared by Messrs. Gene R. Ploskey, William T. Nagy, and Dr. Larry R. Lawrence, Fisheries Engineering Team, Water Quality and Contaminant Modeling Branch (WQCMB), Environmental Processes and Effects Division (EPED), Environmental Laboratory (EL), U.S. Army Engineer Research and Development Center (ERDC), with support from Ms. Deborah S. Patterson, DynTel Corporation, Vicksburg, MS, Messrs. Carl R. Schilt and Peter N. Johnson, AScI Corporation, Mclean, VA, Dr. John R. Skalski, School of Fisheries, University of Washington, Seattle, and the U.S. Army Engineer District, Portland. The research was conducted under the general supervision of Dr. Mark S. Dortch, Chief, WQCMB; Dr. Richard E. Price, Chief, EPED; and Dr. John W. Keeley, Acting Director, EL. Technical oversight was provided by Messrs. Blaine Ebberts and Marvin Shutters, U.S. Army Engineer District, Portland.

Many other people made valuable contributions to this study. The Statistical Oversight Committee was organized and facilitated by Mr. Gary Johnson, Pacific Northwest National Laboratory. It was attended by three statisticians including Drs. Skalski, University of Washington, Lyle Calvin, Oregon State University, and Cliff Pereira, Oregon State University, as well as by study investigators and sponsors. Messrs. Gary Weeks and Mike Burczynski, AScI Corp., helped with the deployment and troubleshooting of hydroacoustic equipment. Many people processed hydroacoustic data to provide counts of tracked fish including Dr. Lawrence, Ms. Patterson, Mr. Schilt, Mr. Weeks, Mr. Burczynski, Ms. Gina George, Ms. Athena Stillinger, Mr. Jason King, ERDC contract students, Mr. Roger and Mrs. Nancy Bradford, ERDC contractors, and Mses. Hope Waite and Ellen Czaika, ERDC contract students. Ms. Toni Schneider, WQCMB, provided supervision for contract students at ERDC and managed interagency transfers and allocation of funds. Messrs. Dean Ballinger and Jeffry Kamps, Smolt Monitoring Program, National Marine Fisheries Service, provided smolt bypass data for Powerhouse 2. Riggers from the Bonneville Project repaired and moved a spanmount at the Powerhouse 2 ice/trash sluice chute and trash racks at turbine units and the prototype surface collector (PSC) to facilitate the installation, repair, and removal of hydroacoustic equipment. Riggers also welded transducer mounts and chain links to trash racks to facilitate cable routing, and they shuffled blocked and unblocked trash racks at 3-or 5-day intervals to create test treatments at the PSC. Cardiopulmonary resuscitation training and coordination with the Bonneville Project was provided by Ms. Jennifer Sturgill, Fishery Biologist, Bonneville Lock and Dam. Sawtooth Technologies, Incorporated, Stevenson, WA, provided 
people to check all hydroacoustic systems hourly at night. Schlosser Machine, Head River, Oregon, fabricated transducer mounts.

At the time of publication of this report, Director of ERDC was Dr. James R. Houston. Commander was COL James S. Weller, EN.

This report should be cited as follows:

Ploskey, G. R., Nagy, W. T., Lawrence, L. R., Patterson, D. S., Schilt, C. R., Johnson, P. N., and Skalski, J. R. (2000). "Hydroacoustic evaluation of juvenile salmonid passage through experimental routes at Bonneville Dam in 1998," ERDC/EL TR-01-2, U.S. Army Engineer Research and Development Center, Vicksburg, MS.

The contents of this report are not to be used for advertising, publication or promotional purposes. Citation of trade names does not constitute an official endorsement or approval of the use of such commercial products. 


\section{Conversion Factors, Non-SI to SI Units of Measurement}

Non-SI units of measurement used in this report can be converted to SI units as follows:

\begin{tabular}{|l|l|l||}
\hline Multiply & By & To Obtain \\
\hline \hline cubic feet/second (cfs) & 0.02831685 & cubic meters/second \\
\hline degrees (angle) & 0.01745329 & radians \\
\hline feet & 0.3048 & meters \\
\hline
\end{tabular}




\section{Summary}

\section{Overview}

This technical report describes results of studies conducted by the U.S. Army Engineer District, Portland, and the U.S. Army Engineer Research and Development Center, Vicksburg, MS. The overall goal was to resolve critical uncertainties in the implementation of surface-collection technologies for bypassing juvenile salmon at Bonneville Dam. Studies in fiscal year 1998 addressed questions of immediate concern for continued testing of surfacecollector concepts at Bonneville Dam relative to the use of existing and alternative bypass technologies. Submerged traveling screens (STS) have been used at Bonneville Dam since the early 1980s, and a few specific sluice gates at Powerhouse 1 are routinely opened to facilitate juvenile passage. Extended submerged bar screens (ESBS) that have been tested and deployed at other dams on the Columbia and Snake rivers since the early 1990s represent another bypass technology being considered for use at Bonneville Dam.

The goals of this study were to evaluate the following:

a. Potential of a Prototype Surface Collector (PSC) with two deep slots to improve fish-passage efficiency (FPE) over the fish-guidance efficiency (FGE) provided by STS in Units 1 and 2 and a prototype ESBS in Intake 8b.

$b$. Potential of the sluice chute as a corner surface collector to improve FPE of juvenile salmon at Powerhouse 2.

The following objectives, listed by powerhouse, were developed for spring and summer out-migrations to meet the two goals:

Powerhouse 1:

a. Compare the FPE of the PSC under two experimental treatments consisting of 5- or 20-ft ${ }^{-}$slot widths at middle intakes of Units 3 and 5. The PSC was located in front of Units 3-6, but Units 4 and 6 were not operating during the 1998 season.

${ }^{1}$ A table of factors for converting non-SI units of measurement to SI units is presented on page xi. 
b. Estimate the FGE of STS and the passage rate of fish through Units 1 and 2 adjacent to the south end of the PSC.

c. Estimate the FGE of a prototype ESBS and the rate of fish passage through the middle intake of Unit 8.

d. Identify and quantify diel patterns in fish passage and efficiency at all monitored passage routes and quantify effectiveness of the PSC and sluice chute.

Powerhouse 2:

a. Estimate the rate of fish passage through the sluice chute.

b. Estimate the FGE and rate of fish passage through Units 11, 12, and 13.

c. Test for significant effects of opened and closed sluice-chute treatments on the following:

(1) Combined FPE of the sluice chute and STS in Units 11-13.

(2) FPE of the sluice chute relative to total juvenile fish passage at Units 11-13.

(3) FPE of the sluice chute relative to the sluice chute and Units 11-13.

d. Compare the FPE at the sluice chute relative to fish passage through the juvenile bypass system (JBS) at Powerhouse 2.

$e$. Identify and quantify diel patterns in fish-passage metrics at monitored routes at Powerhouse 2.

Our approach was to use fixed-aspect hydroacoustics to evaluate the passage of juvenile salmon and the efficiency and effectiveness of several experimental passage routes at Bonneville Dam. Routes at Powerhouse 1 included the PSC, units adjacent to the PSC with STS, and Intake 8b with an ESBS. At Powerhouse 2, routes included the sluice chute, Units 11-13 adjacent to the sluice chute, and the JBS. Tests were designed and conducted to determine if 5- and 20-ft-wide slot treatments altered fish-passage indices at the PSC. The width of the 40-ft-deep slots was changed to provide stratified random treatments lasting 2 days each at Intakes $3 \mathrm{~b}$ and $5 \mathrm{~b}$ in spring and summer. Tests at Powerhouse 2 consisted of 24-hr opened and closed sluice-chute treatments on fish-passage metrics for the sluice chute and Units 11-13. 


\section{Prototype Surface Collector and Adjacent Turbine Units}

The 1998 data showed that the PSC was highly efficient and effective in collecting juvenile salmon in spring and summer. First, both slot and in-turbine sampling estimated PSC efficiencies $\geq 80$ percent in spring and summer, and effectiveness estimates by both methods were similar and highly correlated. Correcting slot samples for potential intertracker bias reduced the estimate of mean efficiency of the $20-\mathrm{ft}$ slot from 95 to 90 percent and of the mean of the $5-\mathrm{ft}$ slot from about 85 to 70 percent. However, the correction failed to change our conclusion that the PSC was very efficient and effective. In-turbine sampling estimated efficiencies of 89-90 percent for both spring and summer. Slot sampling showed that fish passage and PSC efficiency were significantly higher for the $20-\mathrm{ft}$ slot treatment than for the 5 - $\mathrm{ft}$ treatment in spring and summer. Inturbine sampling provided the same conclusion for summer. In-turbine estimates of efficiency for the 5- and 20-ft treatments in spring were within 4 percent of each other (92 versus 88 , respectively), and while statistically higher for the 5 -ft slot, the difference probably is not biologically meaningful. We found that significantly more fish passed under the 5 - $\mathrm{ft}$ slot than under the 20 - $\mathrm{ft}$ slot in summer $(\mathrm{P}=0.0079)$ but not in spring. This difference might be related to greater downward flows at the 5-ft slot and the relatively smaller size and reduced swimming capability of subyearling salmon in summer relative to that of yearling salmon sampled in spring.

Although in-turbine sampling was only intended to be a check on slot sampling, three problems with slot sampling inside the PSC made us rely heavily on in-turbine data. First, PSC slot samples were often contaminated with entrained air bubbles within 1-2 m of the water's surface, particularly for the $20-\mathrm{ft}$ opening. Fish traces embedded in noise were not trackable, resulting in underestimates of slot passage that could have been as much as 17 percent with a uniform vertical distribution or higher if the distribution were skewed toward the surface. Second, some of the flow entering the PSC in the middle module circulated laterally into the side modules and returned to the middle module as an eddy. This circulation pattern made it possible, if not likely, that some fish were counted multiple times, especially during sampling of the sides of the $20-\mathrm{ft}$ slot. If multiple counts on side transducers caused the skewed distribution of fish passage toward the sides of the 20 -ft-wide slot, overestimates could have been 44 percent in spring and 25 percent in summer. Third, systematic differences in numbers of fish counted by people tracking fish at slot entrances and another tracker counting fish passing under the collector could have inflated estimates of PSC passage by 11-45 percent. However, a 45-percent bias correction reduced PSC efficiency only by 5 percent for the 20 -ft slot and 15 percent for the 5 -ft slot.

In-turbine sampling had two important limitations that may have made it less sensitive to effects of 5- and 20-ft slot treatments than sampling slot entrances. First, in-turbine transducers could not sample fish passing through the PSC and into the center sluice gate, which was opened 1-1.5 $\mathrm{m}$ to reduce turbulence in the PSC. Second, the single downlooking transducer in each of six intakes could not sample fish in the upper $3 \mathrm{~m}$ of the intake, at depths where many fish pass. Beam 
diameters were too narrow within $3 \mathrm{~m}$ of the transducer to reliably return greater than or equal to four echoes required for detection given a pulse repetition rate of 15 pings per second and flow rates through the beam. This low detectability probably made in-turbine sampling less capable of detecting differences in 5- and 20 - $\mathrm{ft}$ slot treatments than slot sampling because larger spatial expansions were required for "collected" fish.

In spite of limitations to in-turbine sampling, we were confident that fish were only counted once and that we could accurately classify fish as collected or uncollected based upon their range from the downlooking transducer. The distribution of slopes of thousands of fish trajectories in hydroacoustic beams indicated that all fish were moving downward and most within $10 \mathrm{~m}$ of the transducer had similar linear trajectories. Therefore, fish passing under the collector floor were very unlikely to dart upward closer to the transducer where they would be classified as "collected." In addition, analysis of the effect of cutoff range on PSC efficiency revealed that efficiency was not very sensitive to cutoff range within $\pm 0.5 \mathrm{~m}$ of the range we used.

Since a limiting factor for future development of surface collection is how much water can be handled, the question of the size and number of slots is extremely important. Effectiveness data indicate that presenting many 5 - $\mathrm{ft}$ slots might be better than presenting a few $20-\mathrm{ft}$ slots, given equal volumes of water to be passed. We believe it is important not to equate slot width with the volume of water that can be passed but to select a slot width based upon its effectiveness. Based upon sampling of PSC slots and intakes, the 5-ft slot was twice as effective, relative to flow, in passing juvenile salmon than the 20 -ft slot in both spring and summer. Estimates of PSC effectiveness from in-turbine and PSC slot sampling were highly correlated. The 5-ft slot treatment passed over 6 times more fish than would be expected based upon the proportion of flow passing through the slot relative to flow passing into the turbine in spring and summer. The $20-\mathrm{ft}$ slot treatment only passed 3.1 times more fish than would be expected from the proportion of flow entering the slot relative to the whole turbine. At 2,750 cfs, the 20 -ft-wide slot passes 2.81 times more water than the 5 - $\mathrm{ft}$ slot (980 cfs) and therefore usually passed more fish per unit of time in spite of differences in effectiveness.

Slot-entrance counts of fish at PSC Units 3 and 5 were significantly correlated, although on average the Unit 3 opening collected more fish than the Unit 5 opening, perhaps due to lateral flow patterns. For all treatments, Units 3 and 5 had the same slot opening ( 5 or $20 \mathrm{ft}$ ). The Unit 3 slot averaged 2.8 times more fish than the Unit 5 slot during 5-ft slot treatments. The Unit 3 slot also averaged 1.4 times more fish than the Unit 5 slot during 20 - $\mathrm{ft}$ slot treatments. In the lateral flow along the PSC, Unit 3 was located downstream of Unit 5, and fish may have had more time to get close to the upstream face of the PSC before encountering its opening. At Unit 5, the 20-ft slot passed more fish than the 5-ft slot, and this could account for lower among-unit differences during 20-ft slot treatments. 
Unlike the efficiency of the PSC, which was high in spring and summer, mean FGE of submerged traveling screens in Intakes $1 \mathrm{~b}$ and $2 \mathrm{~b}$ both decreased seasonally. The FGE also was consistently higher at Intake $1 \mathrm{~b}$ (79 percent in spring and 62 percent in summer) than at Intake $2 \mathrm{~b}$ ( 46 percent in spring and 21 percent in summer), perhaps because of the hydraulic characteristics adjacent to each intake. Intake $2 \mathrm{~b}$ was adjacent to a significant eddy and vortex that formed at the end of the PSC and upstream of Intake 2c. The downward forces associated with this hydraulic phenomenon may have drawn fish deeper at Intake 2b. Relative to lateral flow from north to south along the PSC and powerhouse, Intake $1 b$ is further downstream than Intake $2 b$, and lateral flow is gradually slowing. Fish in this area may be distributed higher in the water column than at Unit 2 and therefore may be more readily guided by the STS. Additionally, Unit 1 may pass more fish than Unit 2 because of its corner location, where fish moving south along the powerhouse or west along the old, navigation-lock wall end up at Unit 1.

The efficiency of the PSC slots relative to Units 1,2,3, and 5 was about 60 percent in spring and 50 percent in summer, and slot-width treatments at the PSC had no effect on passage at Units 1 and 2. However, since the six intakes at Units 1 and 2 were 3.2 times wider than two 20-ft-wide PSC slots and 12.6 times wider than two 5-ft PSC slots, we also calculated a width-standardized efficiency that averaged 85 percent. This suggests that fish are more likely to enter the PSC slots than to enter the adjacent turbines, and that the only reason passage estimates were similar was due to the greater size of the turbine passage route. An obvious difference between the two types of openings is that the PSC is open to the sky and turbine intakes are not open.

\section{Extended-Submerged Bar Screen at Intake 8b}

Unlike the efficiency of the PSC slots or the sluice chute, the FGE of an extended-length bar screen declined significantly from spring through summer. Our hydroacoustic sampling and National Marine Fisheries Service (NMFS) net sampling both showed that numbers of guided fish declined and numbers of unguided fish increased from spring through summer, although daily variability was high for both methods. Hydroacoustic estimates of FGE for the ESBS averaged 80 percent in spring, but declined significantly during summer to about 40 percent. Netting estimates by the NMFS showed a similar pattern, although the summer decline was more pronounced. Estimates averaged $70-75$ percent in spring and declined to about 20 percent by the end of summer. Summer FGE was lower than estimates obtained from in-turbine sampling at The Dalles, John Day, and McNary dams, where it ranged from 53-64 percent.

Counts of ESBS-guided fish by hydroacoustics and gatewell dipping both indicated a significant decline from spring through summer. Hydroacoustic estimates were lower than netting estimates in spring but similar to netting estimates in summer. Nonetheless were correlated. Hydroacoustic counts of unguided fish gradually increased from spring through summer, and netting estimates showed a similar rate of change, although daily variability was high for 
both methods. On average, hydroacoustic estimates of unguided fish were about 33 percent of netting estimates in spring and 50 percent of netting estimates in summer.

High daily variation and poor correlations by the two methods were not surprising given the 50 percent spatial coverage of most fyke netting and low temporal coverage of hydroacoustic sampling. Estimates of FGE by hydroacoustics and netting were significantly correlated, although the $\mathrm{r}^{2}$ was only about 0.35 . If an objective of sampling is to obtain a high correlation between the two methods, more effort is required for both methods. Better correlations between hydroacoustic and netting samples can be obtained, but only with increased sampling, particularly for hydroacoustics. With hydroacoustic sampling time split among Units 1,2, and 8, the effort was only sufficient to detect broad seasonal trends. The quarter-time sampling rate of hydroacoustics was minimal relative to the nearly continuous sampling with nets for 1-2 hr. Gatewell-dipping estimates of guided fish were on average 1.7 times higher than hydroacoustic estimates in spring, but estimates were similar in summer. Even with the underestimate of guided fish in spring, mean hydroacoustic estimates of FGE were higher than mean netting estimates because the downlooking transducers consistently underestimated numbers of unguided fish by an average factor of two. This error compensation in the FGE estimate shows the advantage of using a ratio estimate over a "quantitative" passage estimate from hydroacoustics.

\section{Sluice Chute and Adjacent Units at Powerhouse 2}

Turbine intake extensions (TIES) on the south end of Powerhouse 2 were removed in 1998. Consequently, relatively laminar bulk flows moved along the powerhouse toward the sluice chute, and water entering the sluice chute was less turbulent than in prior years. Removal of TIES provided a low noise environment for hydroacoustic sampling with three uplooking split-beam transducers. A pulse repetition rate of 37 pings per second provided uniform and adequate detectability despite high-water velocities and short-sampling ranges.

Hydroacoustic evaluations of fish passage at the Powerhouse 2 sluice chute and Units 11-13 provided conclusive evidence that the sluice chute has great potential as a corner surface collector. All metrics comparing the sluice chute to Units 11-13 remained high and relatively stable through summer, unlike the FGE of Units 11-13, which declined from spring to summer. Combined efficiency of the sluice chute and STS in Units 11-13 averaged 90 percent in spring and summer when the sluice chute was open, but STS efficiency alone (sluice closed) was only 55 percent in spring and 30 percent in summer. The efficiency of the sluice chute relative to total passage at Units 11-13 plus passage at the sluice chute averaged 83 percent in spring and 81 percent in summer. The effectiveness metric indicated that about five times more fish were passed by the sluice chute than would be expected from the proportion of water passing through the chute relative to the total for the chute and Units 11-13. Even though the sluice chute had $<1.1$ percent of the combined cross-sectional area of adjacent units, it passed significantly greater numbers of fish. Fish passage through the sluiceway 
averaged 5,888 per day in spring. Passage averaged 4,246 fish per day in summer, excluding observations from the last 2 days when passage was dominated by American shad.

The proportion of fish relative to the proportion of water passing through the sluice chute relative to Units 11-13 and the sluice chute or "sluice-chute effectiveness" averaged 5.8 in spring and 4.6 in summer. In spring, the FGE of Units 11-13 was significantly lower when the sluice chute was opened (FGE = $0.45)$ than when the sluice chute was closed $(\mathrm{FGE}=0.59)$. Mean FGE did not differ among sluice treatments in summer.

Similar seasonal trends in fish passage were found for the sluice chute and the Powerhouse 2 JBS, and mean sluice-chute efficiency relative to the JBS was 20 percent in spring and 25 percent in summer. This is high considering that sluice-chute flow represents only about 2 percent of the flow from which fish are screened to the JBS. We could not estimate potential bias for sluice efficiency relative to the JBS because the two measures were very different. While hydroacoustic sampling of the sluice chute was continuous for $23 \mathrm{hr}$ per day, estimates from the JBS were expanded from counts of fish screened from whatever turbines happened to be operating. Nevertheless, the daily estimates were correlated, with hydroacoustic estimates of sluice passage explaining 58 percent of the variation in fish passage through the JBS.

\section{Comparing Sluice-Chute and In-turbine Estimates of PSC Passage and Effectiveness}

It is likely that differences in estimates of passage at the sluice-chute and two deep slots in the PSC had more to do with opening location, orientation, or other entrance conditions than with the shapes of the openings. This is because of differences in the paths of fish as the approached the two different openings. Paths of fish approaching the PSC became increasingly tortuous as they approached the PSC, but approach paths to the sluice chute were much more direct.

The sluice chute passed significantly more fish than the 5-ft-wide PSC slot in spring and summer and more than the 20 -ft-wide slot in spring. The $20-\mathrm{ft}$ slot passed similar numbers of fish as the sluice chute in summer. The success of the sluice chute probably was due to its location in the corner of the south end of Powerhouse 2 and the removal of TIES from Intakes 11-14. Removal of TIES enhanced lateral surface flow along the south face of Powerhouse 2 toward the sluice chute. The orientation of the sluice chute to intercept some of the lateral flow also was fortuitous. In contrast, PSC openings were oriented oblique to flow. Perhaps an equally important difference was the presence of trash racks in front of PSC slots. There were no trash racks in front of the sluice chute. The PSC trash racks often accumulated trash before the end of the 2-day slot treatments in 1998. Future studies should carefully examine fish behaviors immediately upstream of PSC slots when trash racks are present and absent to see if 
behavior changes. It is possible that trash racks were vibrating, especially under a hydraulic load, and providing stimuli to fish.

\section{Diel Patterns of Fish Passage}

Differences in diel patterns of fish passage most likely are a function of the depth of the hydraulic structures passing fish. Most fish passed through the relatively shallow (13-ft-deep) sluice chute during the day, while the 40-ft-deep slots passed significantly more fish at night in spring and about equal numbers during the day and night in summer. This suggests that deep slots had dielpassage patterns that were in between night-dominated patterns observed for turbines and the diurnal pattern observed for the sluice chute. Hydroacoustic sampling at Intake $8 \mathrm{~b}$, which had the ESBS, indicated much higher fish passage at night, particularly during the hour just after sunset, than during the day. However, no significant diel trend was apparent in hydroacoustic estimates of FGE. 


\section{Introduction}

This technical report describes results of studies conducted by the U.S. Army Engineer District, Portland, and the U.S. Army Research and Development Center, (ERDC), Vicksburg, MS. The overall goal was to resolve critical uncertainties in the implementation of surface-collection technologies for bypassing juvenile salmon at Bonneville Dam. Studies in Fiscal Year 1998 addressed questions of immediate concern for continued testing of surface collector concepts at Bonneville Dam relative to the use of existing and alternative bypass technologies. Submerged traveling screens (STS) have been used at Bonneville Dam since the early 1980s, and a few specific sluice gates at Powerhouse 1 are routinely opened to facilitate juvenile passage. Extended submerged bar screens (ESBS) that have been tested and deployed at other dams on the Columbia and Snake rivers since the early 1990s are another potentially promising bypass technology for Bonneville Dam.

Bonneville Dam is a structurally complex project. From the Oregon shore northward toward Washington, it is composed of a navigation lock, a 10-unit Powerhouse 1, Bradford Island, an 18-gate spillway, Cascades Island, and an 8-unit Powerhouse 2. Principal smolt passage routes at the Bonneville project include the spillway and both powerhouses, but each powerhouse is a complex structure with several different kinds of passage routes. Smolts may pass through 1 of 30 turbine intakes at Powerhouse 1 or 24 intakes at Powerhouse 2. Fish also may pass over 1- to 4-m-deep overflow weirs and through ice and trash sluiceways or through a juvenile bypass system (JBS) if they happen to be screened from the upper part of a turbine intake. In-turbine screens divert fish to gatewell slots where they can pass through a lighted orifice to the JBS channel.

The Bonneville Project has low fish-passage efficiency (FPE) relative to other dams upstream in the Snake and Columbia River System. The average fish-guidance efficiency (FGE) of STS at Bonneville Dam is $\leq 70$ percent in spring and $\leq 40$ percent in summer. With full spill and assuming one-third of the water and fish pass equally through each of the major hydraulic structures, the highest FPE the project could hope to obtain in summer would be only about 60 percent. In 1996, hydroacoustic estimates of FGE in spring for Intake 3B averaged 66 percent. An average hydroacoustic FGE estimate for Intake 3B in summer 1996 was about 46 percent (Ploskey et al. 1998) compared with an average hydroacoustic estimate of 32 percent (20-68 percent) made by Thorne and Kuehl (1989). Fyke net sampling of Intake 3B in summer ranged from 33 to 61 percent with a mean of 41 percent (Gessel et al. 1989). At Powerhouse 2, modifications to trash racks, STS, and the face of the powerhouse increased 
spring netting estimates of FGE to $>75$ percent at times, although steelhead guidance remained $<70$ percent (Gessel et al. 1991). A spring estimate of 65 percent FGE for Intake 12A without a turbine intake extension (Ploskey et al. 1998) was similar to an estimate of 70 percent by Gessel et al. (1989). However, acoustic and fyke-net estimates of FGE for Intake 17B in spring 1988 averaged only 34 and 25 percent, respectively (Magne, Stansell, and Nagy 1989), compared with a hydroacoustic estimate of 39 percent in spring 1996 (Ploskey et al. 1998). Fyke netting of several Powerhouse 2 turbines showed that guidance for subyearling chinook salmon was as high as 60 percent in spring but remained below 30 percent in summer (Gessel et al. 1991). For Intake 18A, hydroacoustic estimates for spring and summer 1996 (31 and 15 percent, respectively) probably do not differ significantly from hydroacoustic estimates of 22 and 13 percent taken in 1988 (Stansell et al. 1990). By contrast, estimates of the FGE of extended-length bar screens at Lower Granite Dam in spring were 87 percent in 1997 and 83 percent in 1998 (Johnson et al. 1998a, b). Similarly, spring FGE of prototype extended screens at John Day Dam ranged from 79 percent for juvenile sockeye to $94-95$ percent for steelhead and coho (Brege et al. 1997). These estimates were comparable with extended screen FGE at McNary Dam in 1991 and 1992 (Brege et al. 1992; McComas et al. 1993). Krcma, Brege, and Ledgerwood (1986) reported an average submerged traveling screen FGE of 72 percent for John Day Dam in spring. Estimates of 69-74 percent were obtained for extended screens at The Dalles Dam in 1993 and 1994 (Brege et al. 1994; Absolon et al. 1995). Brege et al. (1997) reported a mean FGE of 60 percent for subyearling chinook salmon at John Day Dam in summer 1996. This estimate was comparable with estimates of 53-64 percent at McNary Dam (Brege et al. 1992; McComas et al. 1993) and 54-59 percent for The Dalles Dam in 1993 and 1994 (Brege et al. 1994; Absolon et al. 1995).

Until 1996-97, data on vertical distributions of juvenile salmon in forebay areas of Bonneville Dam were limited to fixed-aspect hydroacoustic samples taken in front of trash racks of several turbine intakes at both powerhouses. The Fishery Field Unit sampled smolts with uplooking transducers at several units of Powerhouse 2 in 1985 (Nagy and Magne 1986) and of Powerhouse 1 in 1986. These data clearly show a downward shift in the vertical distribution at night and a strong skew toward the surface during the day. These data reveal nothing about vertical distributions of smolts $>10 \mathrm{~m}$ upstream from structures, although they have implications for selecting depths of collector openings and for explaining day/night differences in FGE.

Available data indicate that the horizontal distribution of smolt passage among intakes is not uniform. Lateral distributions of smolts sampled in gatewells of Powerhouse 1 apparently are influenced by the number and location of operating units and sluice gates as well as the species of smolt (Willis and Uremovich 1981). Interactions among factors may account for a lack of consistency in measures of horizontal patterns by Uremovich et al. (1980), who found concentrations at Units 6,7, and 10. Willis and Uremovich (1981) observed variable patterns depending on operations, and Krcma et al. (1982) observed more fish passage at Units 4-6 than at other units. 
Hydroacoustic sampling in front of Intakes $8 \mathrm{c}-10 \mathrm{~b}$ of Powerhouse 1 from 2200 through $0100 \mathrm{hr}$ in June 1995 showed a distribution highly and consistently skewed toward Unit 10 (Ploskey, Johnson, and Carlson 1996). Units 3, 4, and 6 were inoperable at the time of sampling. The FGE data collected at Powerhouse 2 with in-turbine hydroacoustics (e.g., Magne, Stansell, and Nagy 1989; Stansell et al. 1990) or netting (Gessel, Monk, and Williams 1988; Muir et al. 1989) are of limited value for evaluating the lateral distribution of passage. They typically focused on one or two units at a time. Hydroacoustic sampling of smolts passing through several spillway gates was attempted in the mid 1980s by the Fishery Field Unit. Transducers were mounted on the bottom of gates and aimed upward in the water column and out from the gate. Apparently, noise generated by sound echoing off vortices at some gates masked echoes from smolts and prevented a uniform distribution of sampling effort among gates. The assumption of equal sampling volume among transducers is critical for unbiased estimation of FPE.

Hydroacoustics also has been used on limited spatial and temporal scales to evaluate sampling potential or relative passage among a few routes. Thorne and Kuehl (1989) evaluated the effects of noise on hydroacoustic assessment of passage within several turbines of Powerhouse 1. Results showed that acoustic sampling was feasible at the units they tested. Magne, Rawling, and Nagy (1986), Magne, Stansell, and Nagy (1989), Magne 1987, and Stansell et al. (1990) compared smolt passage through turbine Units 11 and 17 with passage estimates obtained by netting and found a good correlation for hydroacoustic and net estimates of FGE.

In 1996-97, the Portland District acquired data on the distribution of smoltsized fish in the forebay of the Bonneville Project to ameliorate an information deficiency identified by Giorgi and Stevenson (1995). Day and night mobile hydroacoustic surveys were conducted in 1996 (Ploskey et al. 1998) and 1997 (BioSonics Incorporated 1998). These studies provided the first useful vertical distribution data at multiple transects running parallel to and concentrated within 10-250 m of each powerhouse. Vertical distributions of fish were also sampled along more widely spaced transects upriver from each forebay to the Bridge of the Gods. Radio telemetry studies of out-migrating smolts also were conducted in 1996 by the U.S. Geological Survey. Based upon results of 1996 studies, a prototype surface collector (PSC) was located at Units 3-6 of Powerhouse 1 in winter 1997-98, and plans were made to test the sluice chute at Powerhouse 2 as a prototype corner collector.

The PSC at Powerhouse 1 and the sluice chute at Powerhouse 2 were not intended to be fish-bypass structures during 1998 tests. Both passage routes were used solely for testing to assess the merits of surface-collection concepts at Bonneville Dam. All fish in the PSC passed through the structure and into the turbine intake rather than through a bypass channel. Likewise, fish entering the sluice chute passed through the sluiceway channel to the Powerhouse 2 tailrace without concern for the quality of the outfall site. 
The goals of this study were to evaluate the following:

a. Potential of a PSC with two deep slots to improve FPE over the FGE provided by STS in Units 1 and 2 and a prototype ESBS in Intake 8b.

b. Potential of the sluice chute as a corner surface collector to improve FPE of juvenile salmon at Powerhouse 2.

The following objectives, listed by powerhouse, were developed for spring and summer out-migrations to meet the two goals:

Powerhouse 1:

a. Compare the FPE of the PSC under two experimental treatments consisting of 5- or 20-ft slot widths at middle intakes of Units 3 and 5. The PSC was located in front of Units 3-6, but Units 4 and 6 were not operating during the 1998 season.

b. Estimate the FGE of STS and the passage rate of fish through Units 1 and 2 adjacent to the south end of the PSC.

c. Estimate the FGE of a prototype ESBS and the rate of fish passage through the middle intake of Unit 8.

d. Identify and quantify diel patterns in fish passage and efficiency at all monitored passage routes and effectiveness of the PSC and sluice chute.

Powerhouse 2:

a. Estimate the rate of fish passage through the sluice chute.

b. Estimate the FGE and rate of fish passage through Units 11, 12, and 13.

c. Test for significant effects of opened and closed sluice-chute treatments on the following:

(1) Combined FPE of the sluice chute and STS in Units 11-13.

(2) FPE of the sluice chute relative to total juvenile fish passage at Units 11-13.

(3) Passage effectiveness of the sluice chute relative to the sluice chute and Units 11-13.

d. Compare the fish passage and efficiency at the sluice chute relative to fish passage through the (JBS) at Powerhouse 2.

e. Identify and quantify diel patterns in fish-passage metrics at monitored routes at Powerhouse 2. 
Our approach was to use fixed-aspect hydroacoustics to evaluate the passage of juvenile salmon and the efficiency and effectiveness of several experimental passage routes at Bonneville Dam. Routes at Powerhouse 1 included the PSC, units adjacent to the PSC with STS, and Intake 8b with an ESBS. At Powerhouse 2, routes included the sluice chute, Units 11-13 adjacent to the sluice chute, and the JBS. Tests were designed and conducted to determine the effects, if any, of 5- and 20-ft-wide PSC slot treatments on fish-passage indices at the PSC. The width of the 40-ft-deep slots was changed to provide stratified random treatments lasting 2 days each at Intakes $3 \mathrm{~b}$ and $5 \mathrm{~b}$ in spring and summer. Tests at Powerhouse 2 consisted of 24-hr opened and closed sluice-chute treatments on fish-passage metrics for the sluice chute and Units 11-13. 


\section{Materials and Methods}

\section{Prototype Surface Collector and Units 1-2}

There were three trash-rack slots in the front of the center intakes of each PSC unit. The slots were 40.5-46.5 ft deep depending upon the surface elevation of the water and either 5 or $20 \mathrm{ft}$ wide depending upon the configuration of trash racks. The center trash-rack slot was $5 \mathrm{ft}$ wide, and slots on either side of center were $7.5 \mathrm{ft}$ wide. Riggers could place open or blocked trash racks into the side slots to create 20- or 5-ft-wide slot openings. The three trash racks for each slot were pinned together vertically so they could be moved with one pickup with a crane. Storage slots for panels that were not being used were located in front of $\mathrm{A}$ and $\mathrm{C}$ turbine intakes. From 3-5 hr were needed to change the configuration in six slots of Units 3 and 5. Treatments usually were changed between 0700 and $1100 \mathrm{hr}$ according to the design in Table 1, and the same treatment was applied to the center intake of Units 3 and 5 for 2 days whenever treatments changed. A 5- or 20-ft treatment was randomly selected for the first 2 days of each 4-day experimental block, and the alternate treatment was applied for the remaining 2 days.

We estimated fish passage through the PSC with transducers located immediately downstream of the two PSC slot entrances at Units 3 and 5. All transducers transmitted at $420 \mathrm{kHz}$ and 15 pings per second. Sampling of the 20 -ft slot was based upon three uplooking and three downlooking, 7-deg, singlebeam transducers, whereas sampling of the 5-ft slot required only the center uplooking and downlooking pair (Figure 1). The up- and downlooking transducers provided about 65 percent coverage of the cross-sectional area of the 5-ft-wide PSC slot and about 49 percent coverage of the 20-ft-wide slot. Every detected fish in the most distant half of the range of every transducer sampling PSC slots was expanded to the width of the trash-rack slot being monitored using:

$$
\text { EXP_FISH }=\text { SW } /(\text { MID_R } \times \text { TAN }(\text { B0 } / 2) \times 2)
$$




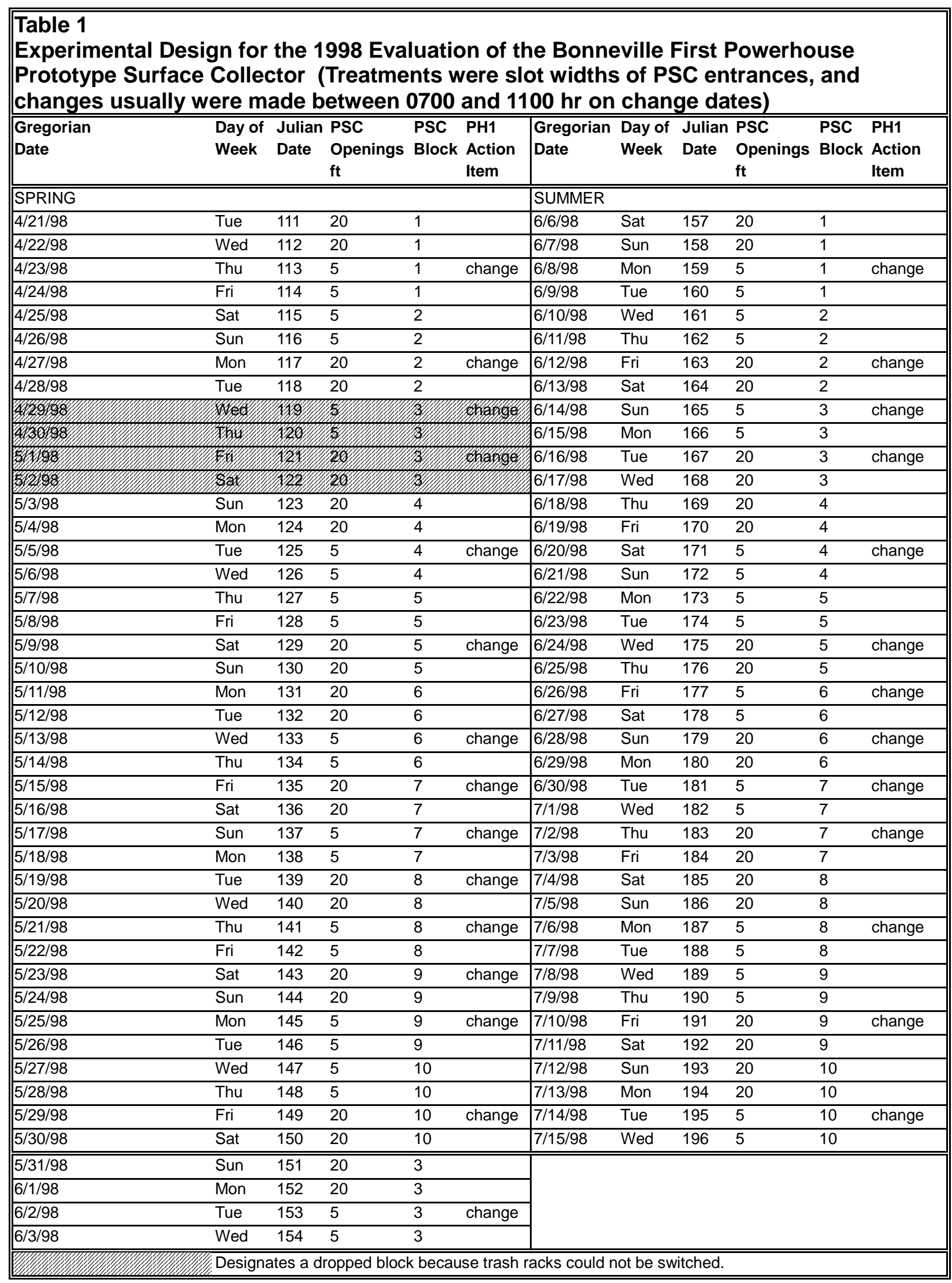




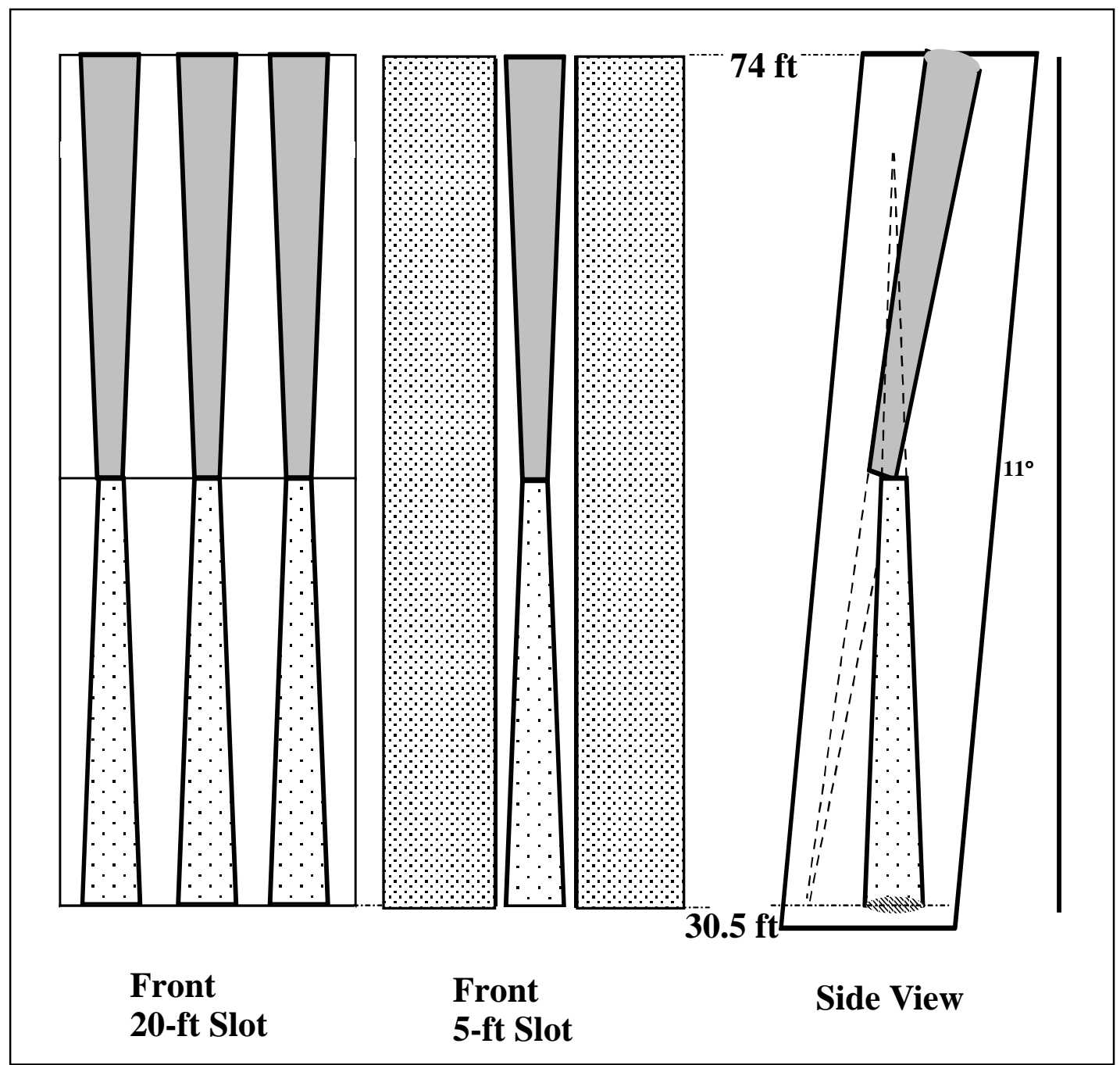

Figure 1. Front views of transducer deployments at 20- and 5-ft-wide slot openings in the PSC and a side view of a typical uplooking and downlooking pair of transducers

where

EXP_FISH $=$ expanded number of fish

SW = slot (turbine intake) width

MID_R $=$ midpoint range of a trace

TAN $=$ tangent

$\mathrm{B} 0=$ effective beam angle in degrees, as determined from detectability modeling

Units of SW and MID_R must be consistent (feet or meters). Effective beam angle was estimated assuming a nominal beam width of $7 \mathrm{deg}$ in a detectability model developed by BioSonics, Incorporated. Effective beam is estimated from 
inputs of the nominal beam angle parallel and perpendicular to the direction of fish movement across the beam, fish velocity, pulse-repetition rate, echoes required for detection, transducer orientation from vertical, and fish-trajectory angle. Model inputs and estimates of effective beam angle are presented in Appendix A. Slot width was $5 \mathrm{~m}$ for the center slot of the PSC and $7.5 \mathrm{~m}$ for each of the side slots at $3 \mathrm{~b}$ and $5 \mathrm{~b}$.

The six transducers at 20 -ft-wide slots were repeatedly sampled sequentially for $1 \mathrm{~min}$ each, as were the two transducers sampling during 5-ft-wide slot treatments. Therefore, each transducer sampled $10 \mathrm{~min}$ per hour during 20 -ft-slot treatments and 30 min per hour during 5-ft-slot treatments. Spatially expanded counts of fish within hours and associated variances were temporally expanded to a whole hour using the methods described in Appendix B.

We also estimated fish passage through and under the PSC using transducers mounted inside the six turbine intakes at Units 3 and 5. Turbine-intake sampling was based upon a single downlooking, $7 \mathrm{deg}$, single-beam transducer mounted on the downstream side and top of the uppermost trash rack (Figure 2). This transducer was aimed straight down, $11 \mathrm{deg}$ off the downstream face of the trash rack. The coverage of the transducer was about 18 percent of the cross-sectional area of the turbine intake. We considered fish passing through the hydroacoustic beam at ranges $<10.5-\mathrm{m}$ to be collected by the PSC. Fish detected at ranges from 10.5 to $21 \mathrm{~m}$ were assumed to have passed below the floor of the PSC. For quality control, we examined slopes of thousands of fish passing through the downlooking acoustic beam as a function of 1-m range strata from the transducer. We wanted to evaluate our choice of $10.5 \mathrm{~m}$ range as a cutoff for categorizing fish as collected or uncollected. We also analyzed FPE estimates for cutoff ranges of $10,10.5$, and $11 \mathrm{~m}$ to determine how sensitive estimates were to our choice of range.

Every detected fish in the beam was expanded to the width of the intake with Equation 1 above using a value of $6.4 \mathrm{~m}$ for slot width. The six transducers were repeatedly sampled sequentially for $1 \mathrm{~min}$ each $10 \mathrm{~min}$ per transducer hour. Spatially expanded counts of fish within hours and associated variances were temporally expanded to a whole hour using the methods described in Appendix B.

The downlooking transducers could not sample fish passing through the top $3.5 \mathrm{~m}$ of the intake because of insufficient hydroacoustic detectability. Therefore, we increased counts of fish at ranges from 3.5 to $10.5 \mathrm{~m}$ from the transducer by a factor of 33 percent to compensate for incomplete sampling of the intake downstream of the PSC. The factor was calculated as the ratio of two crosssectional areas, from the intake down $10.5 \mathrm{~m}$ and from the top down $3.5 \mathrm{~m}$, based upon an intake width of $6.4 \mathrm{~m}$. This factor would be accurate and appropriate if the vertical distribution of fish was uniform from the top of the intake down to $10.5 \mathrm{~m}$. This was our underlying assumption. The factor would underestimate the number of fish collected if the vertical distribution of fish passage was skewed toward the top of the intake, the most common case. It would overestimate numbers of fish collected by the PSC if fish-passage rates were higher from 


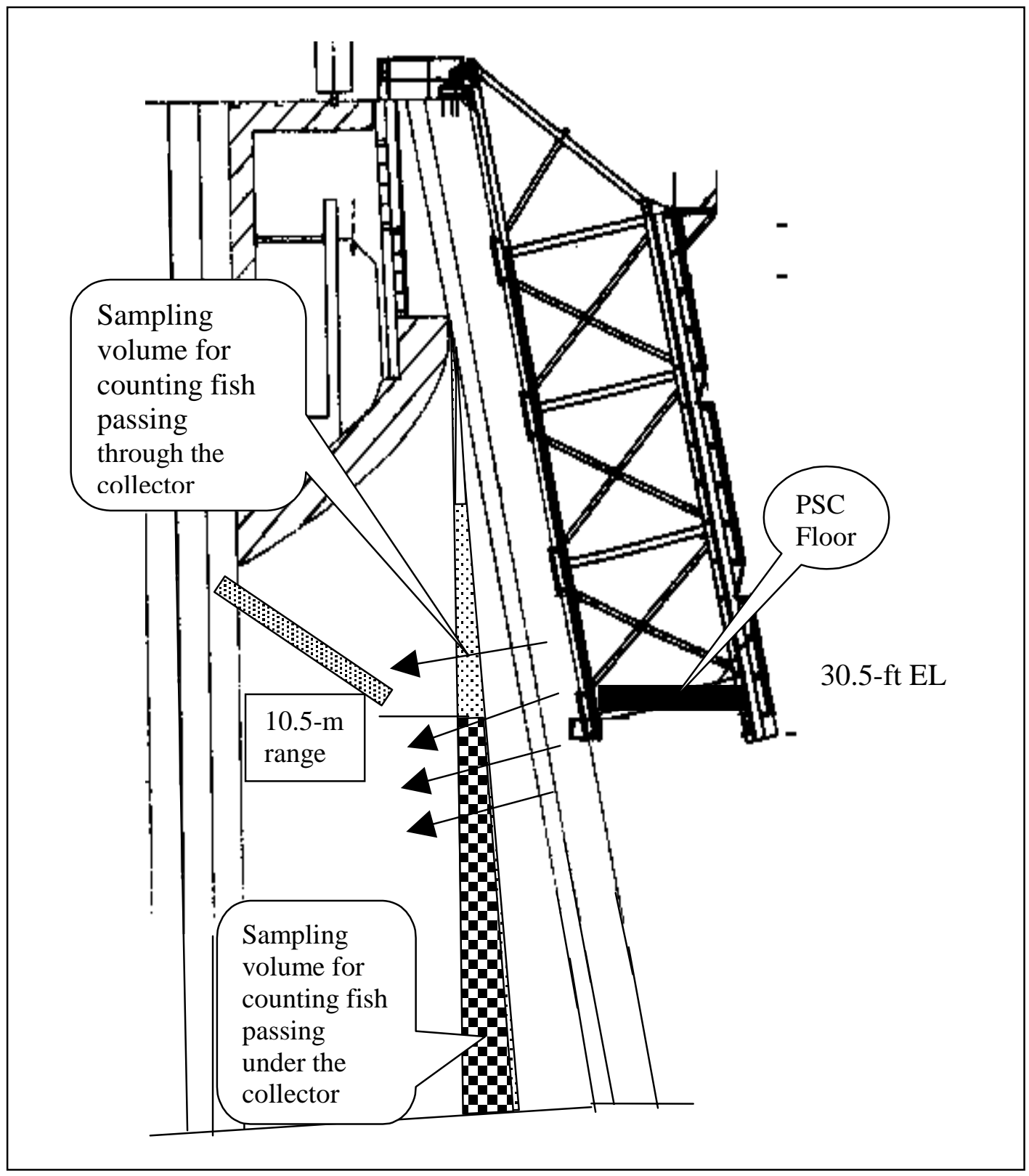

Figure 2. Cross section of one of six intakes at Units 3 and 5 showing the PSC, the in-turbine, downlooking hydroacoustic beam, and the STS. (Arrows indicate the approximate slope but not the magnitude of flow vectors passing though the beam)

3.5 to $10.5 \mathrm{~m}$ from the top of the intake than they were from 0 to $3.5 \mathrm{~m}$ from the top. In our experience, the latter vertical distribution would be rare.

Fish passing through Intakes $1 \mathrm{~b}$ and $2 \mathrm{~b}$ adjacent to the PSC were sampled with one downlooking and one uplooking, $7 \mathrm{deg}$, single-beam transducer (Figure 3). The downlooking transducer was mounted near the top, center of the uppermost trash rack, and aimed 15 deg off the downstream face of the rack to count unguided fish from 9.5 to $21 \mathrm{~m}$ from the transducer. The uplooking 


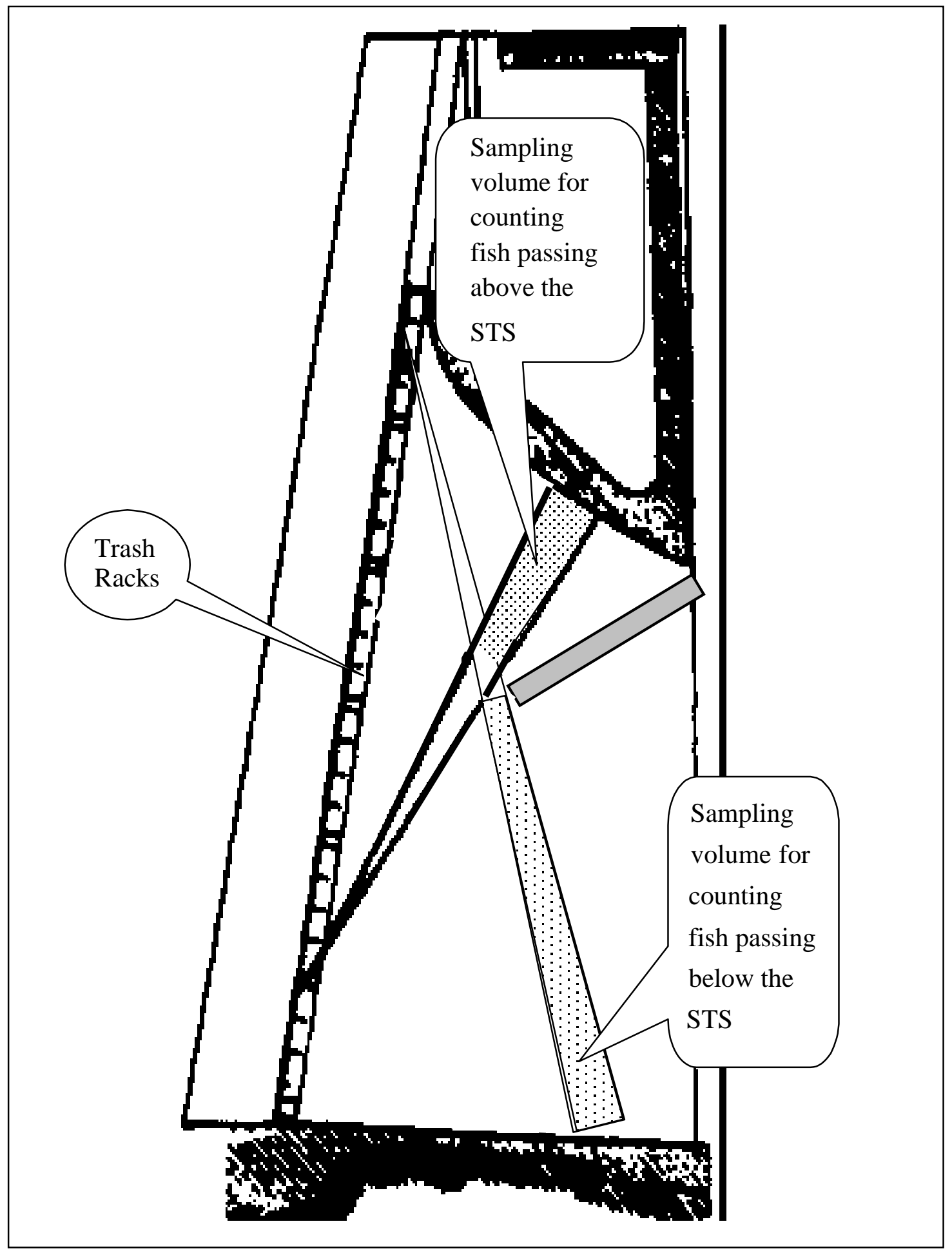

Figure 3. Cross-sectional view through a Powerhouse 1 turbine intake showing an STS and hydroacoustic beams for sampling fish passing above and below the screen (These counts are used to estimate fish passage and guidance efficiency) 
transducer was mounted at the bottom of the fifth trash rack from the top and aimed up 24 deg off the downstream face of the rack to count guided fish $>10.1 \mathrm{~m}$ from the transducer. Each transducer transmitted $420 \mathrm{kHz}$ sound at 25 pings per second during six 1-min periods per hour, $23 \mathrm{hr}$ per day. The frequency of sampling could not be increased because the four transducers were in a slow multiplex sequence with four transducers in Intake 8b. Every detected fish was expanded to the width of the intake using Equation 1 above and a value of $6.4 \mathrm{~m}$ for slot width. Each transducer was sampled once every $8 \mathrm{~min}$ or $6 \mathrm{~min}$ per transducer hour (10 percent sampling). Spatially expanded counts of fish within hours and associated variances were temporally expanded to a whole hour using the methods described in Appendix B. The FGE of Intakes $1 \mathrm{~b}$ and $2 \mathrm{~b}$ was estimated as the number of STS-guided fish divided by the sum of numbers of guided and unguided fish per hour, day, or season. The variance in FGE also was estimated by hour, day, and season using methods described in Appendix B.

We compared the daily passage of fish through PSC openings with daily passage through Units 1 and 2 in several ways. We plotted rates through the respective routes in a paired bar chart, and we calculated PSC efficiency relative to total passage through the PSC and Units 1 and 2 (six intakes). We also compared passage per square foot of opening because six intakes at Units 1 and 2 represent a passage route that is six times larger than two $20-\mathrm{ft}$-wide openings and 23.9 times larger than two 5-ft-wide openings.

\section{Extended-Submerged Bar Screen}

The FGE of an ESBS in Intake $8 \mathrm{~b}$ was estimated from samples of numbers of guided and unguided juvenile salmonids detected with four 7-deg, single-beam transducers (Figure 4). Two transducers were mounted on trash racks below the tip of the bar screen and aimed upward (30 deg off the trash-rack plane) toward the ceiling to count guided fish above the ESBS. Unguided fish were sampled with two downlooking transducers mounted at the pivot point of the ESBS and aimed downward $25 \mathrm{deg}$ off the downstream side of the ESBS toward the intake floor. Transducers were located to sample just left and right of the intake centerline without overlap in coverage. The four $420-\mathrm{kHz}$ transducers were slow multiplexed at 60-sec intervals, and the pulse rate for each transducer was 25 pings per second. A ping rate of 25 per sec was required to ensure adequate detectability of smolts at short sampling ranges on the uplooking beam (Appendix A). Every detected fish was expanded to the width of the intake using Equation 1 above and a value of $6.4 \mathrm{~m}$ for slot width. Slow multiplexing provided seven 1-min samples of guided and unguided fish per transducer hour or 14 min of sampling per hour (23 percent sampling). Spatially expanded counts of fish within hours and associated variances were temporally expanded to a whole hour using the methods described in Appendix B. The FGE of Intake 8b was estimated as the number of guided fish divided by the sum of numbers of guided and unguided fish per hour, day, or season. The variance in fish passage and FGE was estimated by hour, day, or season using methods described in Appendix B. 


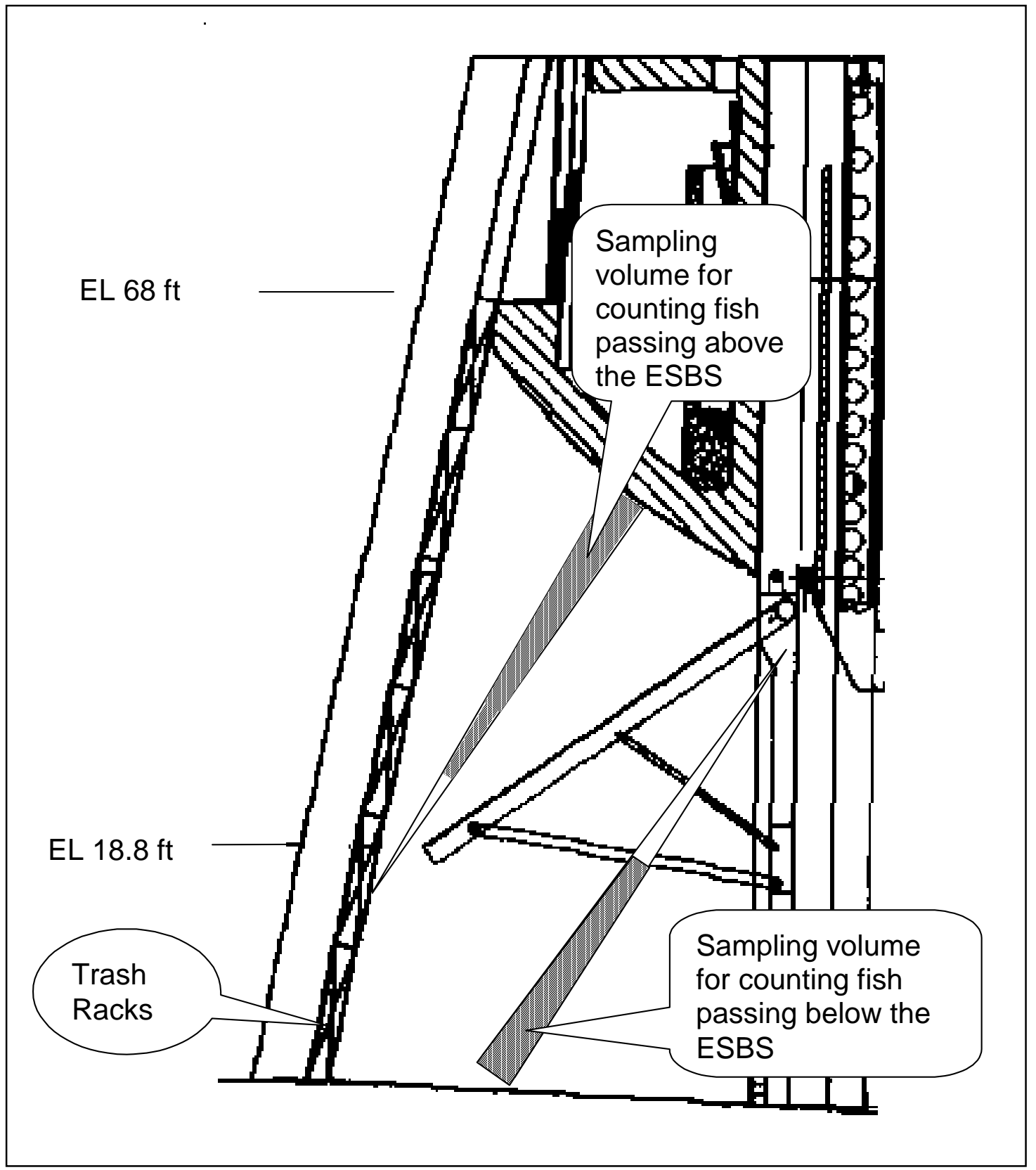

Figure 4. Cross section of Intake 8b showing an ESBS and up- and downlooking hydroacoustic beam for sampling fish passing above and below the ESBS (Shaded areas show the volumes in which fish were counted)

\section{Sluice Chute and Unit 11-13 Passage}

The sluice chute at Powerhouse 2 was opened or closed according to a randomized schedule (Table 2) to provide treatments for evaluating the effect of sluice-chute operation on a variety of fish-passage metrics. Juvenile fish passage 


\begin{tabular}{|c|c|c|c|c|c|}
\hline $\begin{array}{l}\text { Table } \\
\text { Experi } \\
\text { Bonne } \\
\text { Metric } \\
\text { preser } \\
\text { treatm } \\
0500 \mathrm{~h} \\
\text { at } 61 \mathrm{f}\end{array}$ & $\begin{array}{l}\text { nental Des } \\
\text { ille Secon } \\
\text { at Units } 1 \\
\text { ted in Gre } \\
\text { nt began. } \\
\text { the next } \\
\text { MSL) }\end{array}$ & $\begin{array}{l}\text { for the } \\
\text { owerho } \\
\text { and the } \\
\text { an and } \\
\text { atments } \\
\text { Open tı }\end{array}$ & $\begin{array}{l}\text { est o } \\
\text { lice } \\
\text { e Po } \\
\text { orme } \\
\text { at } 0 \\
\text { nts v }\end{array}$ & $\begin{array}{l}\text { f the Effe } \\
\text { Chute on } \\
\text { werhous } \\
\text { ats for the } \\
0500 \text { hr ar } \\
\text { were with }\end{array}$ & $\begin{array}{l}\text { he } \\
\text { Passage } \\
\text { es are } \\
\text { each 24-hr } \\
\text { ended to } \\
\text { eir crest }\end{array}$ \\
\hline & & & & & \\
\hline Block & Date & Treatment & Block & Date & Treatment \\
\hline 1 & $\begin{array}{ll}4 / 20 / 98 & 110 \\
4 / 21 / 98 & 111\end{array}$ & $\begin{array}{l}\text { Open } \\
\text { Closed }\end{array}$ & 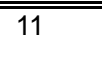 & $\begin{array}{ll}5 / 10 / 98 & 130 \\
5 / 11 / 98 & 131\end{array}$ & $\begin{array}{l}\text { Open } \\
\text { Closed }\end{array}$ \\
\hline 2 & $\begin{array}{ll}4 / 22 / 98 & 112 \\
4 / 23 / 98 & 113\end{array}$ & $\begin{array}{l}\text { Closed } \\
\text { Open }\end{array}$ & 12 & $\begin{array}{ll}5 / 12 / 98 & 132 \\
5 / 13 / 98 & 133\end{array}$ & $\begin{array}{l}\text { Closed } \\
\text { Open }\end{array}$ \\
\hline 3 & $\begin{array}{ll}4 / 24 / 98 & 114 \\
4 / 25 / 98 & 115\end{array}$ & $\begin{array}{l}\text { Open } \\
\text { Closed }\end{array}$ & 13 & $\begin{array}{ll}5 / 14 / 98 & 134 \\
5 / 15 / 98 & 135\end{array}$ & $\begin{array}{l}\text { Closed } \\
\text { Open }\end{array}$ \\
\hline 4 & $\begin{array}{ll}4 / 26 / 98 & 116 \\
4 / 27 / 98 & 117\end{array}$ & $\begin{array}{l}\text { Open } \\
\text { Closed }\end{array}$ & 14 & $\begin{array}{ll}5 / 16 / 98 & 136 \\
5 / 17 / 98 & 137\end{array}$ & $\begin{array}{l}\text { Open } \\
\text { Closed }\end{array}$ \\
\hline 5 & $\begin{array}{ll}4 / 28 / 98 & 118 \\
4 / 29 / 98 & 119\end{array}$ & $\begin{array}{l}\text { Closed } \\
\text { Open }\end{array}$ & 15 & $\begin{array}{ll}5 / 18 / 98 & 138 \\
5 / 19 / 98 & 139\end{array}$ & $\begin{array}{l}\text { Open } \\
\text { Closed }\end{array}$ \\
\hline 6 & $\begin{array}{ll}4 / 30 / 98 & 120 \\
5 / 01 / 98 & 121\end{array}$ & $\begin{array}{l}\text { Open } \\
\text { Closed }\end{array}$ & 16 & $\begin{array}{ll}5 / 20 / 98 & 140 \\
5 / 21 / 98 & 141\end{array}$ & $\begin{array}{l}\text { Closed } \\
\text { Open }\end{array}$ \\
\hline 7 & $\begin{array}{ll}5 / 02 / 98 & 122 \\
5 / 03 / 98 & 123\end{array}$ & $\begin{array}{l}\text { Closed } \\
\text { Open }\end{array}$ & 17 & $\begin{array}{ll}5 / 22 / 98 & 142 \\
5 / 23 / 98 & 143\end{array}$ & $\begin{array}{l}\text { Open } \\
\text { Closed }\end{array}$ \\
\hline 8 & $5 / 04 / 98 \quad 124$ & Closed & 18 & $5 / 24 / 98 \quad 144$ & Closed \\
\hline 9 & $\begin{array}{ll}5 / 05 / 98 & 125 \\
5 / 06 / 98 & 126\end{array}$ & $\begin{array}{l}\text { Open } \\
\text { Open }\end{array}$ & 19 & $\begin{array}{ll}5 / 25 / 98 & 145 \\
5 / 26 / 98 & 146\end{array}$ & $\begin{array}{l}\text { Open } \\
\text { Closed }\end{array}$ \\
\hline & 5/07/98 127 & Closed & & $5 / 27 / 98 \quad 147$ & Open \\
\hline 10 & $\begin{array}{ll}5 / 08 / 98 & 128 \\
5 / 09 / 98 & 129\end{array}$ & $\begin{array}{l}\text { Open } \\
\text { Closed }\end{array}$ & 20 & $\begin{array}{ll}5 / 28 / 98 & 148 \\
5 / 29 / 98 & 149\end{array}$ & $\begin{array}{l}\text { Open } \\
\text { Closed }\end{array}$ \\
\hline & & & & & \\
\hline Block & Date & Treatment & Block & Date & Treatment \\
\hline 1 & $\begin{array}{ll}6 / 06 / 98 & 157 \\
6 / 07 / 98 & 158\end{array}$ & $\begin{array}{l}\text { Closed } \\
\text { Open }\end{array}$ & 11 & $\begin{array}{ll}6 / 26 / 98 & 177 \\
6 / 27 / 98 & 178\end{array}$ & $\begin{array}{l}\text { Closed } \\
\text { Open }\end{array}$ \\
\hline 2 & $\begin{array}{ll}6 / 08 / 98 & 159 \\
6 / 09 / 98 & 160\end{array}$ & $\begin{array}{l}\text { Closed } \\
\text { Open }\end{array}$ & 12 & $\begin{array}{ll}6 / 28 / 98 & 179 \\
6 / 29 / 98 & 180\end{array}$ & Closed \\
\hline 3 & 6/10/98 161 & Open & 13 & $\begin{array}{ll}6 / 29 / 98 & 180 \\
6 / 30 / 98 & 181 \\
7 / 01 / 98 & 182\end{array}$ & Open \\
\hline 4 & $\begin{array}{ll}6 / 11 / 98 & 162 \\
6 / 12 / 98 & 163\end{array}$ & $\begin{array}{l}\text { Closed } \\
\text { Open }\end{array}$ & 14 & $\begin{array}{ll}7 / 01 / 98 & 182 \\
7 / 02 / 98 & 183\end{array}$ & $\begin{array}{l}\text { Closed } \\
\text { Closed }\end{array}$ \\
\hline & 6/13/98 164 & Closed & & 7/03/98 184 & Open \\
\hline 5 & $6 / 14 / 98 \quad 165$ & Open & 15 & $7 / 04 / 98 \quad 185$ & Open \\
\hline & 6/15/98 166 & Closed & & $7 / 05 / 98 \quad 186$ & Closed \\
\hline 6 & 6/16/98 167 & Open & 16 & 7/06/98 187 & Closed \\
\hline & 6/17/98 168 & Closed & & 7/07/98 188 & Open \\
\hline 7 & 6/18/98 169 & Open & 17 & 7/08/98 189 & Open \\
\hline & 6/19/98 170 & Closed & & 7/09/98 190 & Closed \\
\hline 8 & 6/20/98 171 & Closed & 18 & 7/10/98 191 & Closed \\
\hline & 6/21/98 172 & Open & & 7/11/98 192 & Open \\
\hline 9 & 6/22/98 173 & Open & 19 & 7/12/98 193 & Open \\
\hline & 6/23/98 174 & Closed & & $7 / 13 / 98 \quad 194$ & Closed \\
\hline 10 & $\begin{array}{ll}6 / 24 / 98 & 175 \\
6 / 25 / 98 & 176\end{array}$ & $\begin{array}{l}\text { Closed } \\
\text { Open }\end{array}$ & 20 & $\begin{array}{ll}7 / 14 / 98 & 195 \\
7 / 15 / 98 & 196\end{array}$ & $\begin{array}{l}\text { Open } \\
\text { Closed }\end{array}$ \\
\hline
\end{tabular}


through the sluice chute was estimated from hydroacoustic counts of fish passing through one of three uplooking, $6 \mathrm{deg}$, hydroacoustic beams (Figure 5). The 420-kHz, split-beam transducers were mounted $1.5 \mathrm{~m}$ apart on a span mount and aimed 10 deg upstream of vertical. The span mount was lowered into a slot immediately upstream of the gate slot down to elevation 52-ft mean sea level (MSL). Each transducer covered about 8 percent of the cross-sectional area of the sluice opening for a combined coverage of 24 percent. Every detected fish was expanded to one-third of the width of the sluice chute using Equation 1 (page 6) and a value of $1.52 \mathrm{~m}$ for one-third of the intake width. Transducers were slow multiplexed to maximize the ping rate of individual transducers at 37 pings per sec and fish detectability close to transducers (Appendix A). A 1-min slow multiplex among transducers provided twenty 1-min samples per transducer hour (33.3-percent temporal sampling). Spatially expanded counts of fish within hours and associated variances were temporally expanded to a whole hour using the methods described in Appendix B. Passage estimates and variance for days and seasons were obtained by summing hourly counts and variances.

The FGE of Intakes $11 \mathrm{~b}, 12 \mathrm{~b}$, and $13 \mathrm{~b}$ was estimated from counts of guided and unguided fish by a pair of $6 \mathrm{deg}$, single-beam transducers mounted in every intake (Figure 6). Guided fish were counted by a transducer mounted at the bottom of Trash Rack 5 and aimed upward toward the ceiling, 15 deg off the plane of the trash rack. Unguided fish were counted by a transducer mounted near the middle of Trash Rack 1 and aimed down 22 deg off the vertical plane of the trash rack. Beam coverage was about 20 percent of the cross-sectional area through which guided and unguided smolts passed. Each pair of up- and downlooking transducers was slow multiplexed at 1-min time intervals so that the ping rate for each transducer ( 25 pings/sec) and detectability (Appendix A) could be maximized. Every detected fish was expanded to the width of the intake using Equation 1 (page 6) and a value of $6.4 \mathrm{~m}$ for slot width. Slow multiplexing the six transducers in center intakes of Units 11-13 provided ten, 1-min samples per transducer hour. Spatially expanded counts of fish within hours and associated variances were temporally expanded to a whole hour using the methods described in Appendix B. The FGE of Intake $8 \mathrm{~b}$ was estimated as the number of guided fish divided by the sum of numbers of guided and unguided fish per hour, day, or season. The variance in fish passage and FGE was estimated by hour, day, and season using methods described in Appendix B.

We calculated a variety of fish-passage metrics for the sluice chute and Units 11-13 according to the methods described in Appendix B. The effects of the sluice chute were evaluated using a t-test to compare mean daily estimates of different fish-passage metrics among treatments each season.

We also compared sluice-chute passage of juvenile salmon to estimates of guided fish passage through all operational turbines at Powerhouse 2. We obtained hourly passage data for the juvenile bypass channel from the Smolt Monitoring Program, NMFS. These data consisted of counts of juvenile salmon passing over a shallow weir in the bypass channel during the first and last 5-min period of every hour. Estimates for the two 5-min samples were averaged, the 


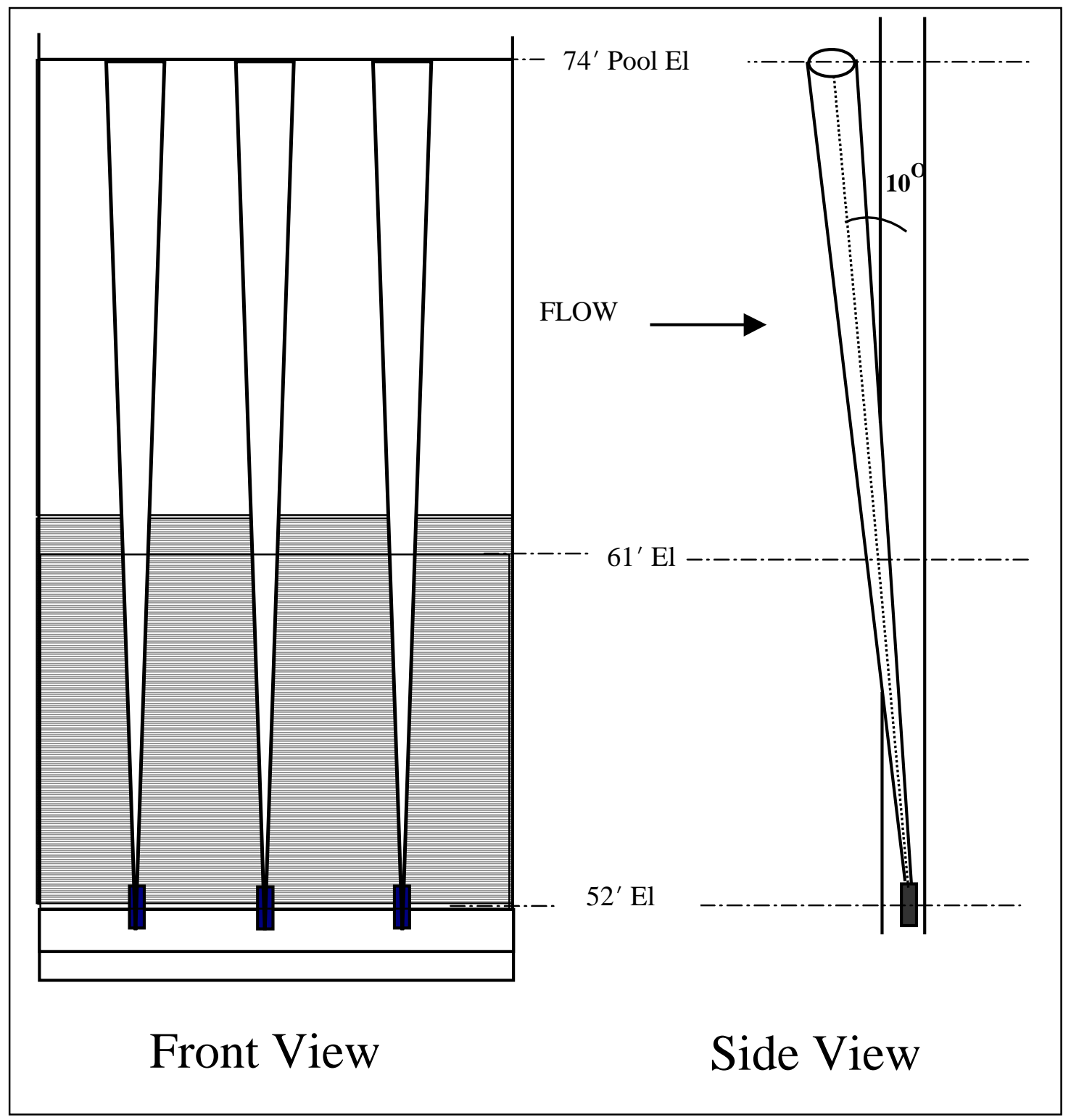

Figure 5. Diagram showing front and side views of hydroacoustic sample volumes of split-beam transducers on a span mount at the Powerhouse 2 sluice chute

mean was expanded to the whole hourly by multiplying by 12 , and within-hour variances were expanded to the whole hour using:

$$
H V A R=\frac{12^{2}\left[1-\frac{2}{12}\right] S^{2}}{2}
$$

where $S^{2}$ is the variance calculated from the two 5-min samples per hour. 


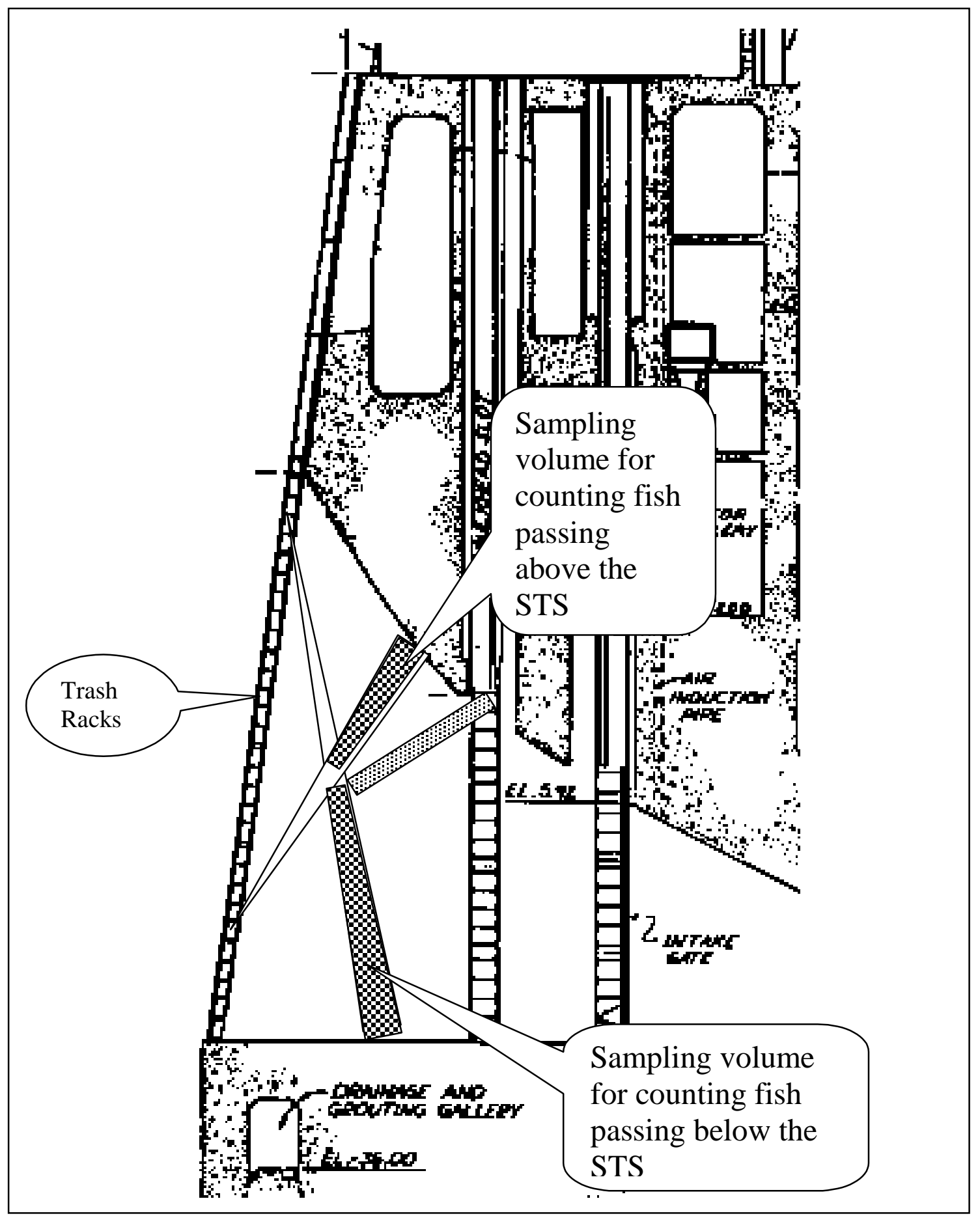

Figure 6. Cross section through a Powerhouse 2 turbine intake showing an STS and hydroacoustic beams for sampling fish passing above and below the STS (Fish counts are used to estimate fish passage and guidance efficiency) 


\section{Integrating Dam Operations Data}

We obtained dam operations data with a 5-min sample frequency from a web site designed and maintained by the U.S. Army Engineer District, Portland. These data included elevations of the forebay and tailrace and the discharge of water for each turbine unit and spill bay. We deleted all hydroacoustic data collected at units that were off and sluice openings when the sluice was closed. We calculated the volume of water discharged through turbines every hour from an average of 12 instantaneous flow readings (cfs) multiplied by 3,600 sec per hour for every turbine sampled. We predicted flow through PSC slots and sluice chute from regression equations fitted to data provided by the Hydraulic Design Section, Portland District. For the PSC slots, these data consisted of flow as a function of turbine discharge and forebay elevation. For the sluice chute, the data consisted of sluice-chute discharge as a function of the elevation of the top of the sluice gate and the forebay water level. Regression equations for predicting flow through PSC slots and the sluice chute made it possible for us to calculate the effectiveness of surface-passage routes for any combination of forebay elevation and turbine discharge or gate opening.

The regression equation for the 5-ft PSC slot was:

$$
\text { Slot } \mathrm{Q}=-12058.848+136.000 \times \mathrm{ELEV}+0.337 \times \mathrm{TQ}
$$

where Slot Q and TQ are slot and turbine discharge in cfs (respectively), and ELEV is forebay elevation in $\mathrm{ft}$ MSL. The $\mathrm{r}^{2}$ of the regression line fitted to 12 observations was 0.99 . For the 20 -ft PSC slot the equation was:

$$
\text { Slot } \mathrm{Q}=-7350.416+80.111 \times \mathrm{ELEV}+0.504 \times \mathrm{TQ}
$$

with the same variables and an $r^{2}$ of 0.74 . The equation for the sluice chute was:

$$
\text { Sluice } \mathrm{Q}=-380.158+213.478 \times(\mathrm{ELEV}-\mathrm{GATE})
$$

where Sluice Q is sluice-chute discharge in cubic feet per second, GATE is the elevation of the top of the sluice gate, and the $r^{2}$ of the regression line fitted to 22 observations was 0.98 . The top of the gate was set at elevation $61 \mathrm{ft} \mathrm{MSL}$ for all but 2 days when high forebay elevations and flows threatened to relocate sluiceway covers on the roadway of the tailwater deck. The top of the gate was set to $66 \mathrm{ft}$ MSL for those days.

\section{Handling Missing Data}

On rare occasions, hydroacoustic samples were missed at one or more transducers because there was a computer lockup, failure of hydroacoustic equipment, or damage to cables or transducers. Fish passage was set to zero when turbine units were off or the sluice chute was closed regardless of the operational state of hydroacoustic equipment. In 1998, missed samples were very rare when units or surface-bypass routes were operational. When samples

were missed, they usually were limited to $<0.5 \mathrm{hr}$ because every data acquisition 
system was checked hourly, $23 \mathrm{hr}$ per day. We lost no samples at transducers in the PSC or turbine Units 3 and 5 lasting for more than $0.5 \mathrm{hr}$ and there were $<10$ occurrences in 80 days of sampling with the 18 transducers. Samples from Units 1,2 , and 8 were lost during one night when a computer lockup went undetected until the download hour at about 0900 the next morning. Debris broke cables to split-beam transducers at the sluice chute, and 2 days were lost in the summer before repairs could be made. It was not possible sample with four transducers at Unit 8 for the first 5 days of spring, because the extended screen was not deployed. In the summer, the screen was removed for 2 days to allow for installation of vibration test equipment.

Choices for handling missing data include estimation of missing values or omission of lost time intervals from passage calculations. We did not estimate daily passage and omitted time intervals if missing data prevented estimates for 8 or more consecutive hours out of $23 \mathrm{hr}$ sampled per day. We did estimate missing values whenever the missing within-hour samples would result in an underestimate of the sum of fish passed per hour. Our approach was to estimate a mean passage rate per minute for the hour containing missing 1-min samples from the nonmissing samples and to apply this average rate to every missing 1-min sample. However, the within-hour variance was based upon sampled data only. For example, if two of six 1-min samples were missing, we calculated a mean rate of passage and its variance for the four available 1-min samples. This mean rate was then applied to each of the two missing 1-min samples. The passage rate for the 6 min sampled per hour was calculated by summing counts for the two estimated 1-minute periods and four sampled periods. However, the within-hour variance was based upon the four 1-min samples only.

\section{Fish Selection Criteria and Intertracker Bias}

As many as 11 people were visually processing hydroacoustic data at different times to identify echo traces that met fish-tracking criteria. Consequently, we felt it was important to quantify and minimize intertracker bias in passage estimates and statistical comparisons. All acquired data were processed without temporal subsampling by seven trackers working full time. Intertracker bias may result in differences in counts for different transducers and arises from differences in the interpretation of what constitutes a fish from a pattern of dots in an echogram drawn on a computer screen. An echogram is a scatter plot of range $(\mathrm{m})$ from a transducer as a function of time (pings). Points on an echogram represent echoes from objects moving through a hydroacoustic beam.

Criteria for accepting a series of echoes as a fish trace varied among transducer locations and aiming angles (Table 3 ). In visually processing echograms, people usually focus on relatively simple criteria such as range of interest, minimum number of echoes, ping gap, linearity, slope, and proximity to noise. Echoes from bubbles entrained in turbulent flow are a common source of noise, but the prevalence of noise varies widely among transducer locations. Fish traces cannot be reliably selected from areas with bubble-generated echoes in turbulent flow. For example, transducers sampling PSC entrances were quite 


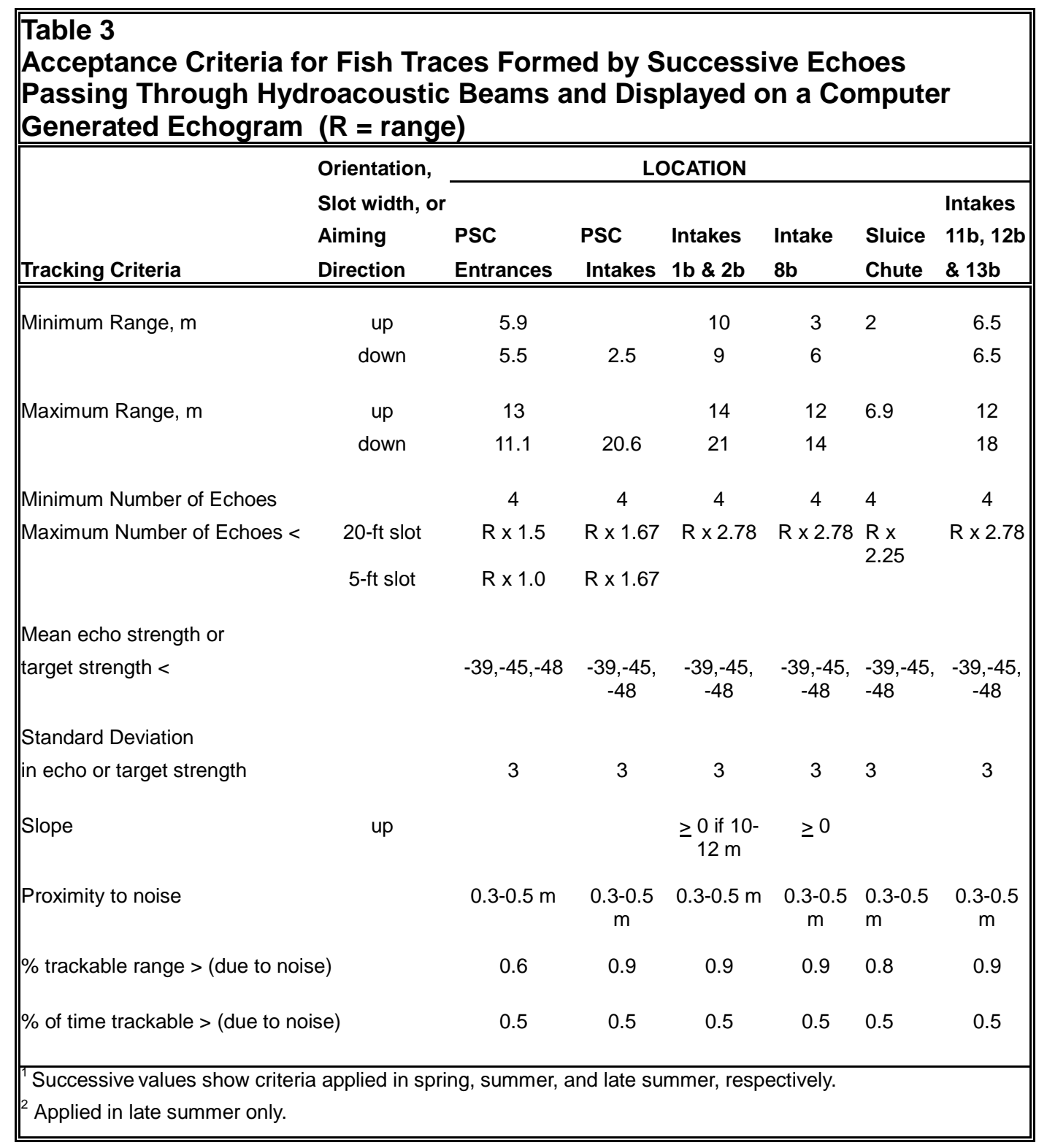

noisy, especially within $2 \mathrm{~m}$ of the surface of the water. Therefore, counts from the entrances underestimated fish passage when noise precluded tracking in part of the sampling range.

Trackers received training to increase the consistency of tracking among systems. Unfortunately, trackers often still had to make subjective decisions based upon qualitative criteria like the proximity of a trace to noise, the density and intensity of echoes from noise relative to echoes from fish, or minimum ping gap. Trackers were taught not to track in noisy areas where four or more echoes might line up by coincidence and look like a fish trace. However, when is noise too dense or a fish trace too close to noise? These decisions vary among trackers and perhaps even for a single tracker depending upon fatigue. Some trackers are consistently more aggressive than others, and some are very conservative. In another example of potential subjectivity, five successive echoes may be 
separated from four other successive echoes by a 5 to 9-ping gap. Although the echoes line up perfectly, a tracker must decide whether this pattern represents one or two fish based upon ping rate and a guess. With a single-beam transducer system, it is impossible to know. It could be one fish with a ping gap resulting from a brief change in aspect as the fish passed through the hydroacoustic beam. Alternatively, two fish could pass successively through the beam with similar trajectories and coincident exit and entrance ranges. A barrel view of the trace generated from three-dimensional split-beam data may provide a definitive answer, but split-beam transducers are four to five times more expensive than single-beam transducers and are not widely used. Many of the tracking criteria in Table 3 can be applied as subletting filters after echograms have been tracked by people. This quality-control check eliminates fish that were inadvertently tracked, but there is no way to add fish that were initially missed.

Intertracker bias was estimated by comparing fish counts and variances for different trackers processing identical data sets in spring and summer. We had available people track the same six 12-min files from each of five sets of transducers in spring and thirty-six, 12-min files from each of the three sets of transducers in summer. Trackers were too busy trying to keep up with routine processing in spring to track more sets of files. By summer, the tracking crew was more experienced and up to date on processing and could to expand the size of the intertracker data set. Transducer sets per system included six at PSC Entrance 3b, six at PSC Entrance 5b, eight at Intakes 1b, 2b, and 8b, three at the sluice chute, and six at Intakes $11 \mathrm{~b}, 12 \mathrm{~b}$, and $13 \mathrm{~b}$. We were not interested in random error that might produce different counts in single files but systematic error that would be evident in differences in counts over multiple files. Most comparisons made with the hydroacoustic data were based upon the sum of counts for 23-46 hr (one hundred fifteen to two hundred thirty (115-230) 12-min files).

\section{Diel Patterns}

Diel patterns in the number of fish passing per hour and averages of associated metrics were plotted against hour of the day for each season. Differences among hours were evaluated by comparing 95-percent confidence intervals about the sums or means rather than by a formal statistical test. 


\section{Results}

\section{Prototype Surface Collector and Adjacent Units}

Sampling of PSC-slot entrances was hampered by entrained air within 2-m of the surface, especially on the sides of the 20 -ft-wide slot, and by circulation of water among the $\mathrm{a}, \mathrm{b}$, and $\mathrm{c}$ modules. Nevertheless, fish counts from uplooking transducers were $\geq 10$ percent higher than counts from downlooking transducers, except on the north side of the 20 -ft opening, and counts on the north and south were higher than counts in the middle (Figure 7). Entrance counts of fish were about 5.5 times higher through the 20 - $\mathrm{ft}$ slot than through the 5-ft slot in spring and 3.2 times higher in summer (Table 4). Noise near the surface usually was dense enough to obscure fish traces, particularly on the north side of the $20-\mathrm{ft}$ opening.

Sampling of PSC entrances suggested that fish passage during 2-day treatments was consistently higher at 20 -ft-wide slots than at 5 -ft-wide slots (Figure 8). Entrance sampling also showed that the efficiency of the PSC was consistently higher for 20-ft treatments than for 5-ft treatments (Figure 9). A paired t-test indicated that similar numbers of fish passed under the PSC during both treatments in spring $(\mathrm{P}=0.627)$, but more passed under the 5 -ft slot than under the 20-ft slot in summer $(\mathrm{P}=0.0079$; Figure 10). Based upon sampling of PSC entrances, the 5-ft slot was twice as effective, relative to flow, in passing juvenile salmon than the 20-ft slot in both spring and summer (Figure 11).

In-turbine sampling required the selection of a range from the downlooking transducers to categorize fish as passing through or under the PSC. We examined slopes of fish traces passing through the hydroacoustic beams and found that a rapid increase in slope between 10 and $11 \mathrm{~m}$ clearly identified the elevation of the tip of the screen (Figure 12). This elevation also corresponds to the elevation of the floor of the PSC. Each point on the graph at ranges $<12 \mathrm{~m}$ were represented by hundreds of observations each season and 95-percent confidence intervals were narrow. All changes in range were downward, away from transducers. Fish passing through the PSC at the elevation of the floor $(10 \mathrm{~m})$ would drop 0.5 to $0.6 \mathrm{~m}$ over a $3-\mathrm{m}$ run from the floor to the center of the hydroacoustic beam. Consequently, we selected 10.5 as the cutoff range for classifying fish as passing through or under the floor. We checked to see how sensitive in-turbine estimates of efficiency might be to cutoff range by calculating efficiency based upon three ranges (Figure 13). The 95-percent confidence 


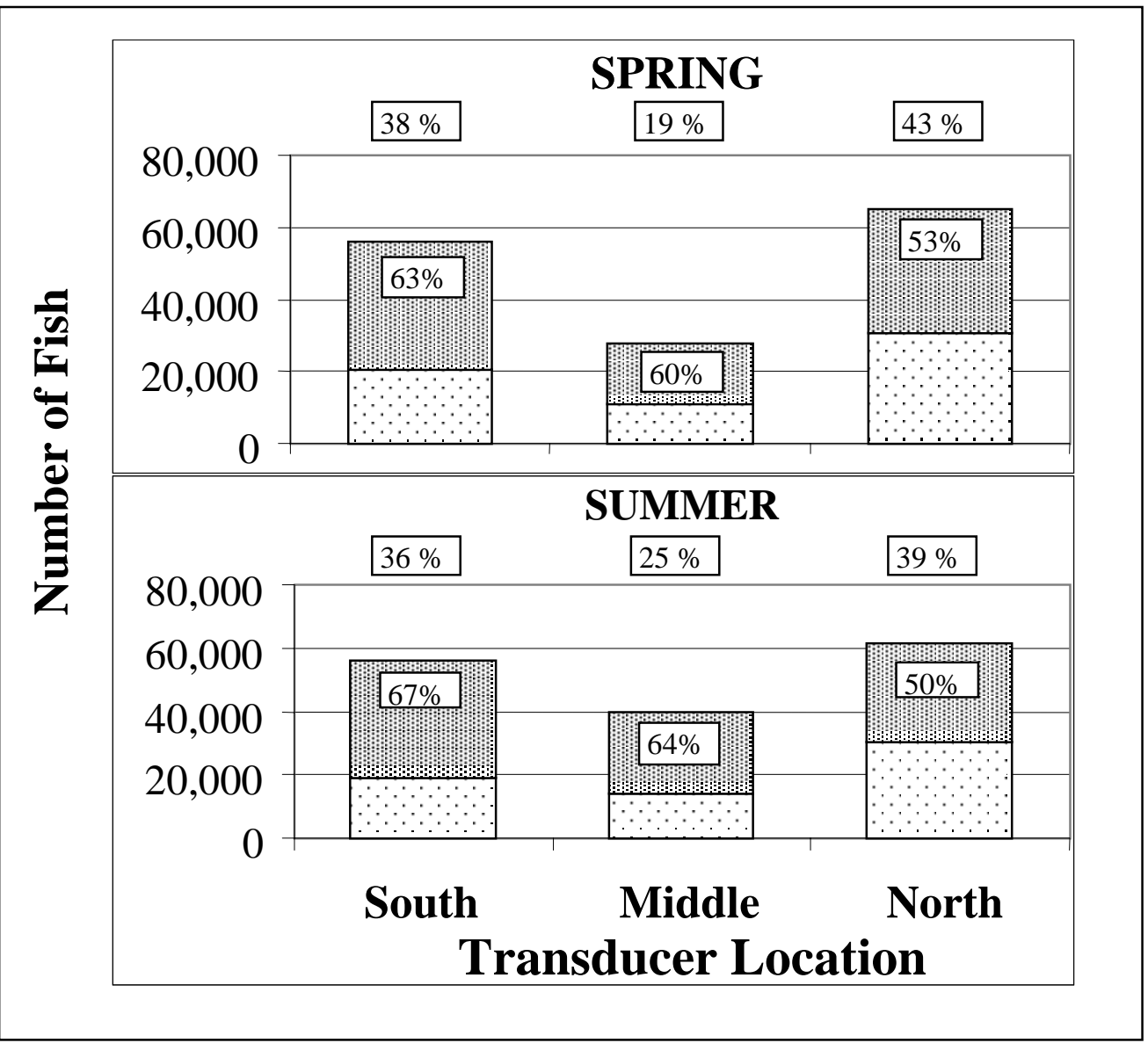

Figure 7. Lateral and vertical distribution of fish passing through 20 -ft-wide slots in the PSC at Intakes $3 b$ and $5 b$ (Percentages at the top of each graph indicate the lateral distribution of fish across the slot entrance. Labels in the upper part of bars show the percent of PSC-collected fish counted in the upper one-half of the slot entrance to the PSC).

interval for the 10.5-m cutoff range usually overlapped efficiency estimates calculated for 10.0- and 11.0-m ranges. Mean efficiency was $90 \pm 4.8$ percent.

Based upon a paired t-test on means from in-turbine sampling, the efficiency of the PSC was higher for the 5-ft-wide slot treatment (0.92) than for the $20-\mathrm{ft}$ slot treatment $(0.88)$ in spring $(\mathrm{P}=0.0053)$. However, the trend was reversed with greater mean efficiency apparent for the 20-ft-wide slot (0.92) than for the 5-ft-wide slot (0.84) in summer ( $\mathrm{P}=0.0106$; Figure 14).

In-turbine sampling revealed no significant difference between the number of fish passing through 20 - and 5-ft-wide slots in spring $(\mathrm{P}=0.1448)$ but showed that more fish passed through the 20-ft slot than through the 5-ft slot in summer (Figure 15). Passage at PSC Slots 3 and 5 were correlated in time, but on average both the 5 - and 20 -ft-wide slots at Unit 3 tended to pass more fish than the same slots at Unit 5 (Figure 16). 


\begin{tabular}{|c|c|c|c|c|c|}
\hline $\begin{array}{l}\text { Table } 4 \\
\text { Distribu } \\
\text { at Intak }\end{array}$ & $\begin{array}{l}\text { of Fish } \\
\text { and } 5 b\end{array}$ & $\begin{array}{l}\text { sage } \\
\text { Sprin }\end{array}$ & $\begin{array}{l}\text { ugh F } \\
\text { d Sum }\end{array}$ & Slots & ances \\
\hline & & & _ateral $\mathrm{Pc}$ & & \\
\hline Treatment & Position & South & Middle & North & Grand Sum \\
\hline Spring & & & & & \\
\hline & Top & & 17,256 & & \\
\hline 5-ft slot & Bottom & & 9,692 & & \\
\hline & All & & & 26,948 & 26,948 \\
\hline $20-\mathrm{ft}$ slot & Top & 35,356 & 16,448 & 34,662 & 86,467 \\
\hline & Bottom & 20,583 & 11,144 & 30,540 & 62,267 \\
\hline & All & 55,939 & 27,592 & 65,202 & 148,733 \\
\hline Summer & & & & & \\
\hline & Top & & 34,275 & & \\
\hline 5 -ft slot & Bottom & & 15,465 & & \\
\hline & All & & & 49,740 & 49,740 \\
\hline $20-\mathrm{ft}$ slot & Top & 37,371 & 25,339 & 30,846 & 93,557 \\
\hline & Bottom & 18,825 & 14,393 & 30,673 & 63,891 \\
\hline & All & 56,196 & 39,733 & 61,519 & 157,448 \\
\hline
\end{tabular}

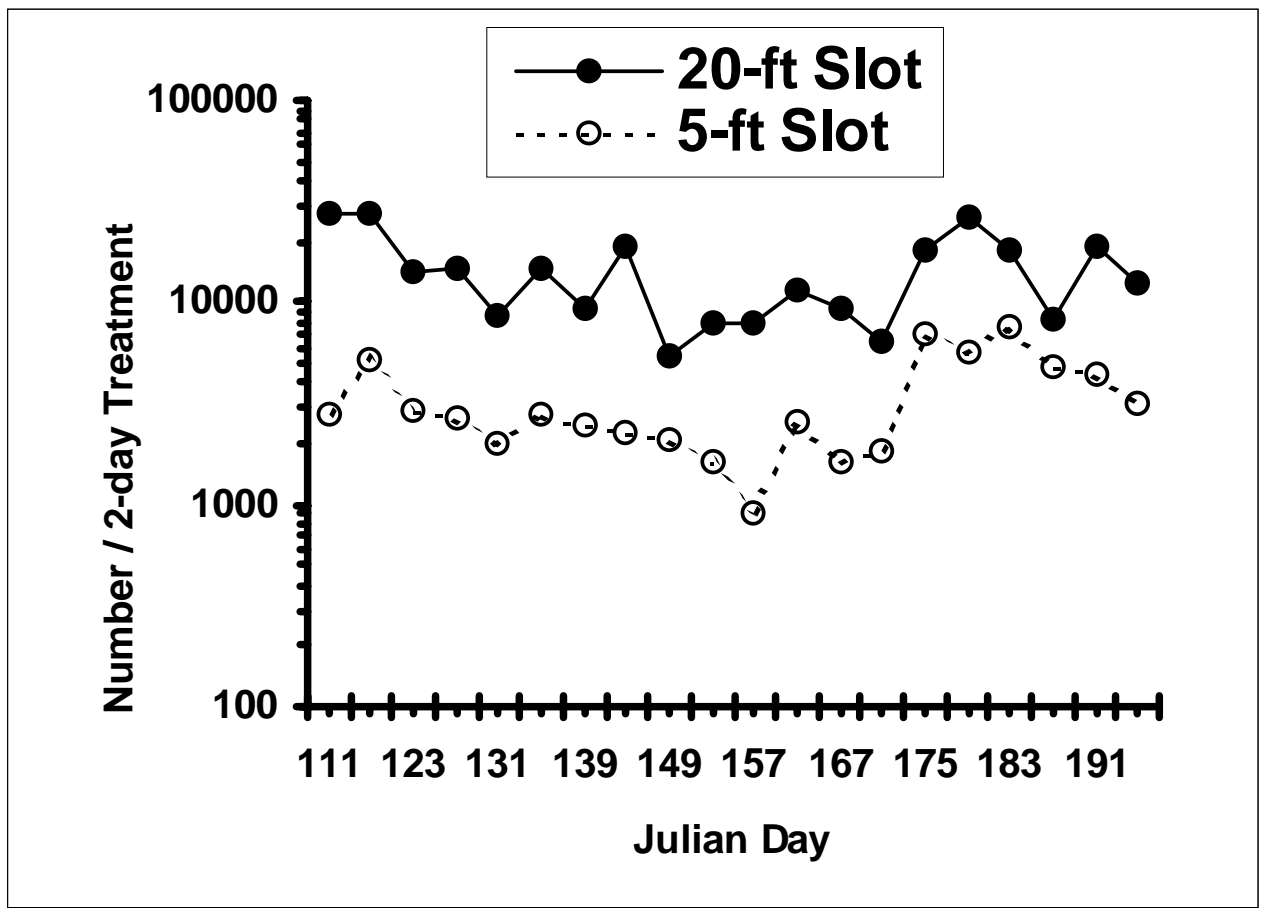

Figure 8. Estimated number of fish counted passing through 5- and 20-ft slot entrances in the PSC based upon slot-entrance sampling

Estimates of PSC effectiveness from in-turbine and PSC-slot sampling were highly correlated (Figure 17), and, therefore, Figure 11 is representative of seasonal trends by either sampling method. The lower plot in Figure 17 is a detail of the upper plot, excluding the outlying maximum point. 


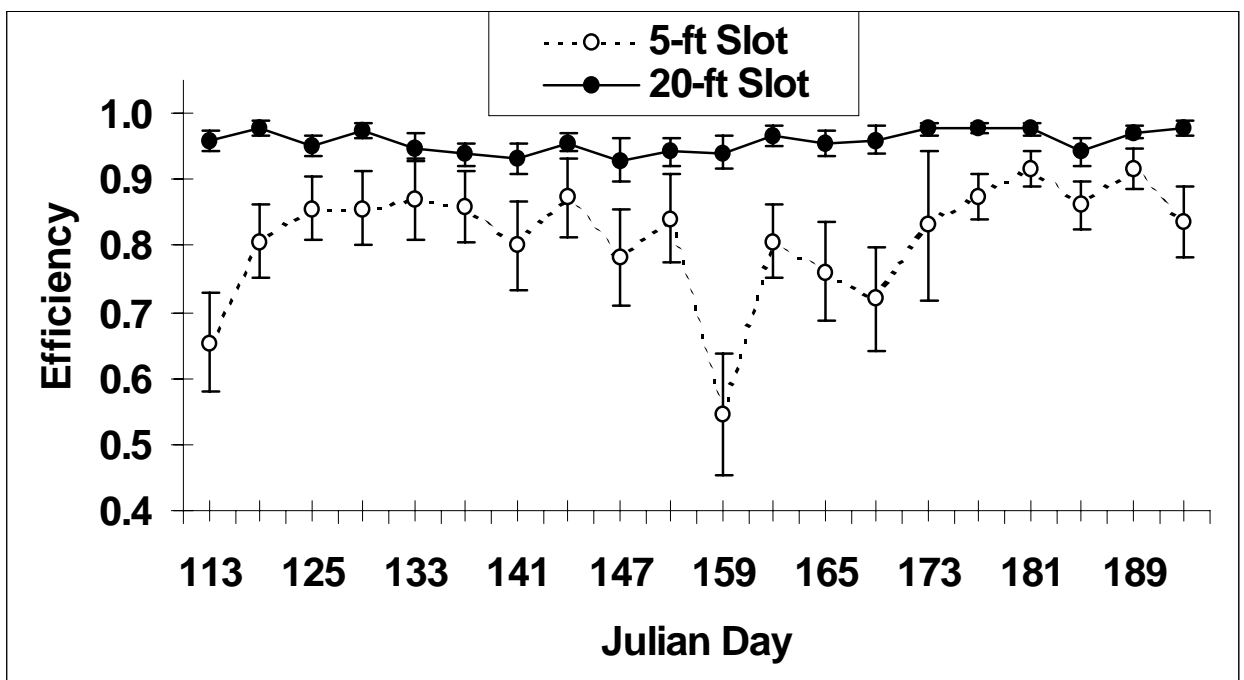

Figure 9. Efficiency of the 5- and 20-ft slot based upon slot-entrance counts and in-turbine estimates of numbers passing under the PSC (Error bars are 95-percent confidence intervals on estimates)

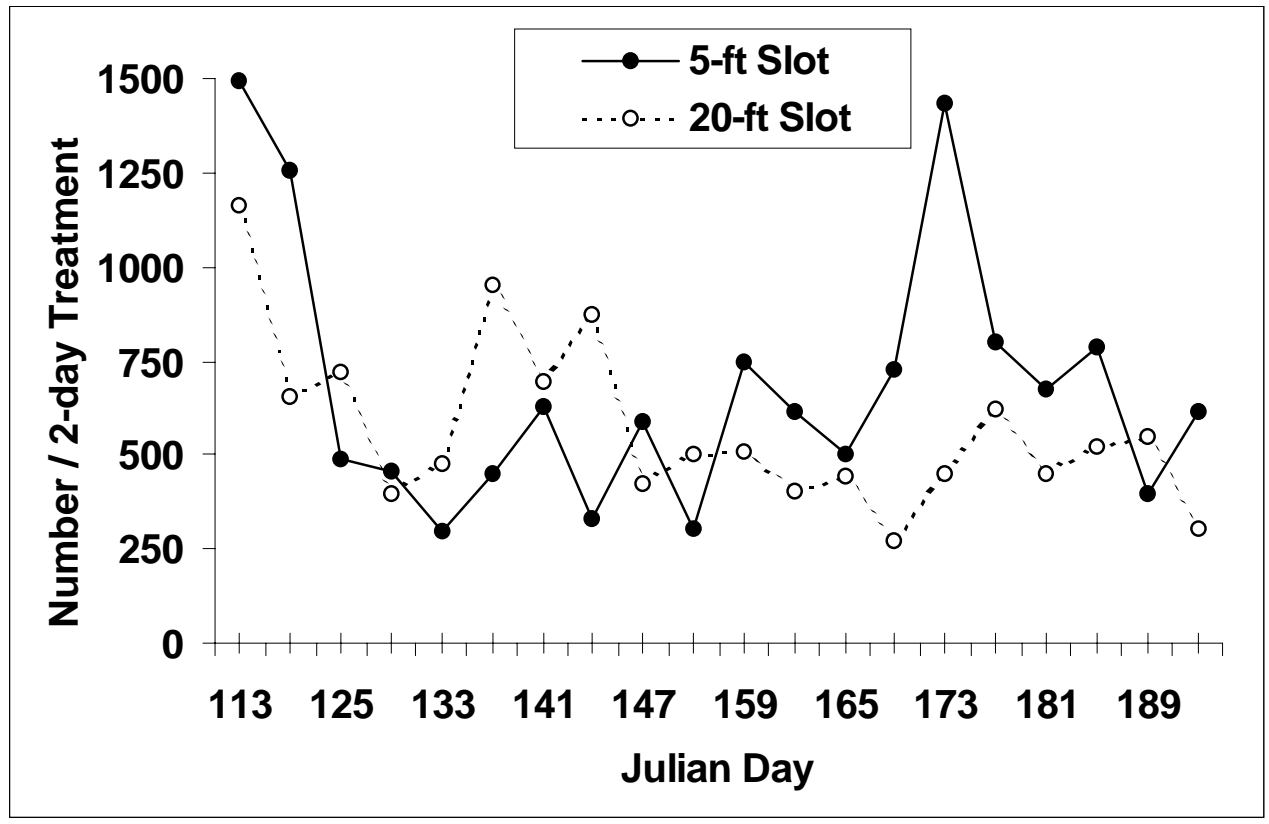

Figure 10. Estimated numbers of juvenile salmon passing under the PSC during 5- and 20-ft-wide slot treatments in spring and summer 1998 as estimated by sampling with a downlooking transducer in the turbine downstream of the PSC

Figure 18 shows that mean density of fish passing through the PSC was significantly higher during 5-ft slot treatments than during 20-ft treatments in spring $(\mathrm{P}=0.0006)$ and summer $(\mathrm{P}=0.0049)$. This result is similar to the finding on passage effectiveness (Figure 11), which is another volume-based estimator. At 2,750 cfs, the 20 -ft-wide slot passes about 2.81 times the volume of water that the 5 -ft slot passes (980 cfs). 


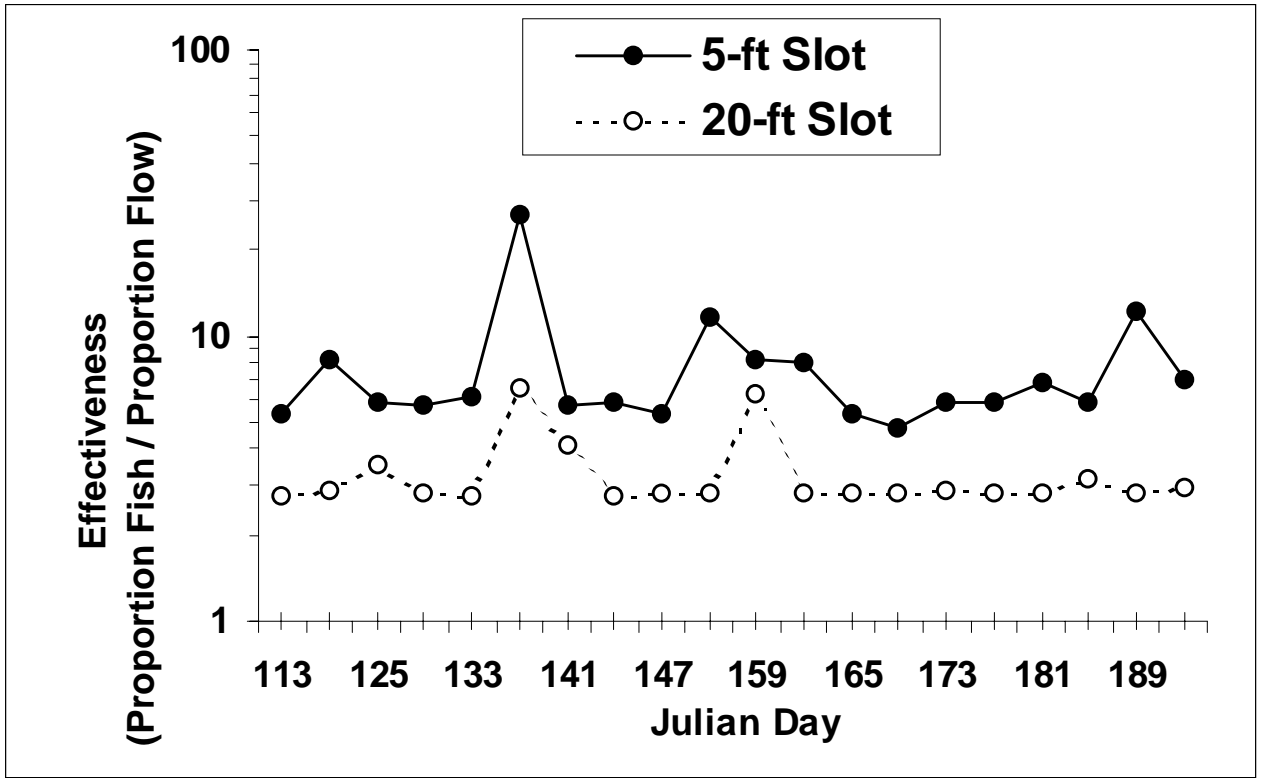

Figure 11. Effectiveness of 5- and 20-ft-wide slots in the PSC based upon slot-entrance counts

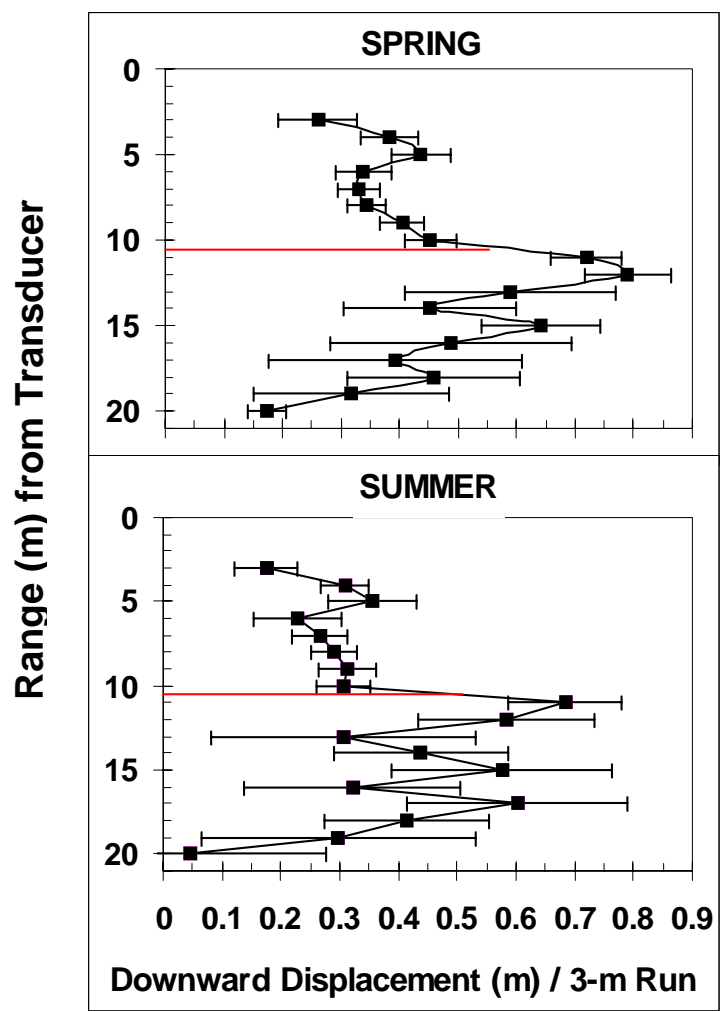

Figure 12. Downward displacements and their 95-percent confidence intervals for fish passing through a downlooking hydroacoustic beam in the turbine intakes downstream of the PSC (Displacement was referenced to a 3-m run because the distance from the PSC floor to the middle of the beam was about $3 \mathrm{~m}$; Error bars are 95-percent confidence intervals on estimates) 


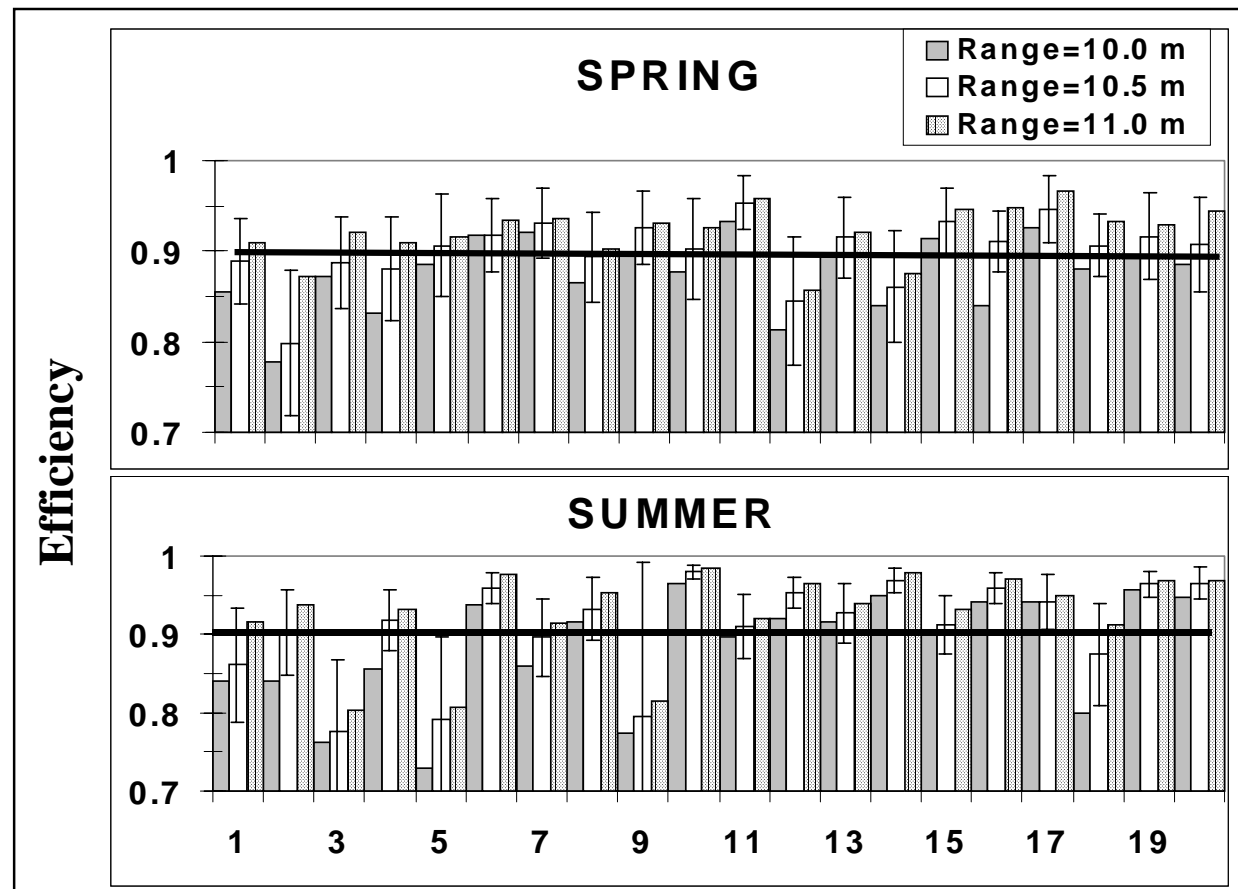

2-Day Treatment

Figure 13. Sensitivity of PSC efficiency estimates from in-turbine transducer beams to the cutoff range for classifying fish traces as passing through or under the PSC (Error bars are 95-percent confidence intervals on estimates)

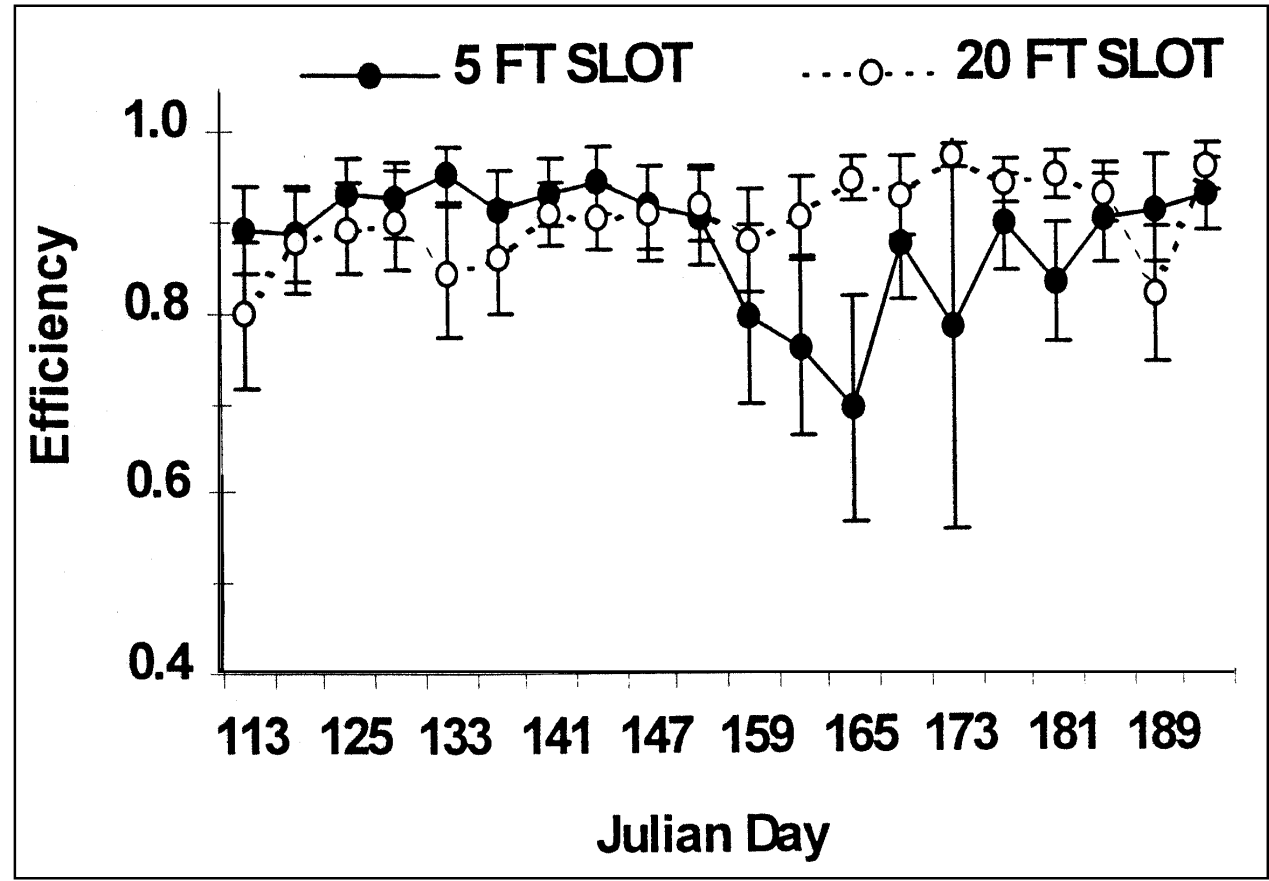

Figure 14. Efficiency of 5- and 20-ft-wide slots estimated from in-turbine counts of fish passing through and under the PSC(Error bars are 95-percent confidence intervals on estimates) 


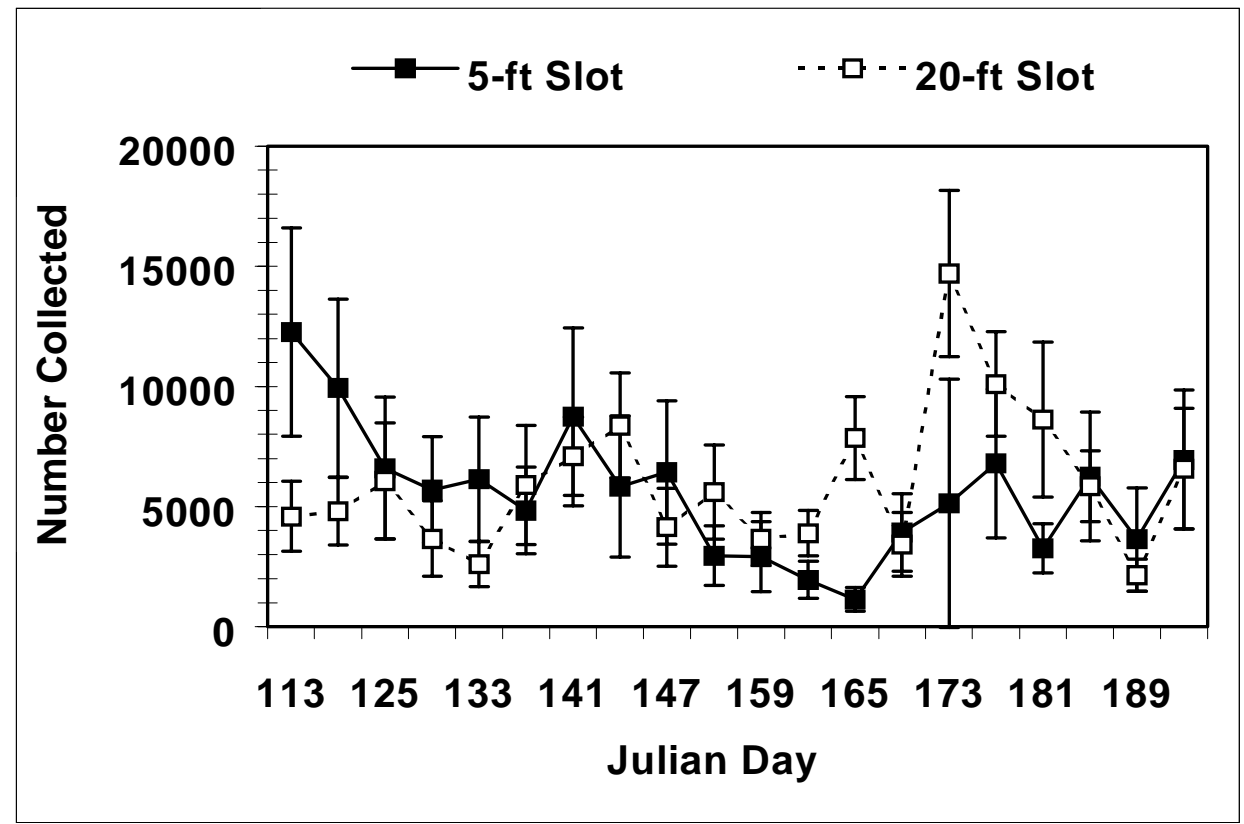

Figure 15. Estimated number of fish collected by the PSC during 2-day, 5and 20 -ft-wide slot treatments based upon in-turbine counts. (Error bars are 95-percent confidence intervals on estimates)

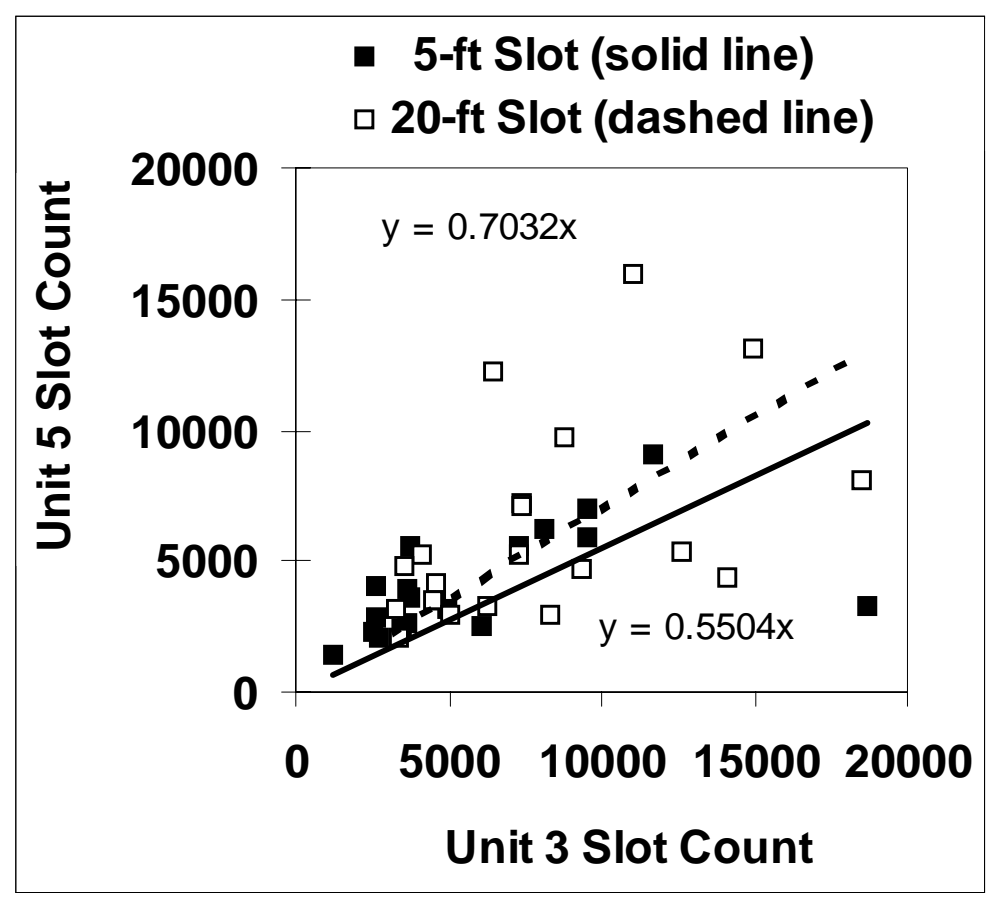

Figure 16. Correlation of numbers of fish collected at Unit 3 with numbers collected at Unit 5 under 2-day, 5- and 20-ft-wide slot treatments 


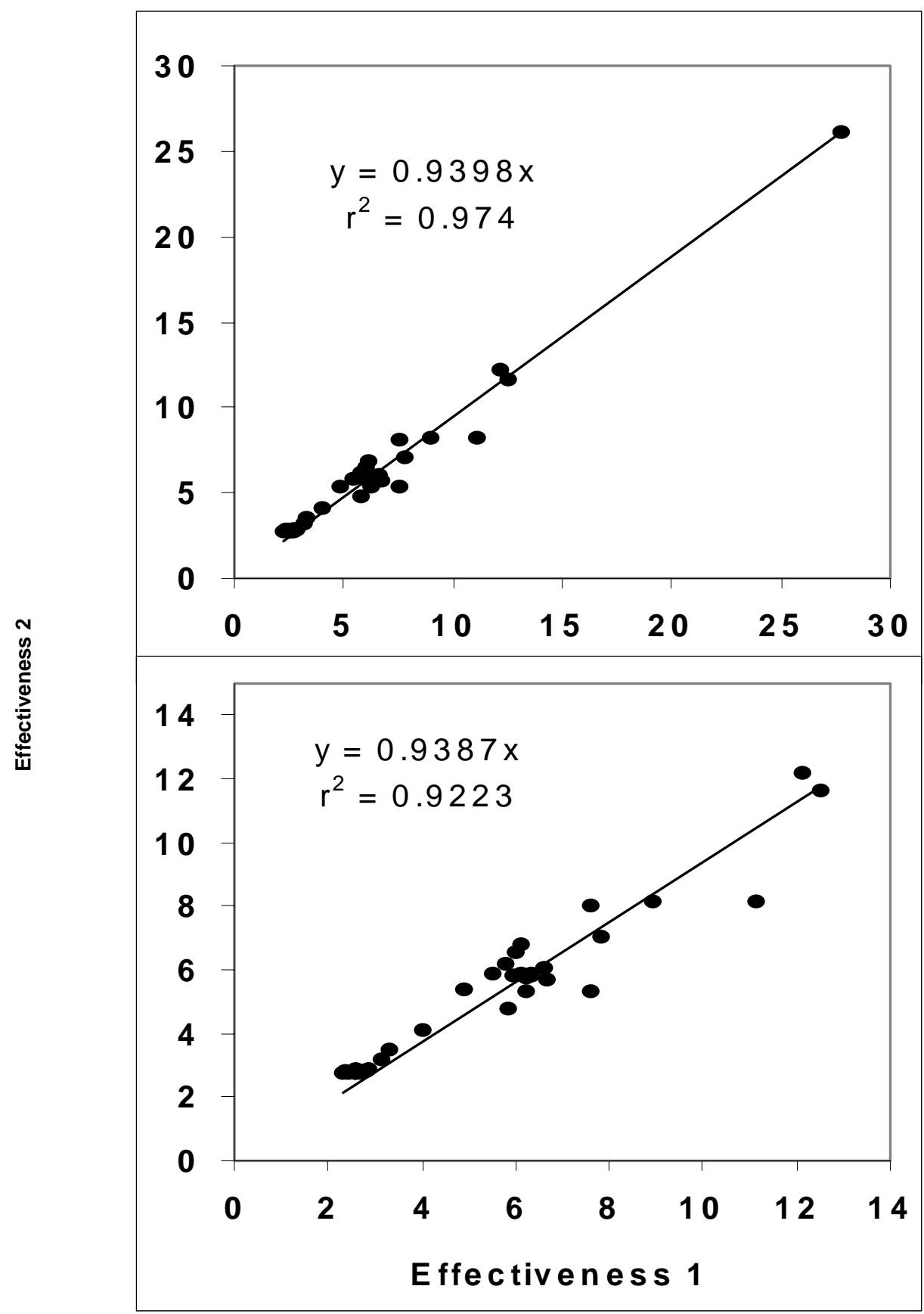

Figure 17. Correlation of two measures of slot effectiveness at the PSC (Effectiveness 1 was estimated from counts of fish at slot entrances, whereas Effectiveness 2 was estimated from in-turbine counts of fish after they had passed through the PSC. The intercept was forced through the origin) 


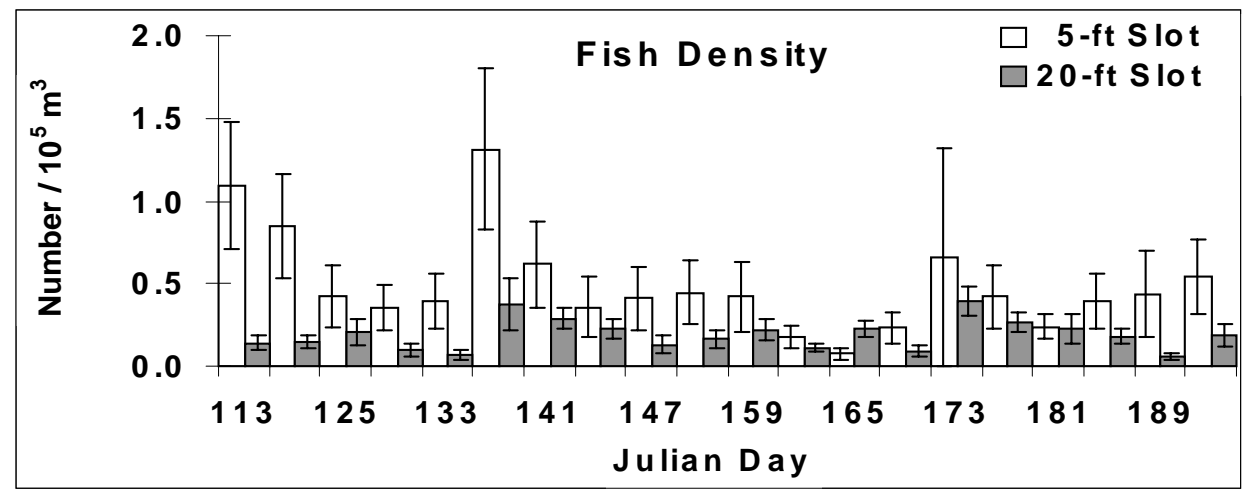

Figure 18. Seasonal trends in the density of fish passing through 5- and 20-ftwide slots in the PSC

Although the day-to-day variability in fish passage at turbine units adjacent to the PSC was high, the FGE of STS of both units declined significantly from spring through summer (Figure 19). The FGE of the screen in Intake 1b was about twice as high as that of the screen in Intake $2 b$ throughout spring and summer.

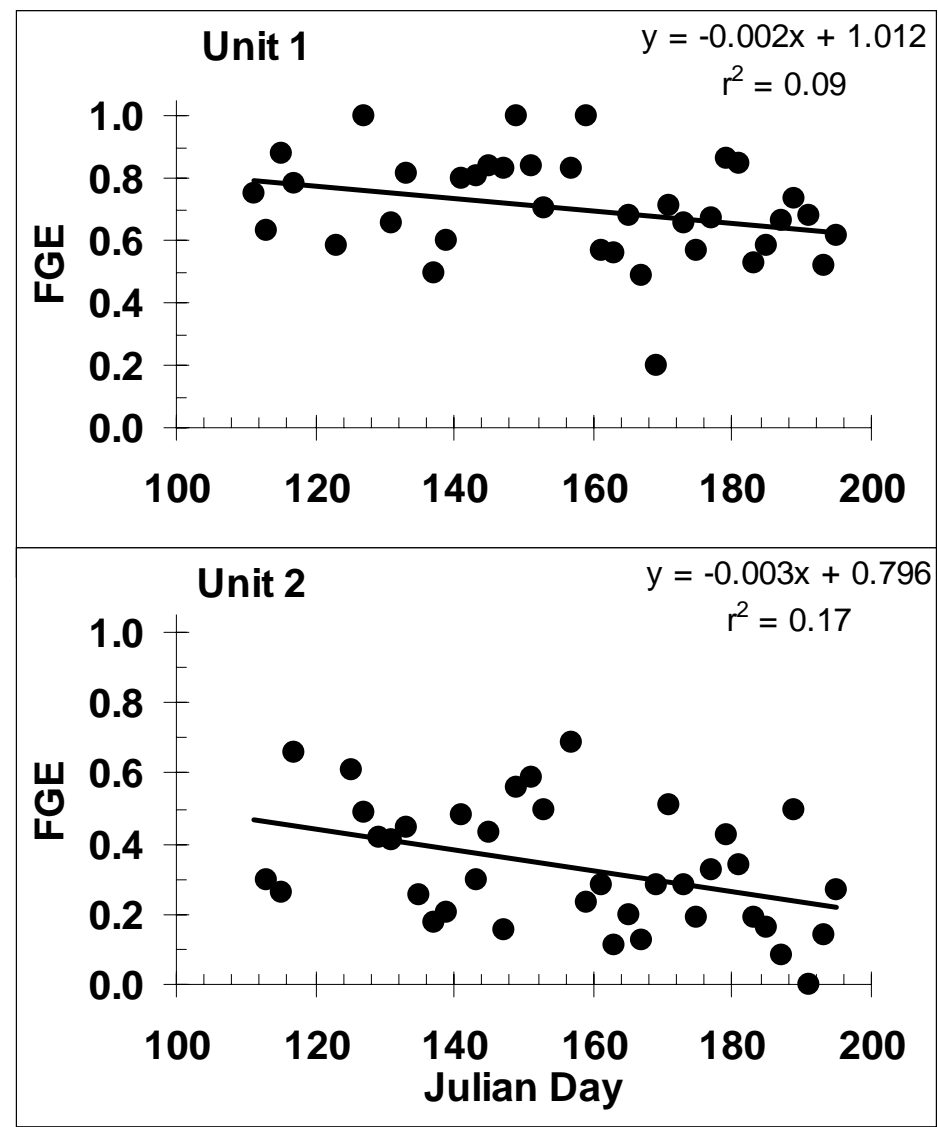

Figure 19. FGE of STS in Intakes $1 \mathrm{~b}$ and $2 \mathrm{~b}$ as a function of Julian date in 1998 
The number of fish passing at Intake $2 b$ also was significantly lower than the number passing at Intake $1 \mathrm{~b}$ (Figure 20). We found no significant difference in the estimated total number of fish passing through Units 1 and 2 (all intakes) between the 5 - and 20 -ft slot treatments in spring $(\mathrm{P}=0.8306)$ or summer $(\mathrm{P}=$ 0.1208; Figure 21).

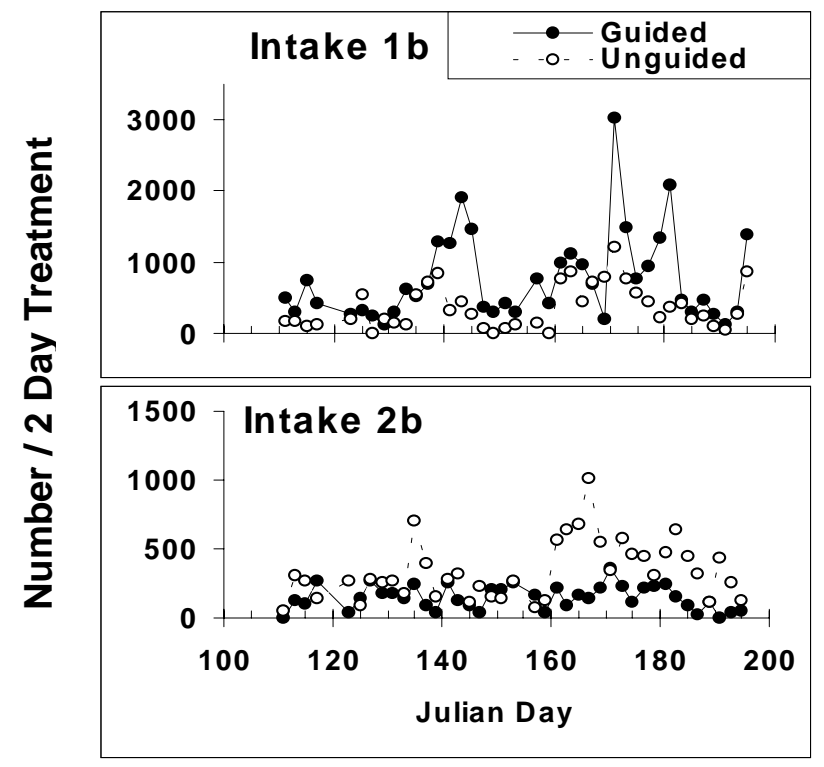

Figure 20. Estimated numbers of fish passing above and below STS in Intakes $1 \mathrm{~b}$ and $2 \mathrm{~b}$

In-turbine estimates of fish passage through the PSC were significantly higher than total passage through all intakes at Units 1 and 2 in spring $(\mathrm{P}=$ $0.0003)$, and estimates were similar in summer $(P=0.6607$; Figure 22). The intakes at Units 1 and 2 were 3.2 times wider than two 40-ft PSC slots and 12.6 times wider than two 5-ft PSC slots. Differences were more pronounced when fish passage was standardized per foot of intake width to account for size differences in passage routes (Figure 23). Efficiency of the PSC relative to Units 1 and 2 averaged 85 percent when we accounted for differences in the width of passage routes (Figure 24), and 50-60 percent when the size of passage routes was ignored.

\section{Extended-Submerged Bar Screen at Intake 8b}

Hydroacoustic estimates of FGE for the ESBS averaged 80 percent in spring but declined significantly during summer (Figure 25) to about 40 percent. Netting estimates by the NMFS showed a similar pattern although the summer decline was more pronounced. They averaged 70-75 percent in spring and declined to about 20 percent by the end of summer (Figure 25).

Estimates of FGE by hydroacoustics and netting were significantly correlated $(\mathrm{P}<0.0001)$, although the $\mathrm{r}^{2}$ was only about 0.35 (Figure 26 ). The hydroacoustic 


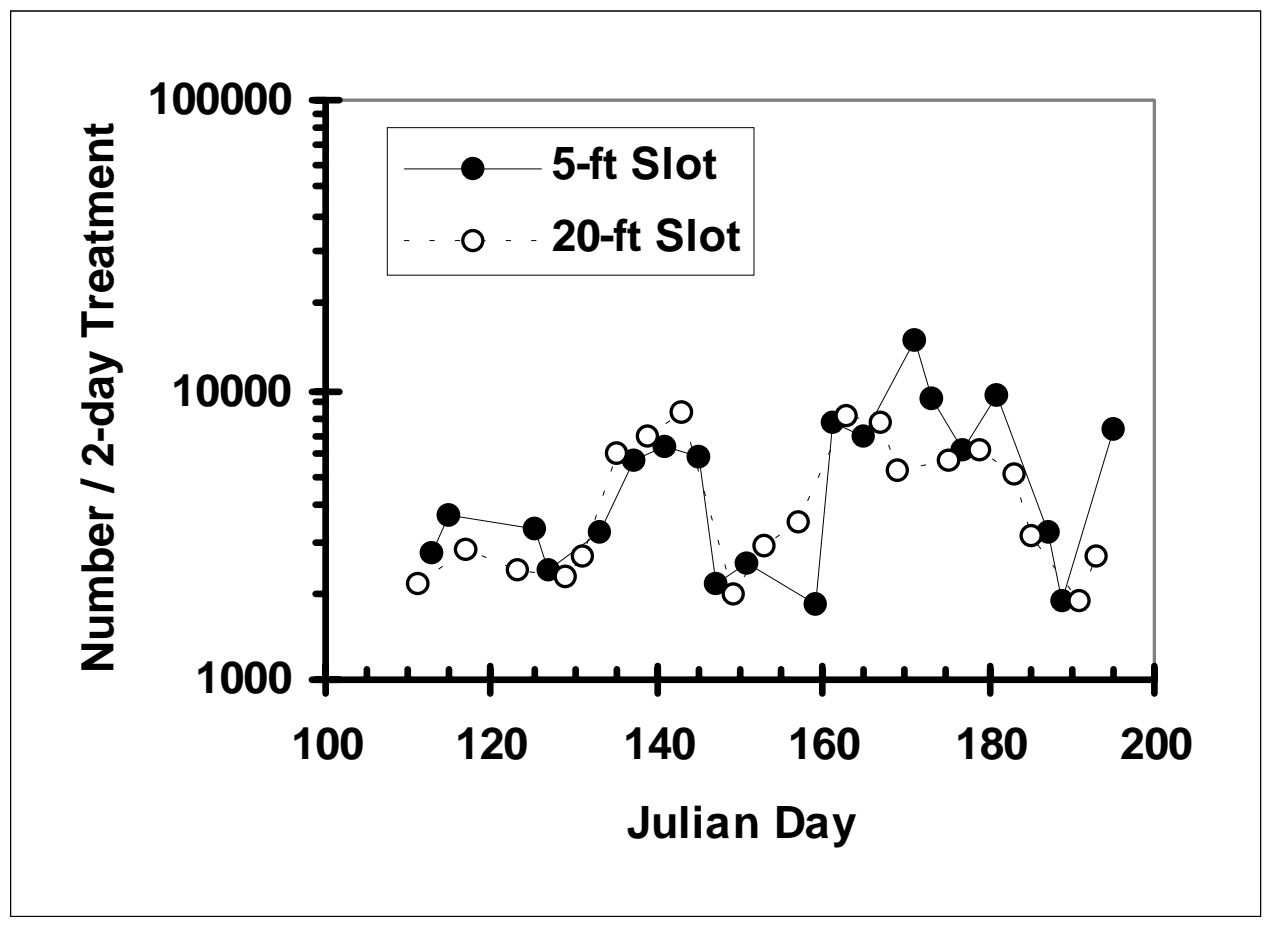

Figure 21. Seasonal trends in estimated numbers of fish passing through Units 1 and 2 by slot-width treatment at the PSC (There was no significant difference among treatments)

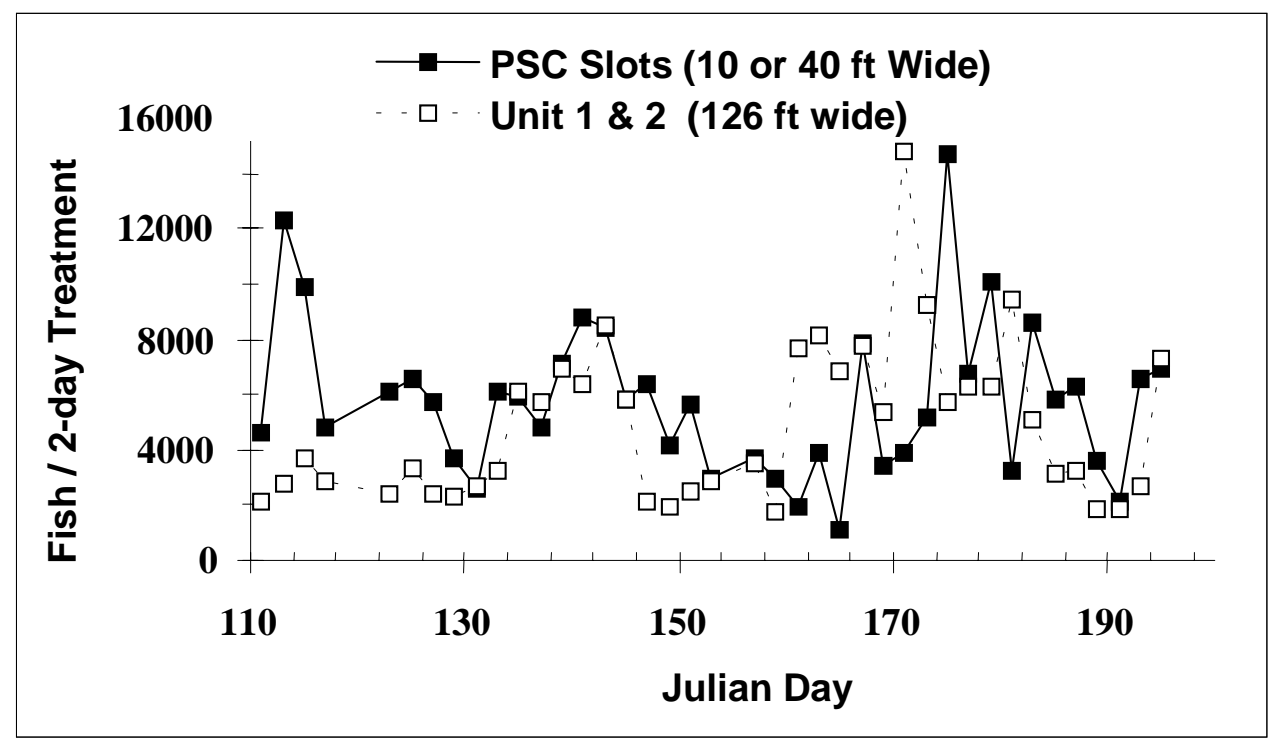

Figure 22. Total fish passage rate at all intakes of Units 1 and 2 relative to rates at two 5-ft- or two 20-ft-wide, 40-ft-deep slots at the PSC 


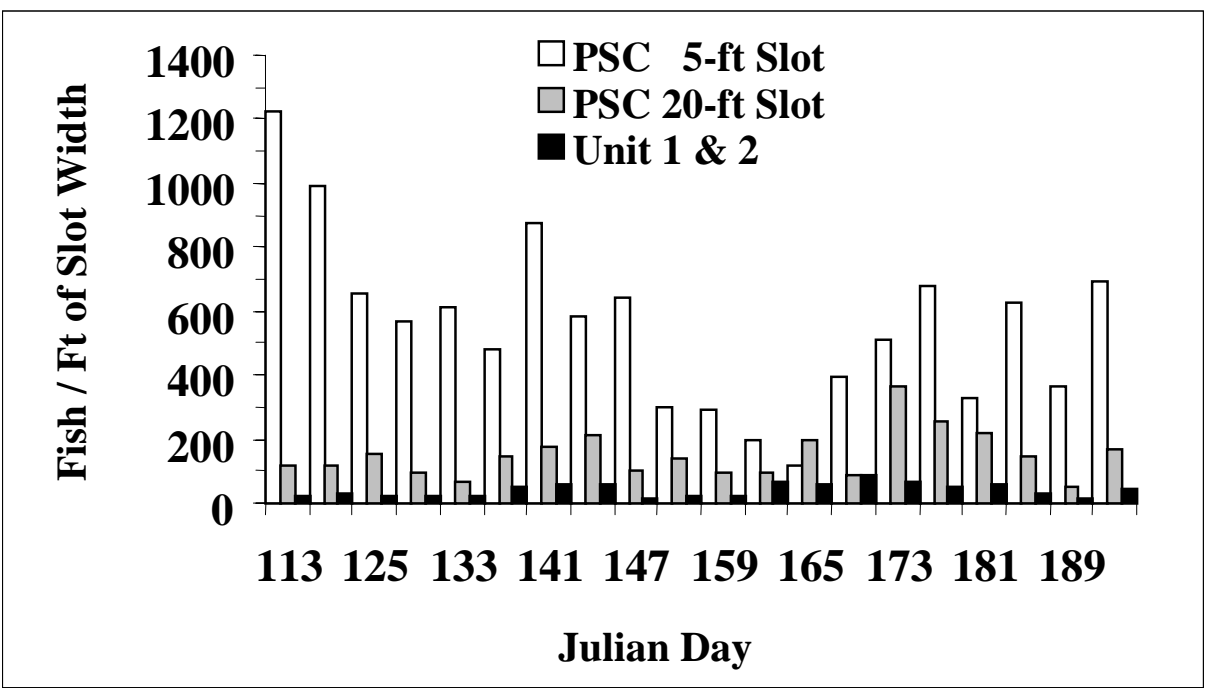

Figure 23. Fish passage rate per foot of slot width at six slots of Units 1 and 2 and two slots at the PSC during 2-day treatments

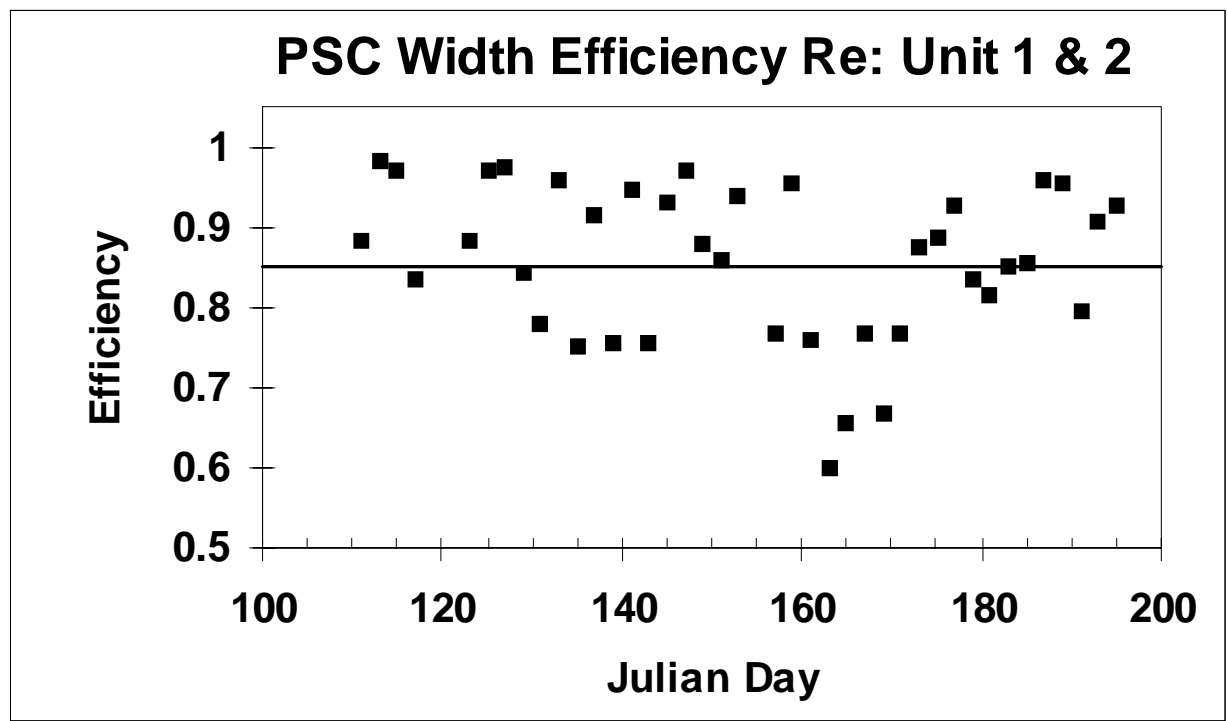

Figure 24. Efficiency of the PSC slots calculated as passage per foot of slot width divided by passage per foot of width through slots and Units 1 and 2 (The horizontal line represents mean efficiency)

sampling by one transceiver and eight transducers was spread among Units 1, 2, and 8 . Temporally, transducers in Intake $8 \mathrm{~b}$ sampled only 14 min per hour (onefourth time sampling), and spatially sampling was limited to about 18 percent of the intake cross section at any instant in time. Netting usually began about $2000 \mathrm{hr}$ and ended within 1-2 $\mathrm{hr}$ when the sample size was believed to be adequate. Most of the in-turbine samples were limited to sampling one-half of the intake cross section.

Counts of ESBS-guided fish by hydroacoustics and gatewell dipping both indicated a significant decline from spring through summer (Figure 27). 


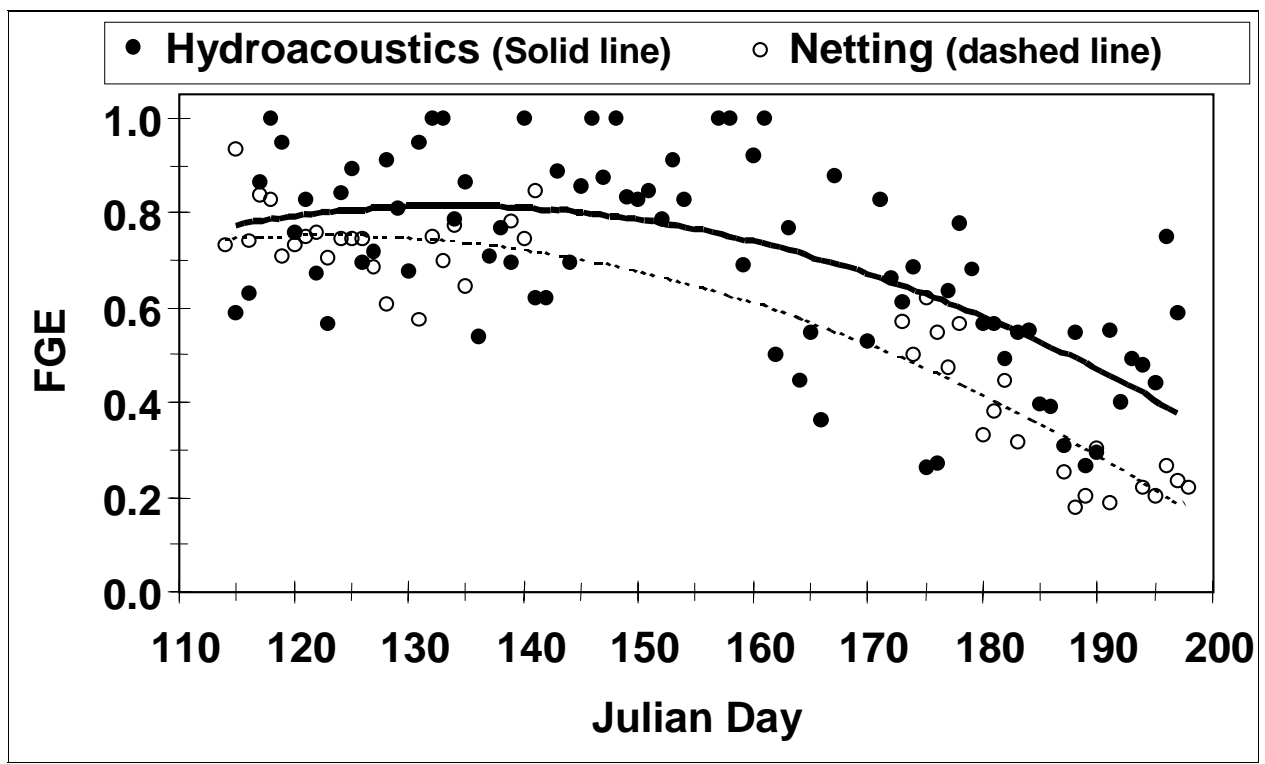

Figure 25. FGE of an extended-length bar screen at Intake $8 \mathrm{~b}$ estimated by fixed-aspect hydroacoustics and netting (Netting data were collected and provided by the NMFS)

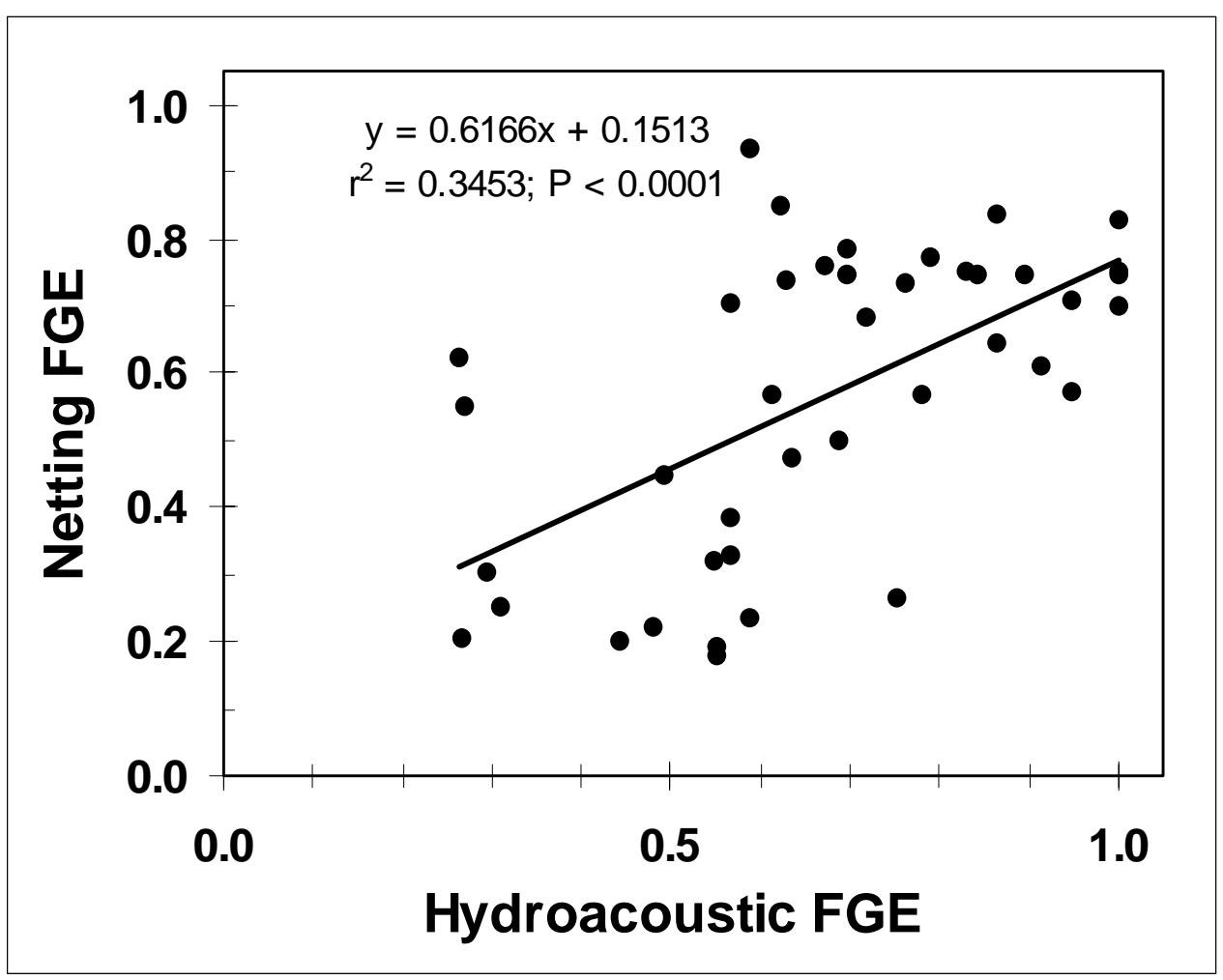

Figure 26. Correlation of netting estimates of FGE provided by the NMFS with hydroacoustic estimates made in this study 


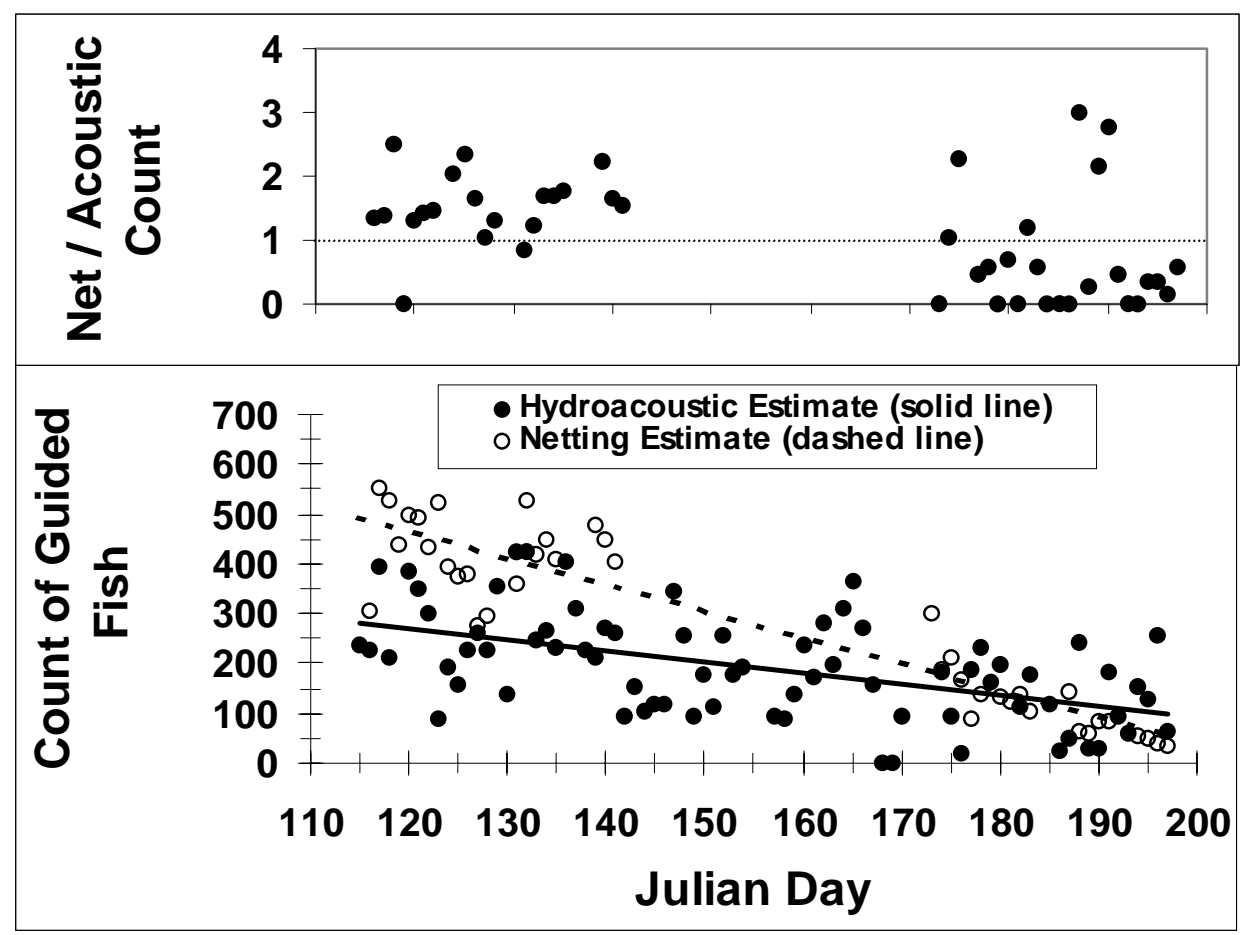

Figure 27. Seasonal decline in numbers of fish guided by an ESBS at Intake 8b (lower plot), as estimated by fixed-aspect hydroacoustics (this study) and netting (NMFS). The upper plot shows the ratio of paired estimates

Hydroacoustic estimates were lower than netting estimates in spring but similar to netting estimates in summer (Figure 27); nonetheless, both estimates were correlated (Figure 28). The slope of a line fitted to the same points but forced through the origin had a slope of 1.28 , i.e., mean hydroacoustic count $\times 1.28=$ mean gatewell counts.

Hydroacoustic counts of unguided fish gradually increased from spring through summer $(\mathrm{P}=0.0142)$, and netting estimates showed a similar rate of change (Figure 29), although daily variability was high for both methods. On average, hydroacoustic estimates were about 33 percent of netting estimates in spring and 50 percent of netting estimates in summer.

\section{Sluice Chute at Powerhouse 2}

Combined efficiency of the sluice chute and STS in Units 11-13 averaged 90 percent in spring and summer when the sluice chute was open, but STS efficiency alone (sluice closed) was only 55 percent in spring and 30 percent in summer (Figure 30). The efficiency of the sluice chute relative to total passage at Units $11-13$ plus passage at the sluice chute averaged 83 percent in spring and 81 percent in summer (Figure 31). 


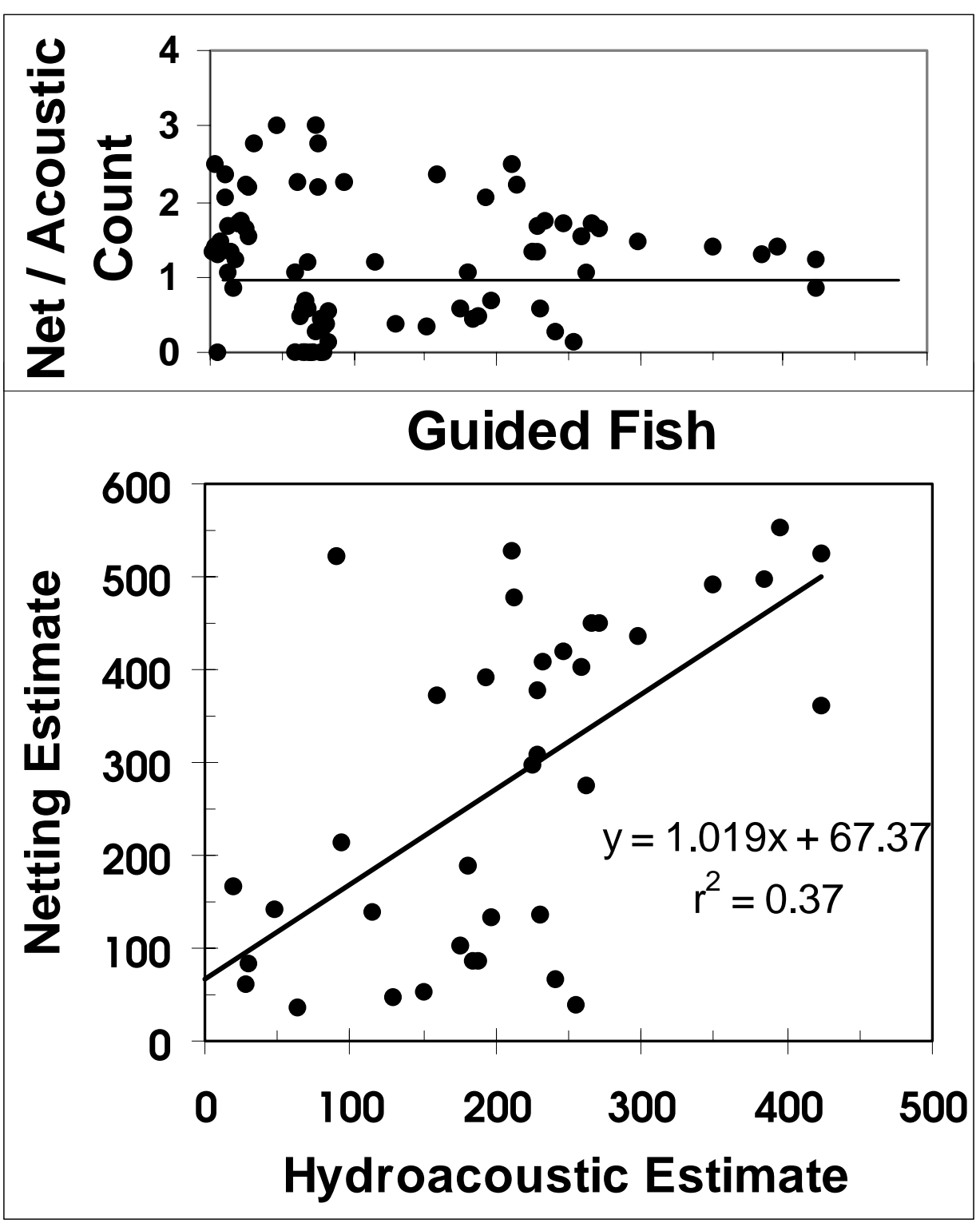

Figure 28. Correlation of estimates of numbers of juvenile salmon guided by an ESBS at Intake 8b, as determined by fixed-aspect hydroacoustic sampling (this study) and by netting (NMFS)

Sluice-chute effectiveness, which is the ratio of the proportion of fish to the proportion of water passing through the sluice chute relative to the total for sluice chute and Units 11-13, averaged 5.8 in spring and 4.6 in summer (Figure 32). The proportion of fish relative to the proportion of water passing through the sluice chute relative to Units 11-13 and the sluice chute together or "sluice-chute effectiveness" averaged 5.8 in spring and 4.6 in summer (Figure 32). Except for a 10-day period from Julian Day 128 through Day 138, when there was a trend of increasing effectiveness, the metric was relatively stable. In spring, the FGE of Units $11-13$ was significantly lower $(P=0.0010)$ when the sluice chute was 


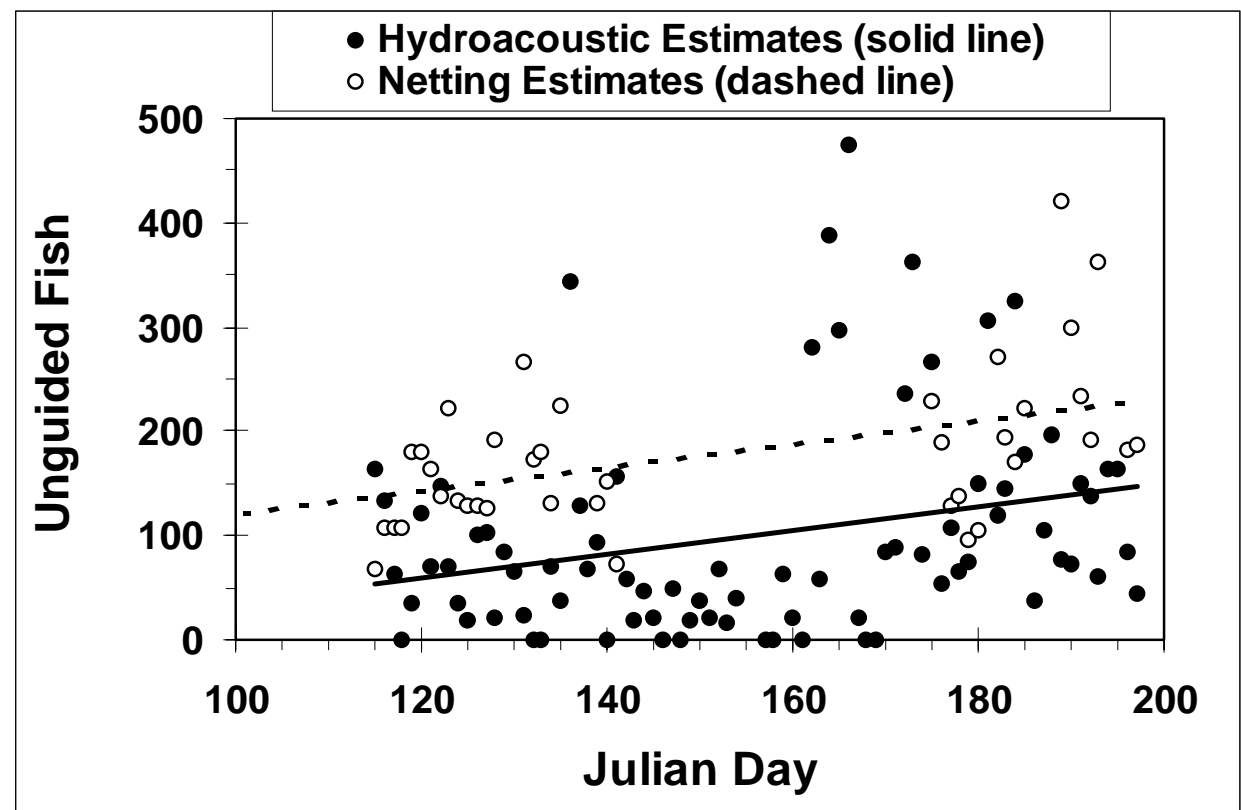

Figure 29. Hydroacoustic and netting estimates of numbers of unguided fish in spring and summer

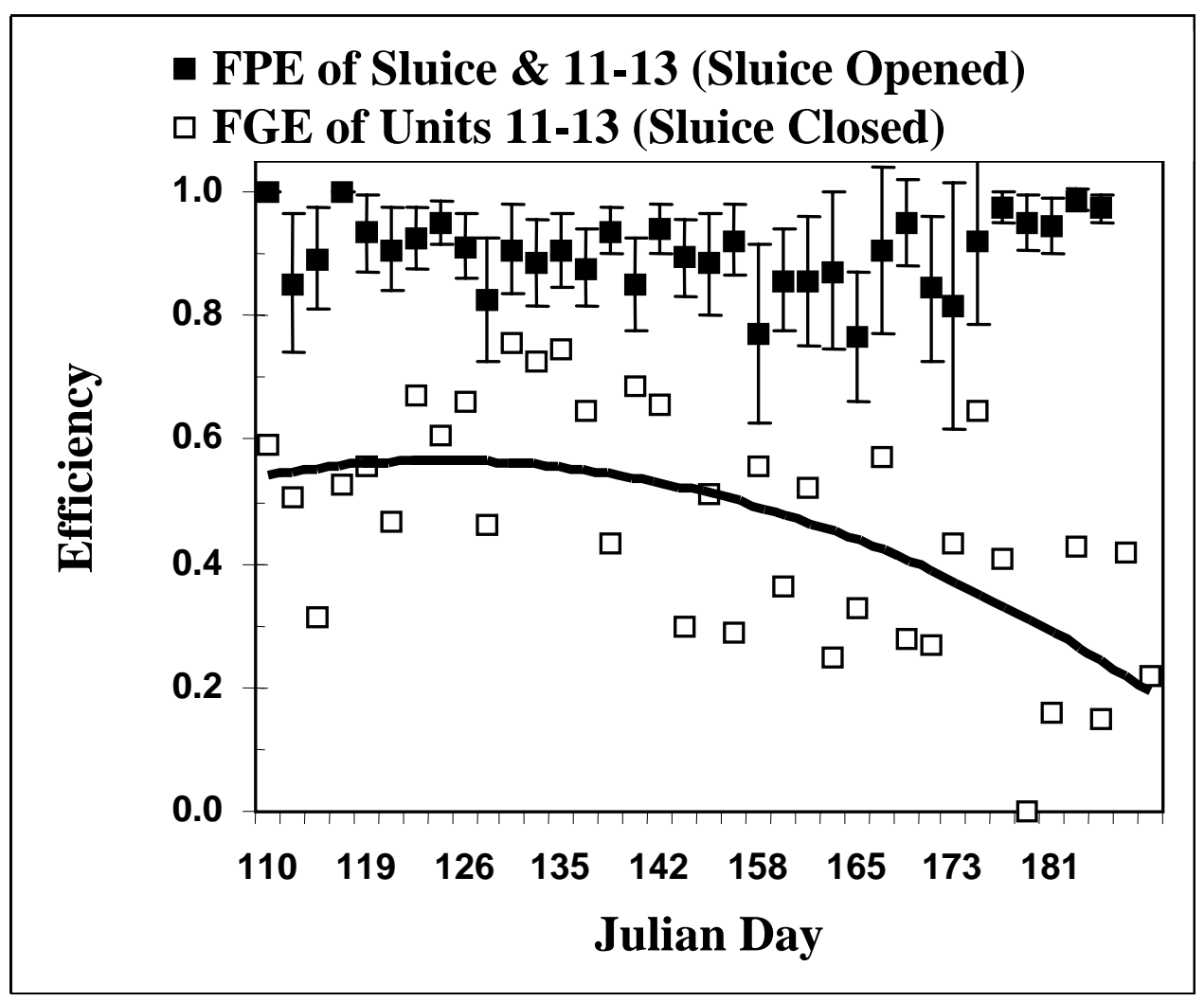

Figure 30. Combined FPE of the sluice and STS in Units 11-13 when the sluice was opened and the FGE of STS alone when the sluice chute was closed (Error bars are 95 percent confidence intervals on estimates) 


\section{Sluice Chute}

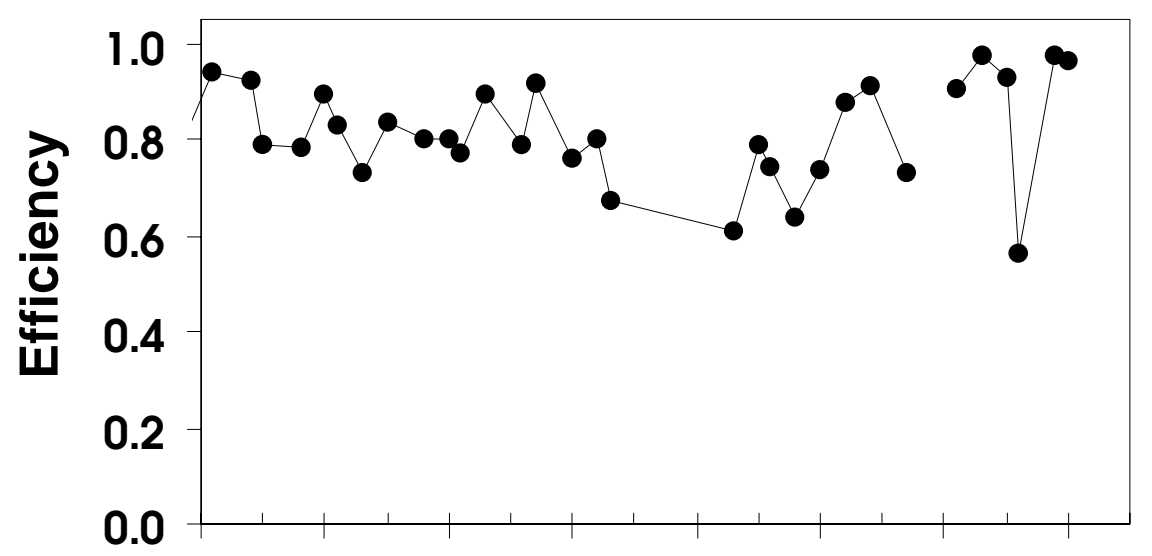

\section{$\begin{array}{llllllll}115 & 125 & 135 & 145 & 155 & 165 & 175 & 185\end{array}$ Julian Day}

Figure 31. Sluice-chute efficiency relative to total passage at the sluice chute and Units 11-13 fish in spring and summer 1998

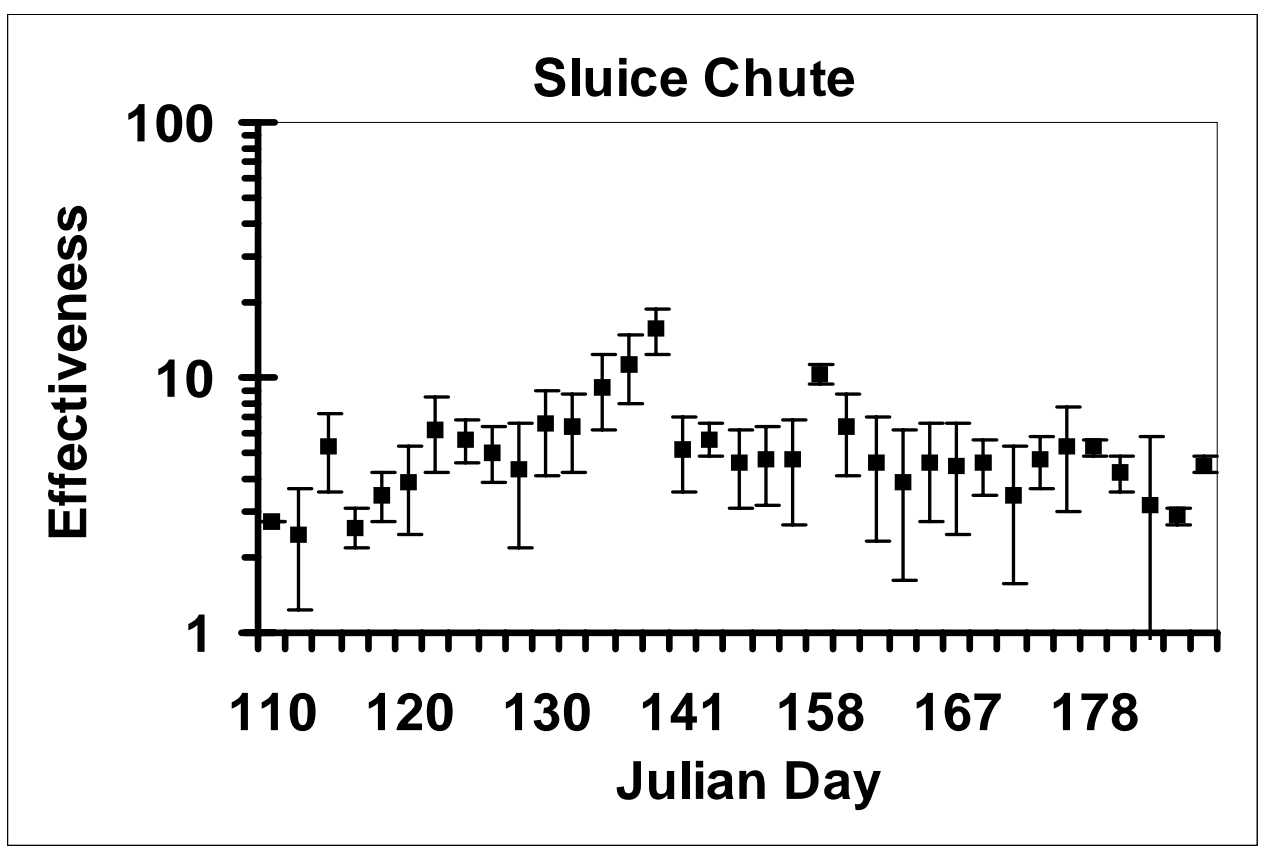

Figure 32. Effectiveness of the sluice chute in terms of the proportion of fish passing through the sluiceway (relative to sluice and Unit 11-13 passage) divided by the proportion of water flowing through the sluiceway (relative to flow through the sluiceway and Units 11-13) (Error bars are 95-percent confidence intervals on estimates) 
opened $(\mathrm{FGE}=0.45)$ than when the sluice chute was closed $(\mathrm{FGE}=0.59$; Figure 33). Mean FGE did not differ among sluice treatments in summer $(\mathrm{P}=0.9614)$.

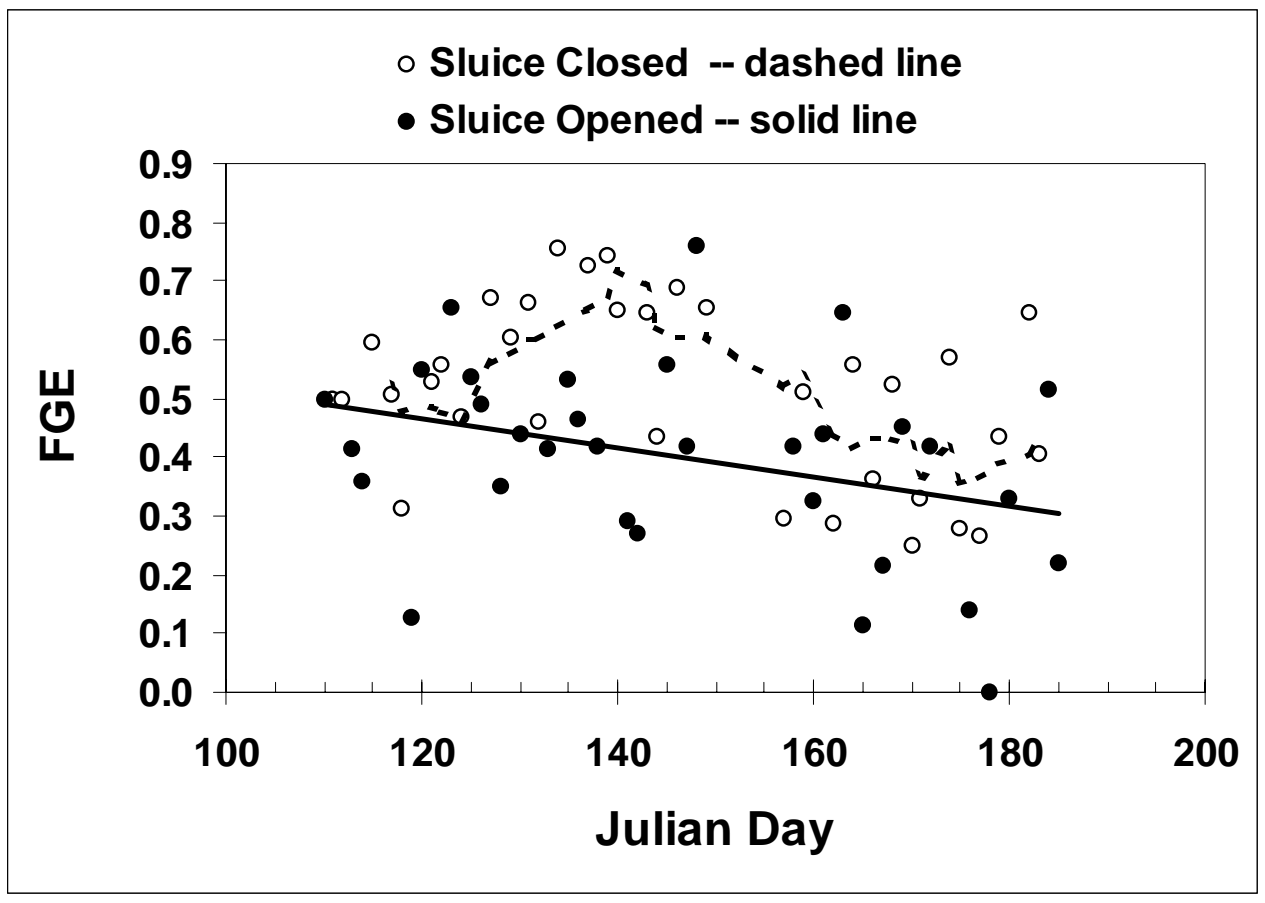

Figure 33. FGE of STS in Units 11-13 in spring and summer as a function of sluice-chute treatment. The dashed line is a 3-day moving average and the solid line is a fitted linear regression line

Daily passage of fish through the sluice chute was much higher than passage of fish through the nine intakes at Units 11-13 (Figure 34). Fish passage through the sluiceway averaged 5,888 per day in spring. Passage averaged 4,246 fish per day in summer, excluding observations from the last 2 days when passage was dominated by American shad. The sluice chute apparently passed substantial numbers of fish that were not evident in adjacent turbines in early spring (Julian Days 114-125). Hydroacoustic estimates of the daily fish passage through the sluice chute and NMFS' estimates for the Powerhouse 2 JBS generally exhibited similar seasonal patterns (Figures 35).

The daily estimates were correlated, with hydroacoustic estimates of sluice passage explaining 58 percent of the variation in JBS passage (Figure 36). The efficiency of the sluice chute relative to the JBS and sluice chute ranged from 9 to 42 percent and averaged 20 percent in spring and 25 percent in summer (Figure 37). Flow through the sluice chute represents $\leq 2$ percent of the flow sieved through the traveling screens at 24 intakes at Powerhouse 2. 


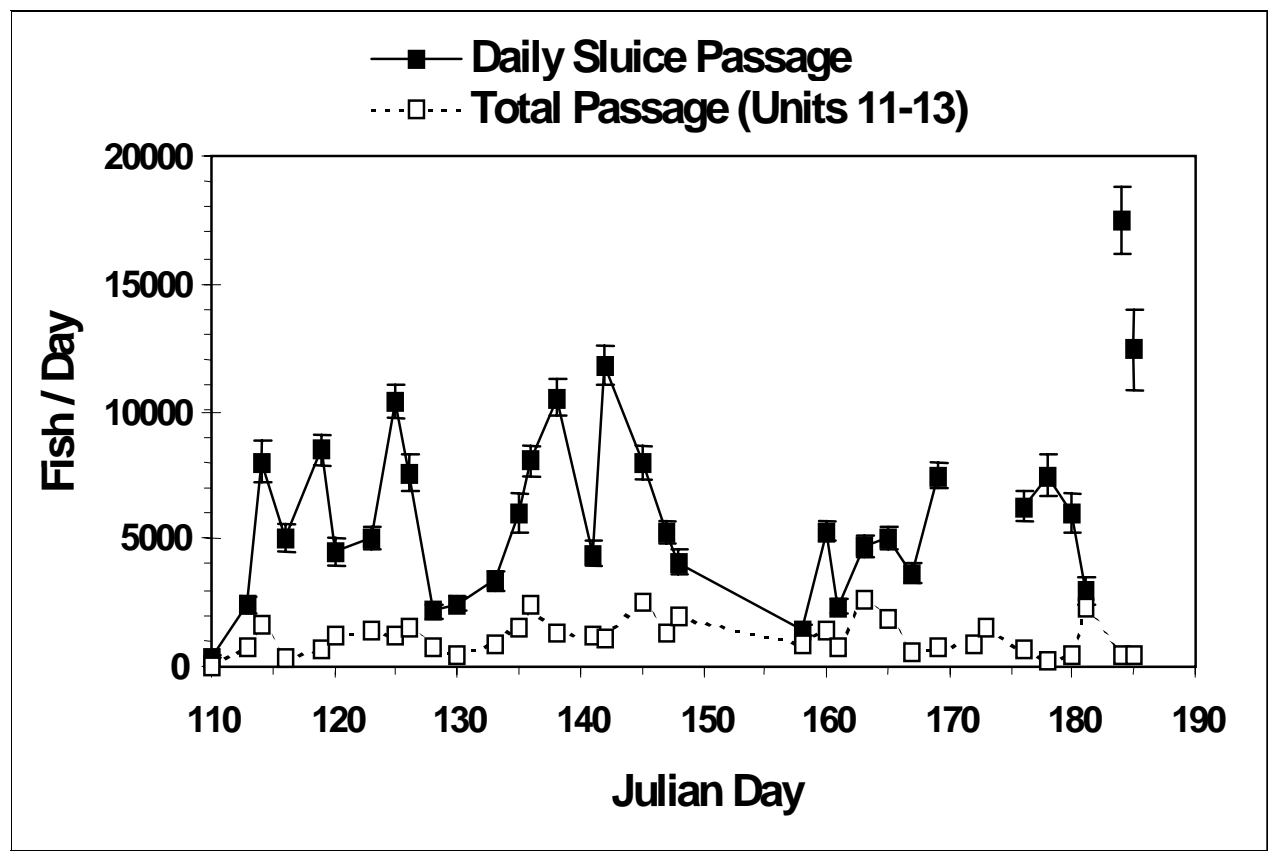

Figure 34. Daily rate of fish passage through the sluice chute and Units 11-13 (Error bars are 95-percent confidence intervals on estimates)

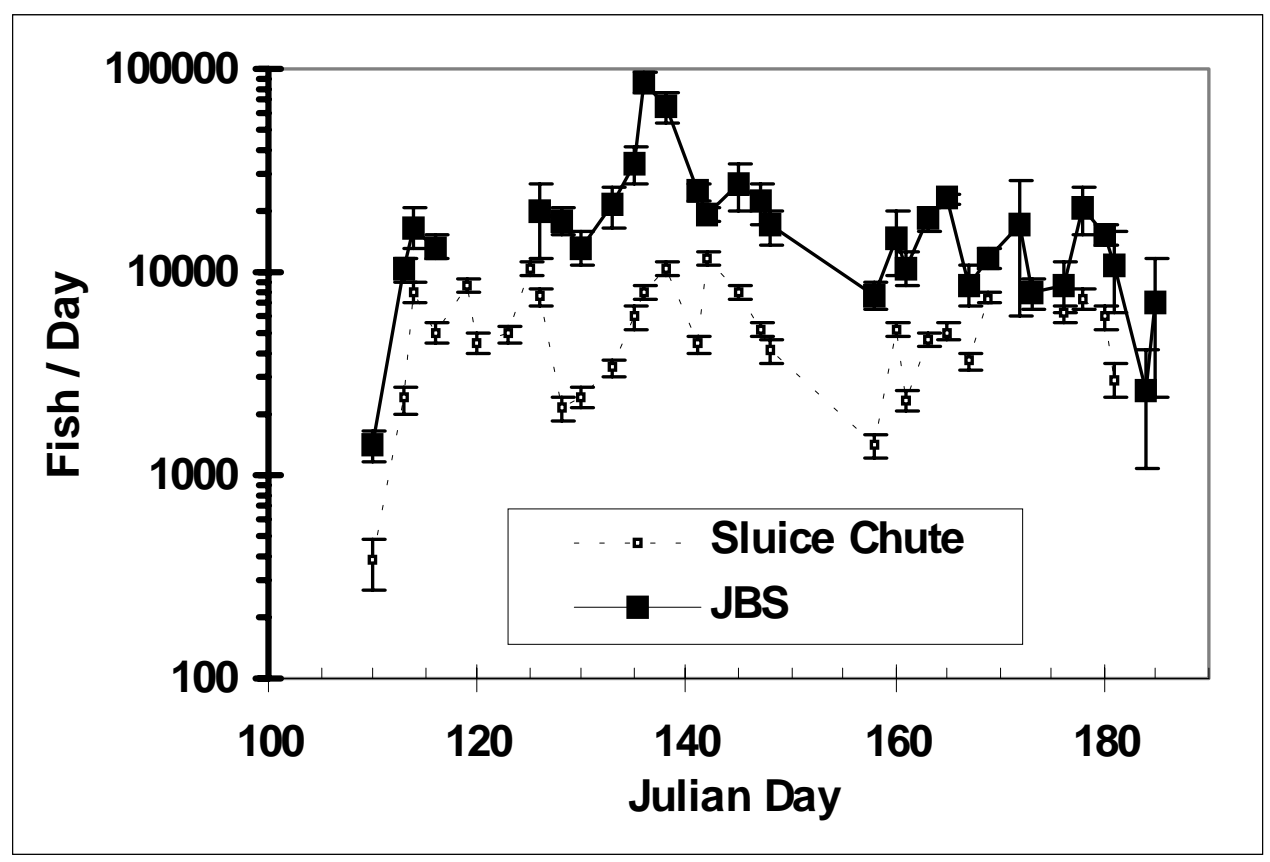

Figure 35. Estimated daily rate of passage of juvenile salmon through the sluice chute and the JBS at Powerhouse 2 in 1998 (Error bars are 95-percent confidence intervals on estimates) 


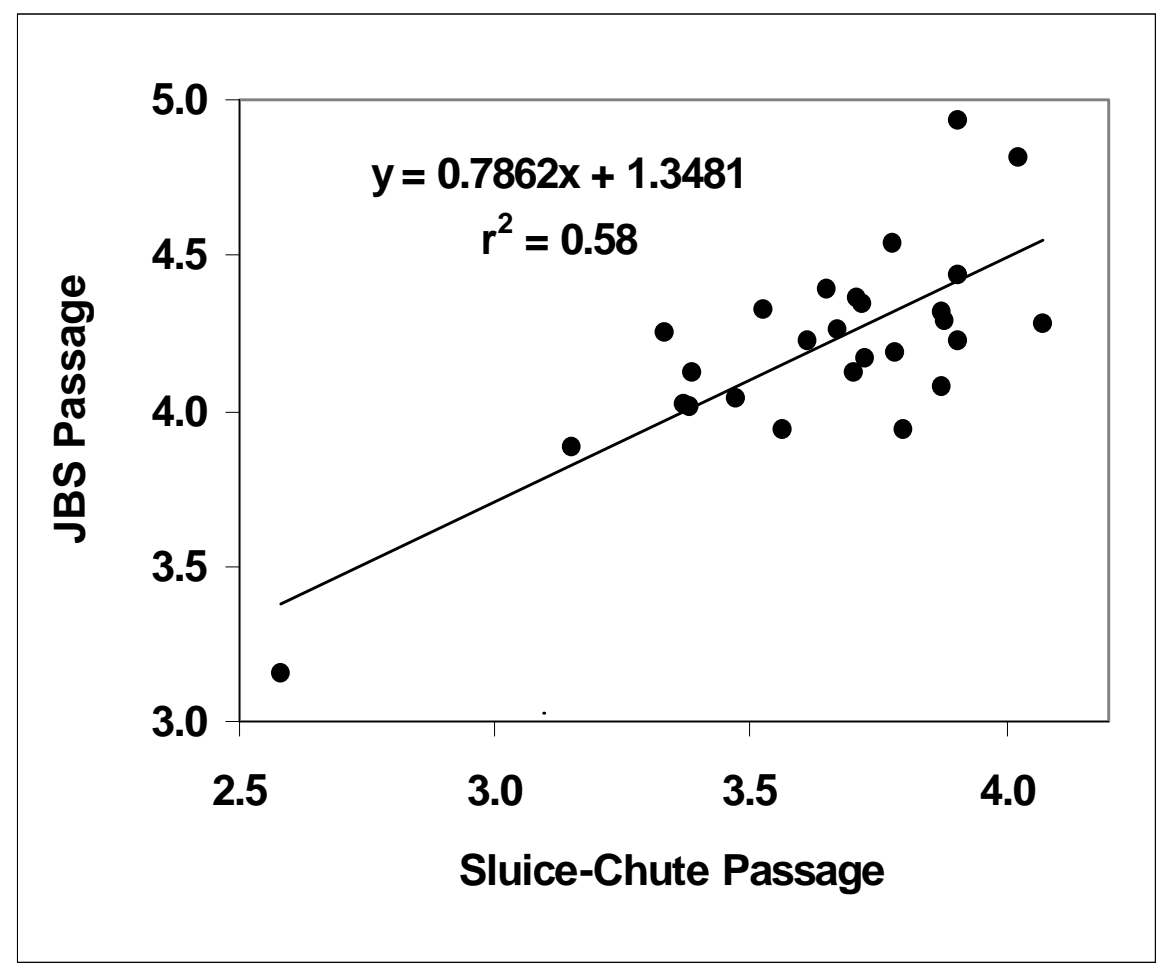

Figure 36. Correlation of FPE through the JBS by the NMFS with hydroacoustic estimates for the sluice chute

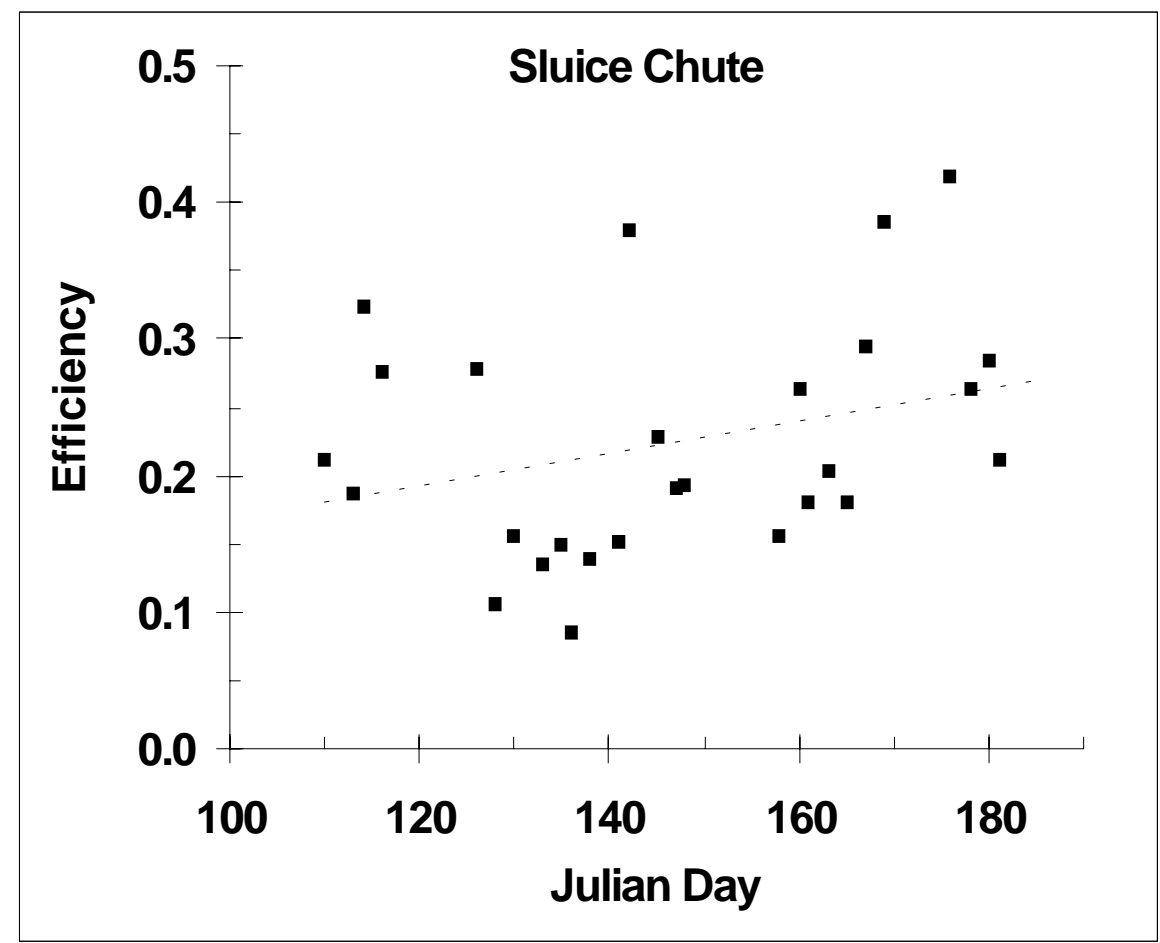

Figure 37. Efficiency of the sluice chute for passing juvenile salmon relative to passage through the sluice chute and the entire Powerhouse 2 JBS 


\section{Diel Trends in Efficiency and Passage}

\section{Prototype collector and adjacent units}

We observed a significant diel pattern of passage at the PSC in spring when passage from 2100 through 0400 was 2.0 (20-ft slot) to 2.9 (5-ft slot) times higher than passage from 0400 through $2000 \mathrm{hr}$ (Figure 38). In summer, the diel pattern was much less obvious than it was in spring (Figure 38), and it differed among slot treatments. For the 5-ft slot, rates were 3.7 times higher from 0700 through $1200 \mathrm{hr}$ than during other hours. For the 20-ft slot, rates tended to be higher from afternoon through midnight than from midnight through noon. The diel patterns for fish passing under the PSC slots in spring were similar to that for fish passing through the PSC (compare Figures 38 and 39). There was no obvious diel trend in hourly passage for fish passing under the PSC in summer (Figure 39). The mean hourly efficiency of the PSC was relatively constant and averaged 90 percent over a 24-hour period in spring and summer (Figure 40). We observed no significant diel pattern in effectiveness for the 5- or 20-ft slot in spring, but we found a significant diel trend in effectiveness for both slot treatments in summer (Figure 41). The mean effectiveness of the 5-ft slot treatment was 8.5 from 0800 through 1100 hours and 5.6 from 1200 through 0700 hours. Means for the 20 - $\mathrm{ft}$ slot were 3.2 from 0800 through 1100 hours and 2.7 from 1200 through 0700 hours $(\mathrm{P}<0.0001)$.

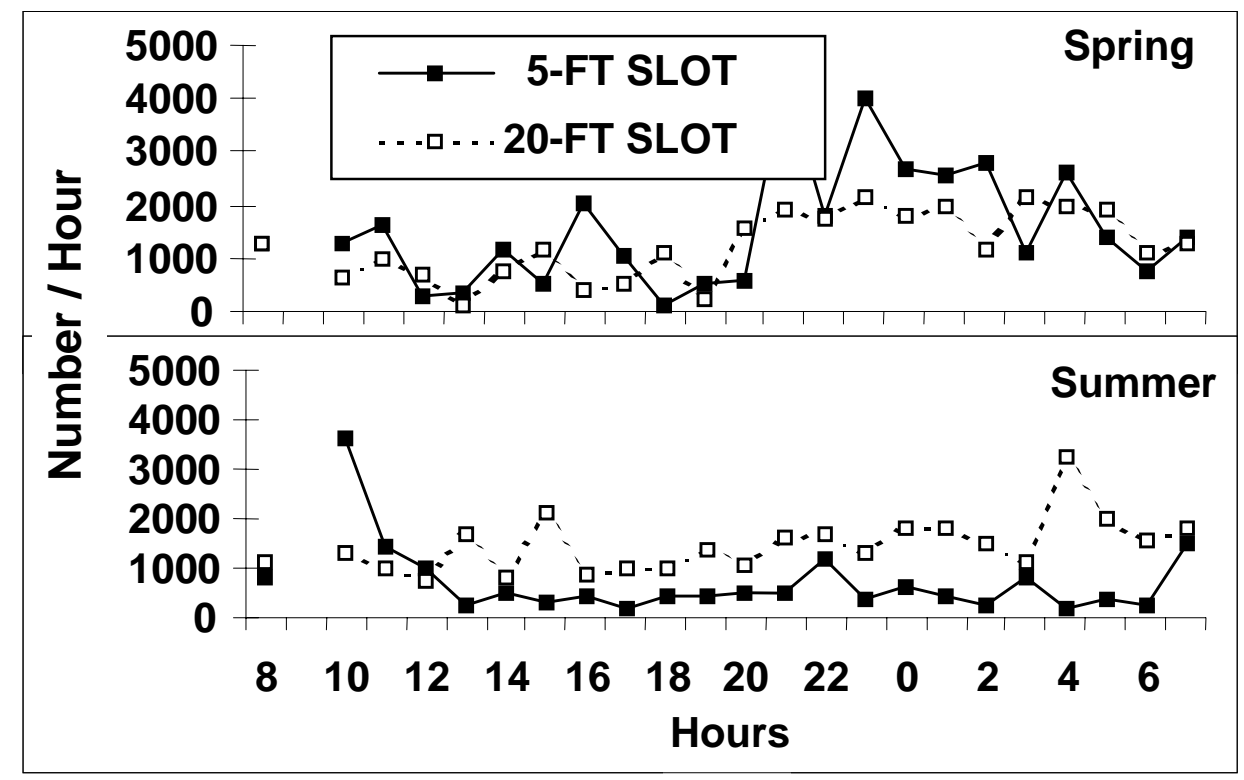

Figure 38. Hourly fish passage through PSC slots in spring and summer 1998, as estimated from in-turbine counts

The diel pattern of passage at Units 1 and 2 was similar in spring and summer with higher rates after sunset than during the day (Figure 42). This pattern was similar to that of the PSC in spring and summer, although the peak at sunset was more pronounced for adjacent units than for the PSC in summer. 


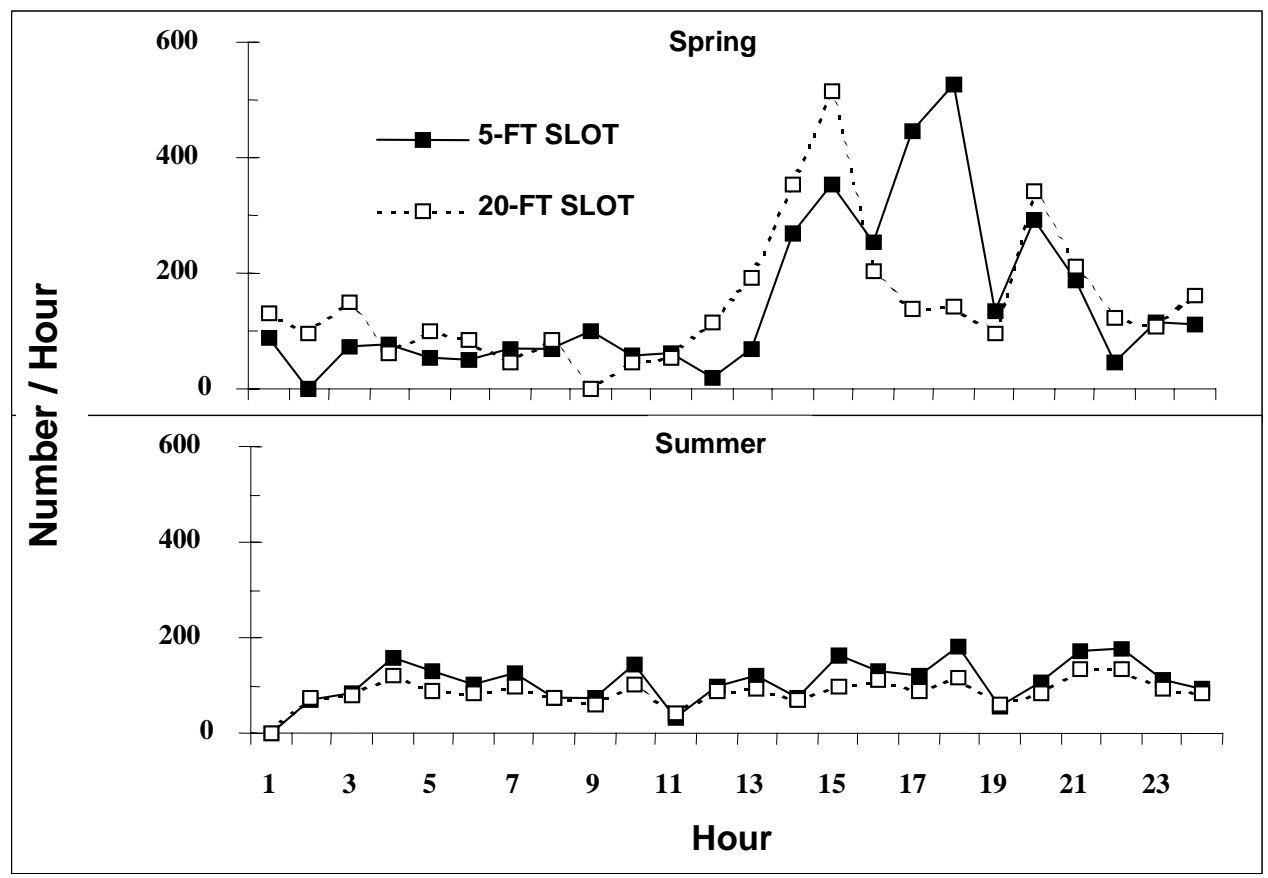

Figure 39. Diel pattern in fish passage under 5- and 20-ft-wide, 40-ft-deep slots in the PSC in spring and summer 1998

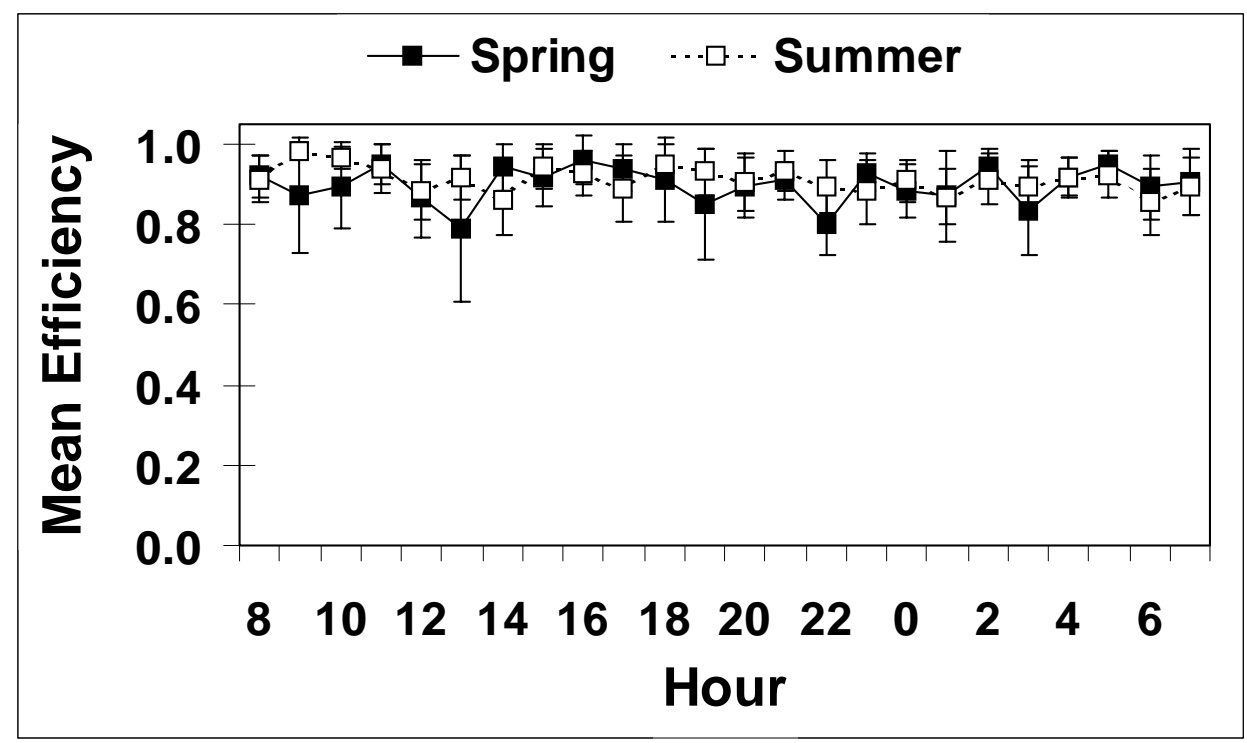

Figure 40. Diel pattern in mean efficiency of the PSC at Powerhouse 1 in spring and summer 1998 (Vertical bars are 95-percent confidence intervals) 


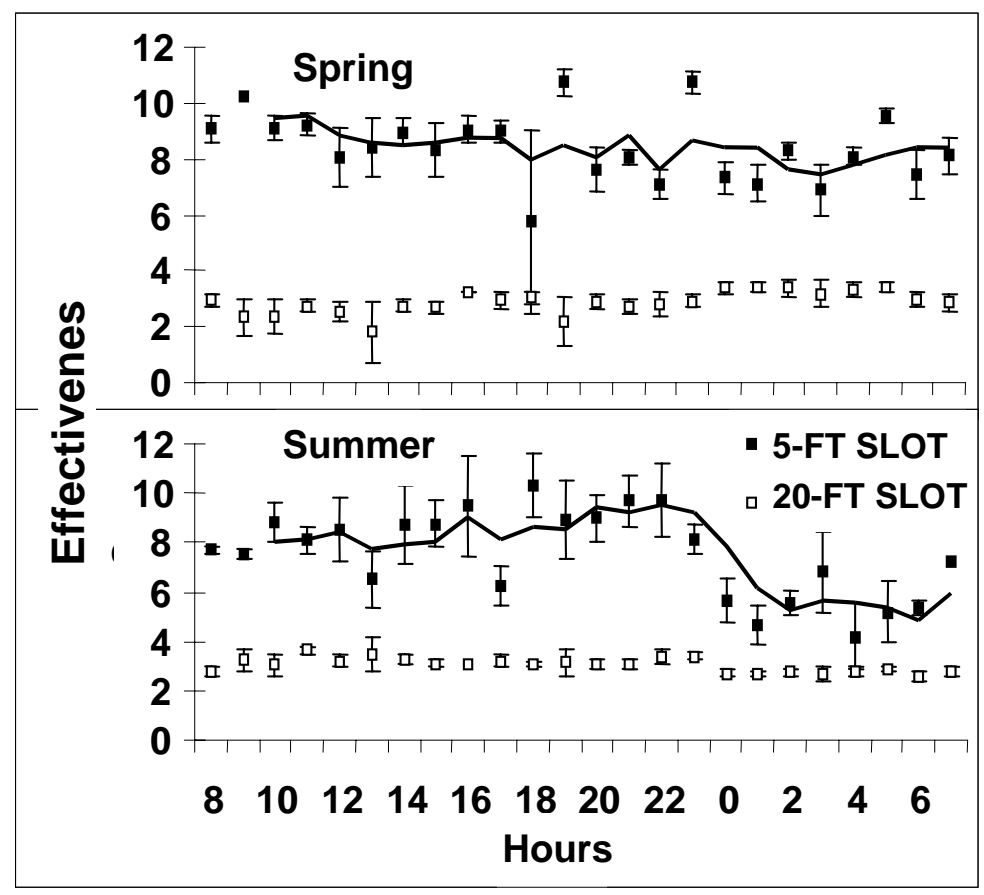

Figure 41. Diel pattern in the effectiveness of the 5- and 20-ft-wide slots in the PSC for passing fish relative to water (Effectiveness relates the proportion of fish at the intake that passed through the slot relative to the proportion water passing there; Error bars are 95-percent confidence intervals on estimates)

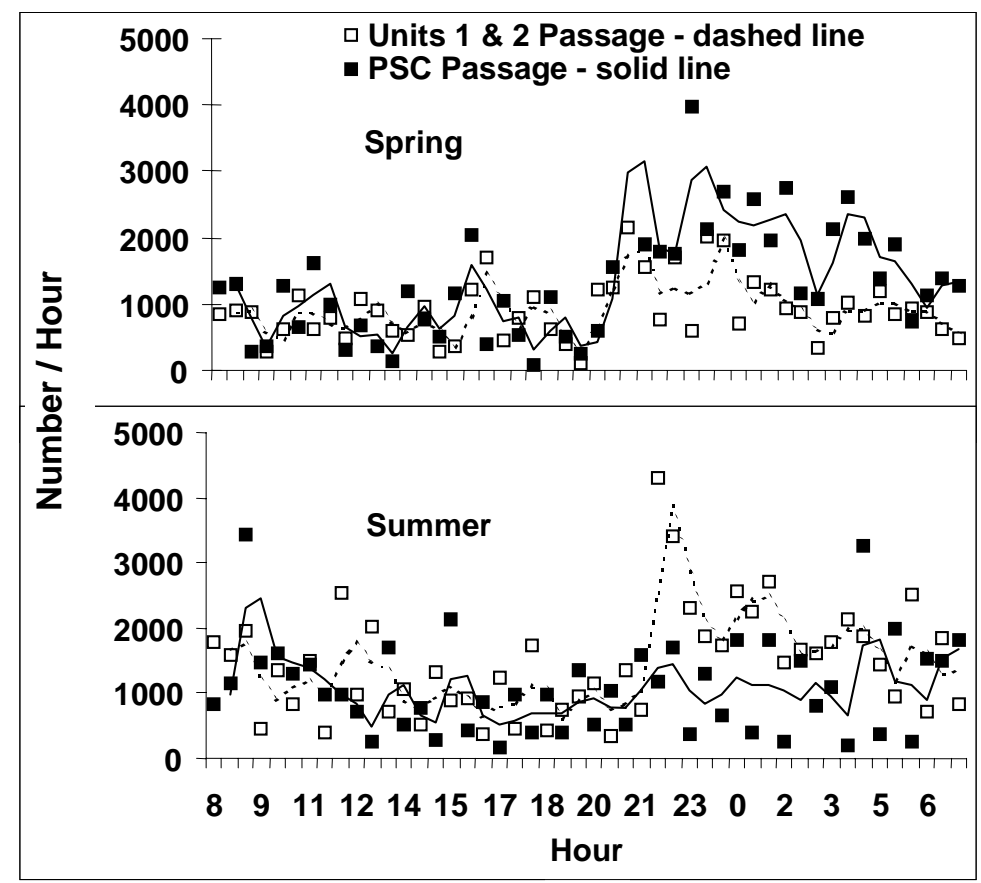

Figure 42. Diel pattern in fish passage at Units 1 and 2 and the adjacent PSC slots in spring and summer 1998 (Lines are 2-hr moving averages of plotted points) 
Figure 43 shows the correlation of hourly rates of passage at Units 1 and 2 with average hourly rates at PSC slots.

\section{Extended-submerged bar screen}

The FGE of the ESBS exhibited no significant diel pattern in spring, but it tended to be more efficient in guiding fish at night than during the day in summer (Figure 44). Hourly rates of passage of guided and unguided fish were higher at night than during the day with peaks often evident just after sunset and at dawn (Figure 45).

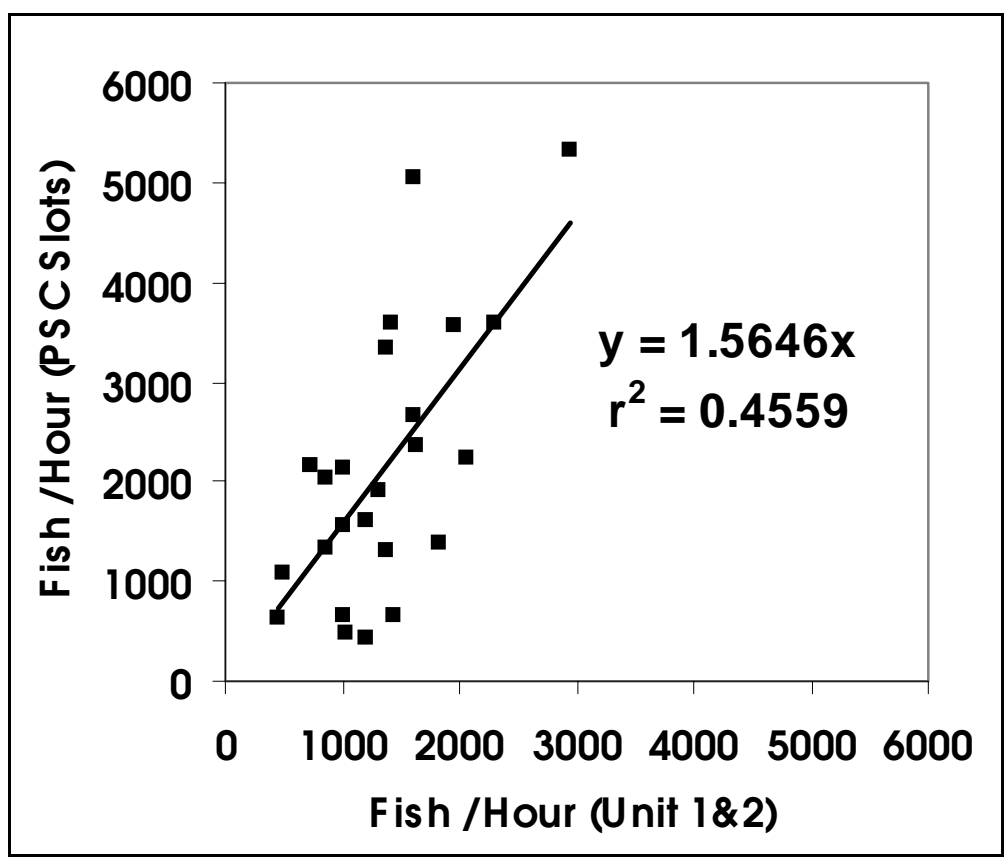

Figure 43. Correlation of hourly passage at PSC slots with hourly passage at adjacent Units 1 and 2

\section{Sluice chute and adjacent units}

The combined efficiency of the sluice chute and STS in Units 11-13 was significantly higher during the day than it was at night whether the sluice chute was opened or closed (Figure 46). Efficiency estimates were more variable among hours for Units 11-13 than for the sluice chute. A similar and more consistent diel pattern was observed in sluice-chute efficiency relative to total passage at all intakes of Units 11-13 and the sluiceway (Figure 47).

Similar diel patterns also were apparent for hourly estimates of sluice-chute effectiveness (Figure 48) and passage (Figure 49). Both metrics were significantly higher during the day (0600 through 2100 hours) than at night (2200 through 0500 hours), further indicating that sluice-chute passage is primarily a daytime phenomenon. 


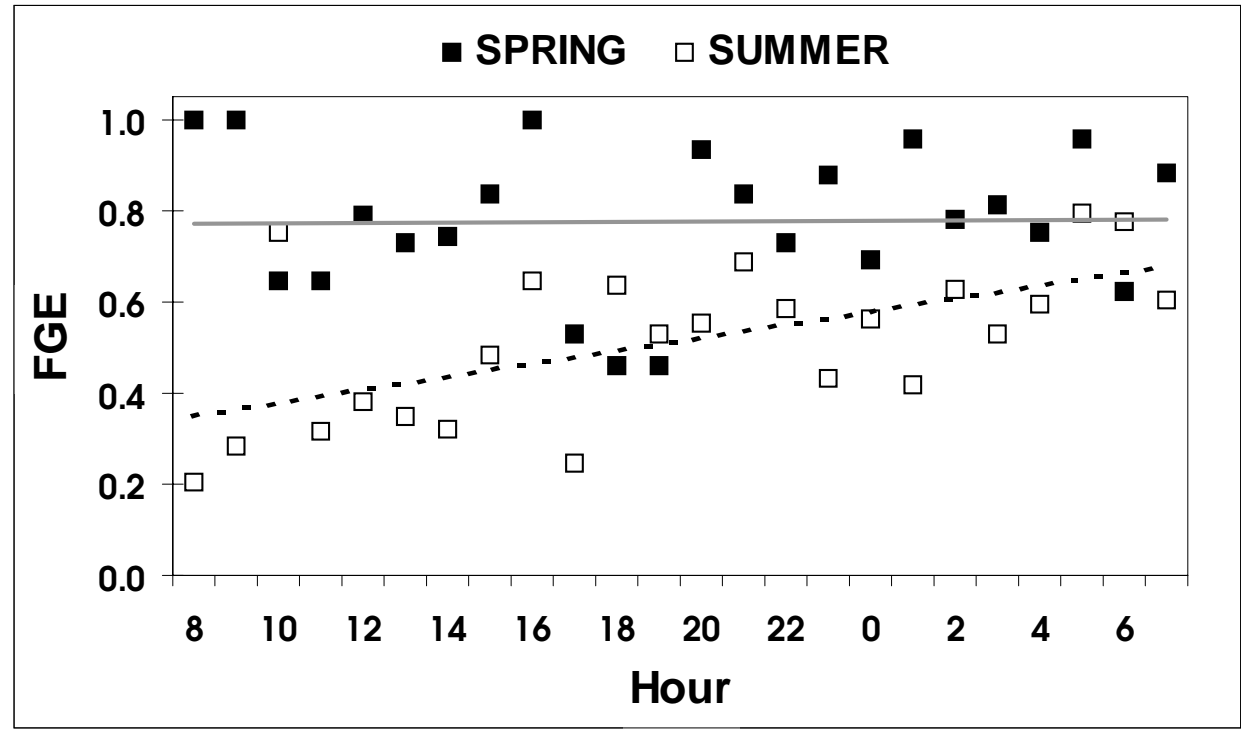

Figure 44. Diel trends in the FGE of an ESBS at Intake 8b of Powerhouse 1 in spring and summer 1998 (The solid line was fit to the spring data and the dashed line to the summer data)

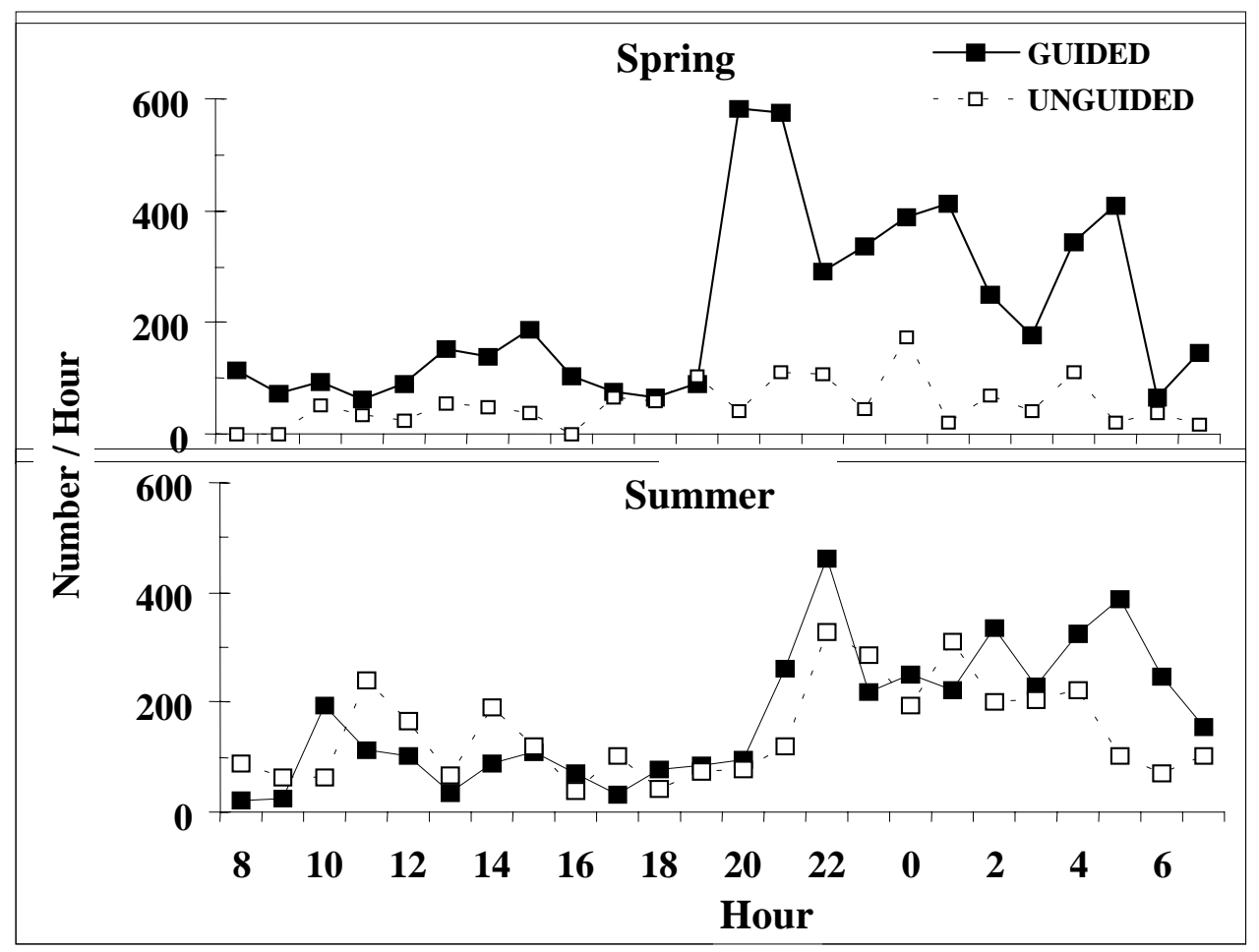

Figure 45. Diel trends in the passage of fish above (guided) and below (unguided) an ESBS at Intake 8b of Powerhouse 1 in spring and summer 1998 


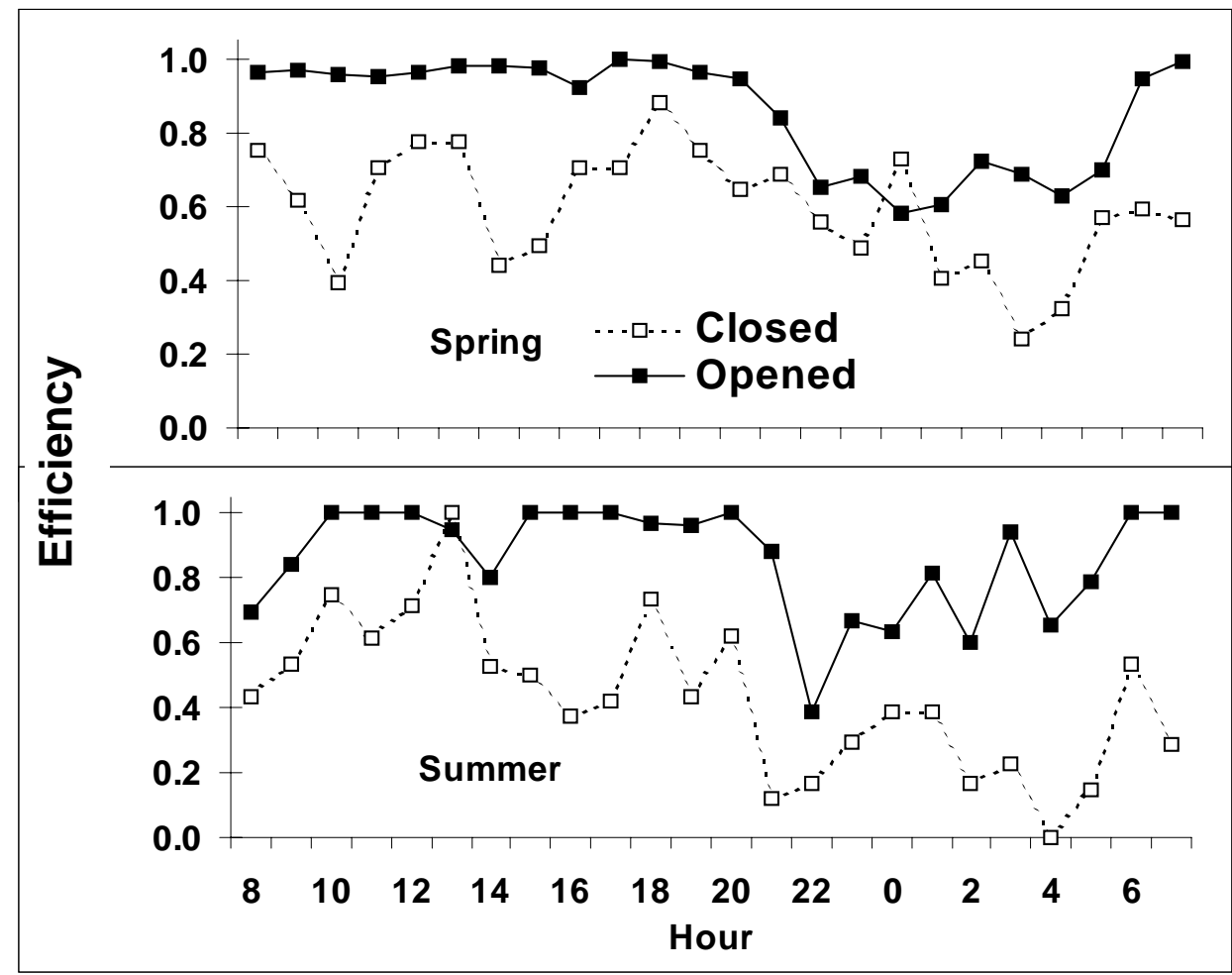

Figure 46. Diel trends in the combined efficiency of the sluice chute and STS in Units 11-13 in spring and summer 1998 (Efficiency was for both the sluice chute and STS when the sluice chute was opened and for the STS only when the sluice chute was closed)

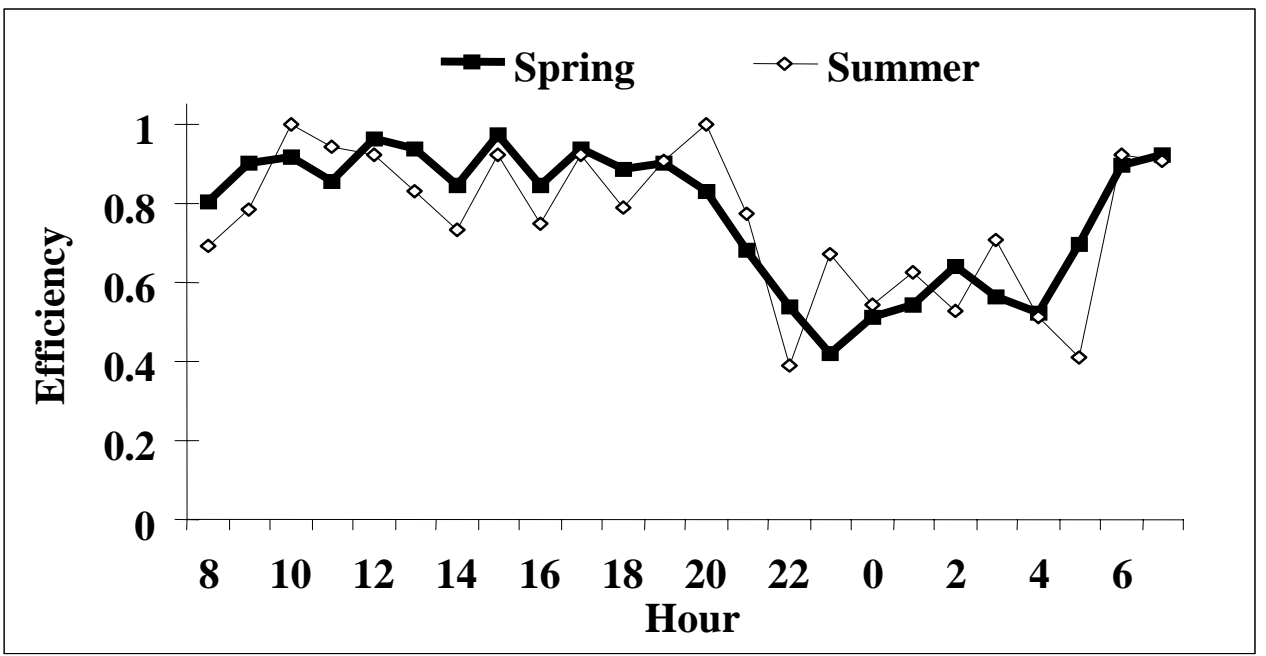

Figure 47. Diel trend in the efficiency of the sluice chute in terms of fish passage at the chute relative to fish passage through the chute and Units 1113 in spring and summer 1998 


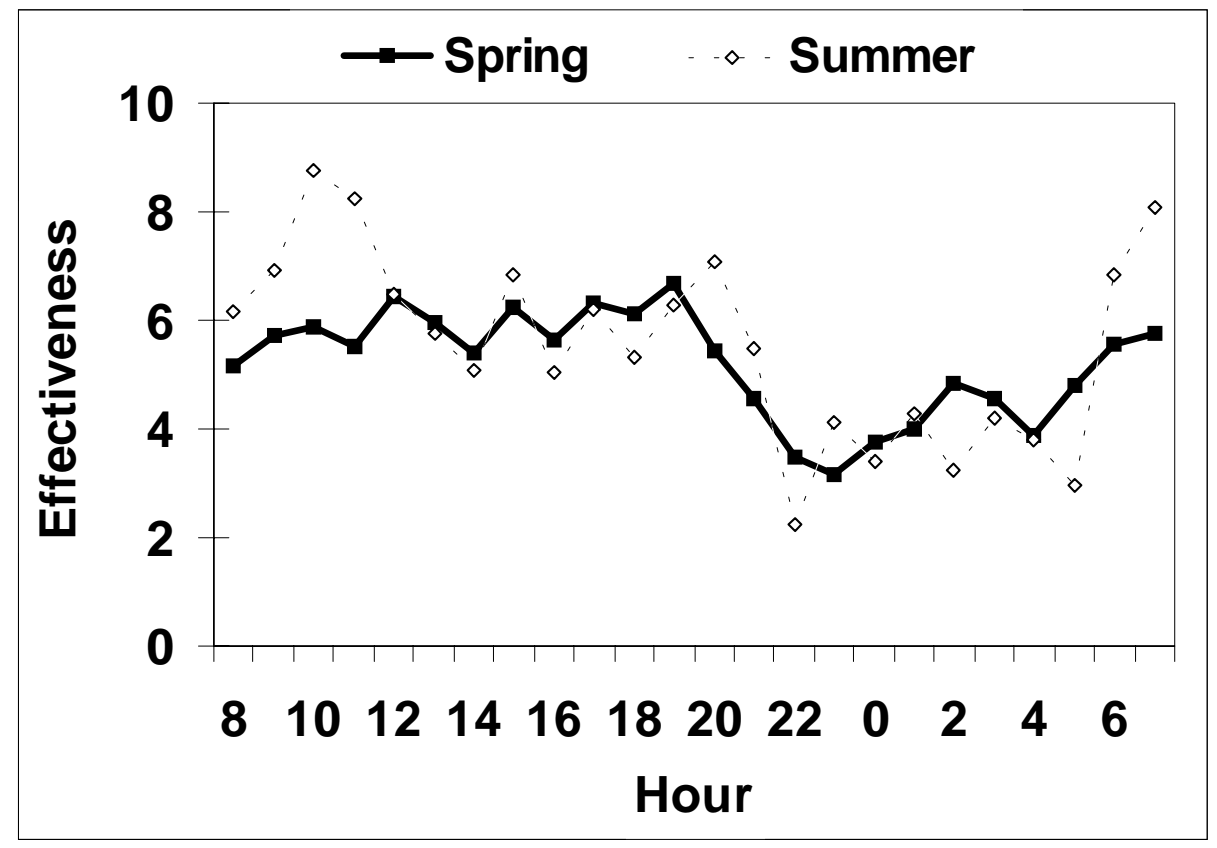

Figure 48. Diel trend in mean effectiveness of the sluice chute, where effectiveness is the proportion of fish passing at the sluice chute relative to the total passing at the sluice chute and Units 11-13 divided by the proportion of water moving through the same routes

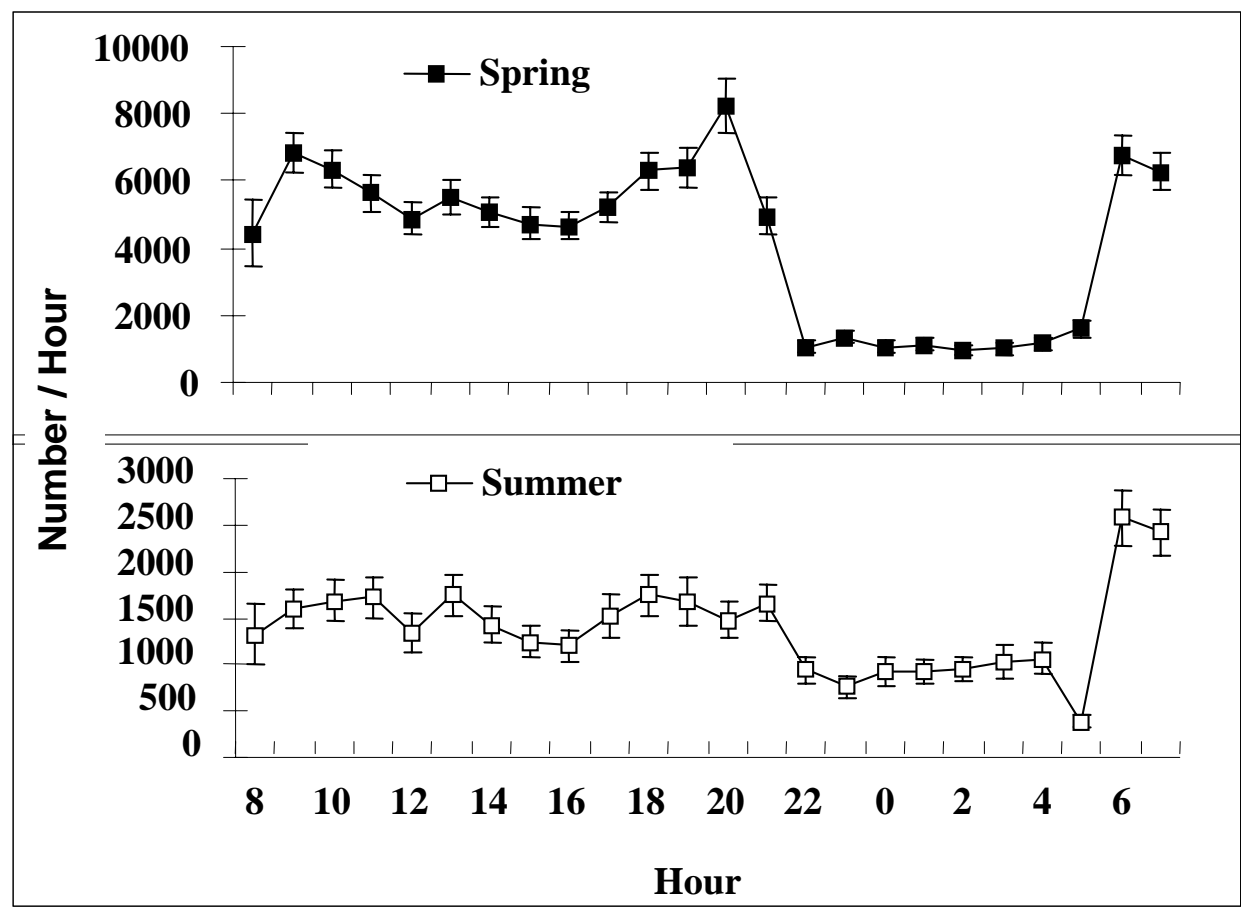

Figure 49. Diel trends in hourly passage of fish through the sluice chute at Powerhouse 2 in spring and summer 1998 (Note that the scale for spring is over three times larger than the scale for summer; Error bars are 95-percent confidence intervals on estimates) 
Like other diel trends for the sluice chute, the density of fish passing per hour also was significantly higher during the day than at night, particularly in spring (Figure 50).

A 3-hr moving average fitted to hourly estimates of FGE revealed a significant diel pattern for Units 11-13 where efficiency was lower at night than during the day (Figure 51). This pattern resulted more from increases in numbers of unguided fish at night (Figure 52) than from increased numbers of guided fish during the day (Figure 53). The peak number of unguided fish that occurred at unset in spring and summer was significantly lower for the opened-sluice treatment than for the closed treatment (Figure 52). The same was true for the peak in numbers of guided fish, particularly in spring (Figure 53).

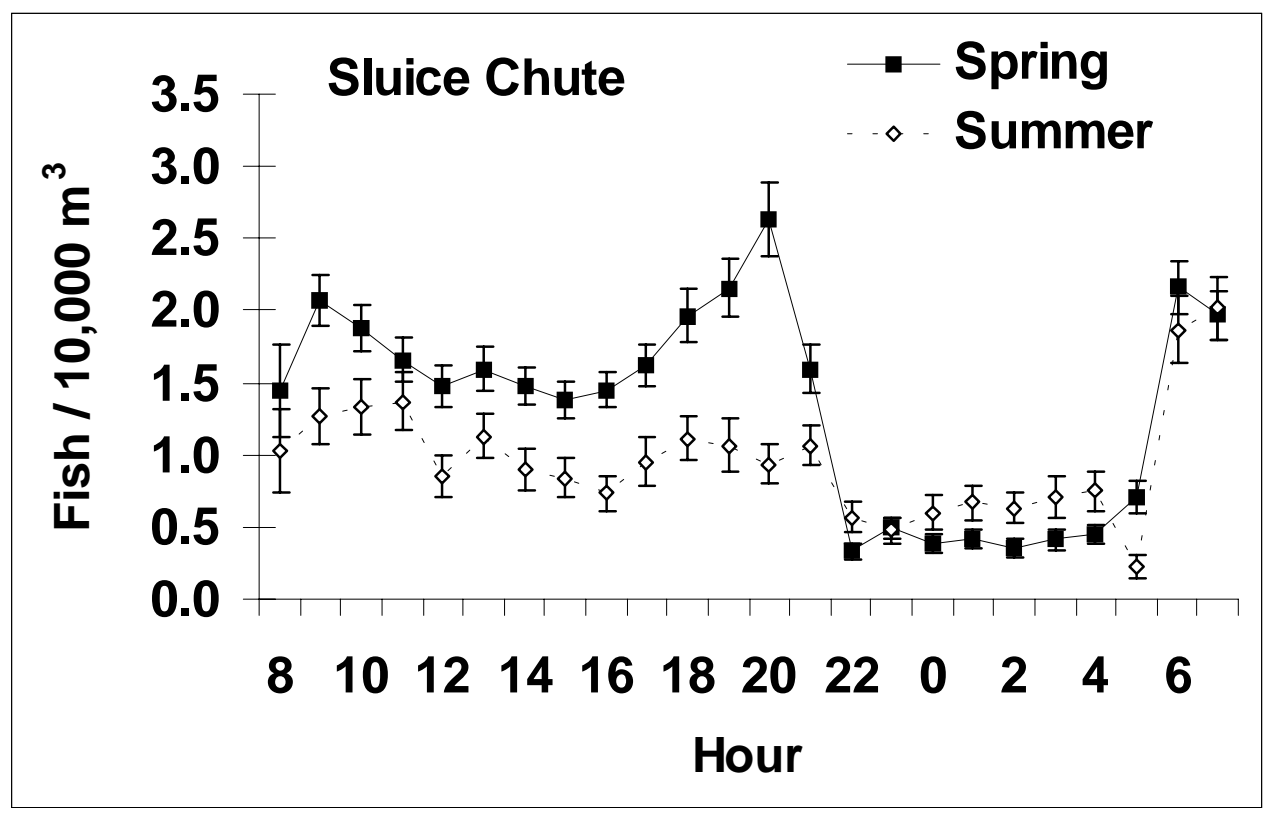

Figure 50. Diel trends in the density of fish passing through the sluice chute in spring and summer 1998 (Error bars are 95-percent confidence intervals on estimates)

\section{Intertracker Differences and Potential Bias}

The potential problem of systematic bias in estimates of metrics as a result of differences in fish counts among human trackers was limited to locations where multiple trackers routinely contributed counts for calculated metrics. These included estimates of efficiency and effectiveness for slot entrances in the PSC and for the sluice chute relative to Units 11-13. Single trackers made all counts contributing to in-turbine estimates of PSC efficiency and effectiveness (Tracker 1) and to FGE estimates at Units 1, 2, and 8 (Tracker 6). Two trackers counted fish passing through Intakes $11 \mathrm{~b}, 12 \mathrm{~b}$, and 13b, but guided and unguided fish in any 12-min file were always counted by the same person. At PSC slots, numbers of "collected" fish were counted by two to four people (Trackers 2, 3, 5, and 7), while the number of fish passing under the collector was counted by 


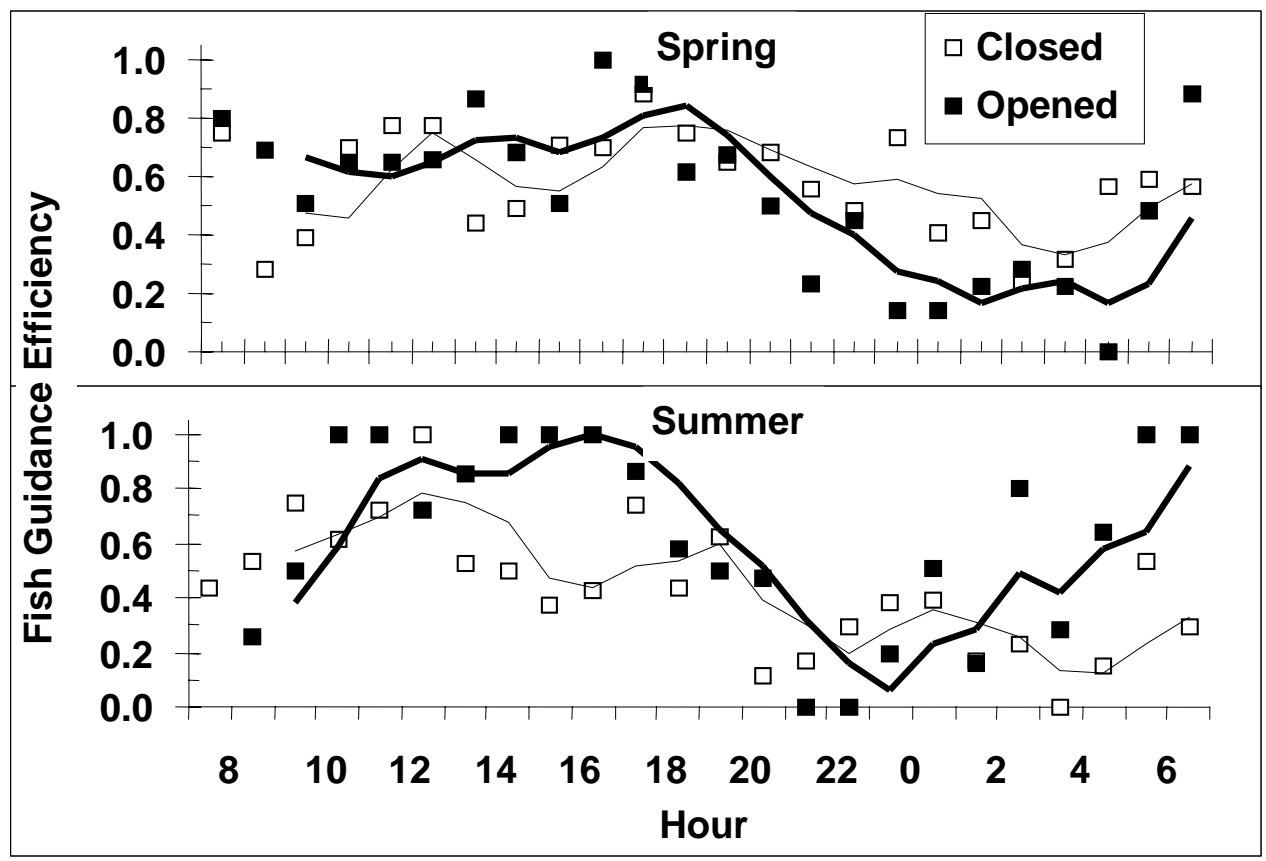

Figure 51. Diel trends in the FPE of STS in Intakes $11 \mathrm{~b}, 12 \mathrm{~b}$, and $13 \mathrm{~b}$ at Powerhouse 2 in spring and summer 1998 (Opened and closed refers to the treatment applied at the adjacent sluice chute. Lines represent 3-hr moving averages for the opened (heavy line) and closed (light line) treatments)

Tracker 1 (Figure 54 - bottom panel). Figure 54 suggests that when Trackers 2 or 3 were counting data from PSC slots, numbers of "collected fish" could have been 1.5-2.0 times higher than if Trackers 5 and 7 had been tracking the same files. Tracker 1 recorded the fewest number of fish from PSC-slot files, but Tracker 1 never actually tracked these data during the year. For the under-PSC files (middle panel of Figure 54), Tracker 1 counted the same number of fish as Tracker 5 and 7, 18 percent fewer fish than Tracker 2, and 33 percent fewer fish than Tracker 3. Therefore, Tracker 1 was more effective relative to other trackers on in-turbine files than on PSC-slot files. The PSC-slot files were relatively noisy, especially within 1-2 $\mathrm{m}$ of the surface, whereas in-turbine files usually were free of noise. At Powerhouse 2, Tracker 4 processed data from the sluice chute while Trackers 8 and 9 processed data from Units 11-13. The upper panel of Figure 54 indicates that counts of fish by these three trackers were similar with Tracker 4 counting 11 percent more fish than Tracker 7 but 21 percent fewer fish than Tracker 8 for the thirty 12-min files.

A second, more thorough examination of intertracker differences in fish counts on the same one hundred-eighty 12-min data files provided additional insight into potential bias in efficiency and effectiveness estimates for the PSC based upon slot-entrance counts. In this test, thirty 12-min files were pooled into one of six sets of files to create a gradient in the number of fish present in each set. Trackers 2 and 5, who normally counted fish at PSC entrances, and Tracker 4 had similar counts for Units 3 and 5 (Figure 55). Tracker 3 posted the highest counts, as before in our 30-file test, and Tracker 1 again had the lowest counts. 


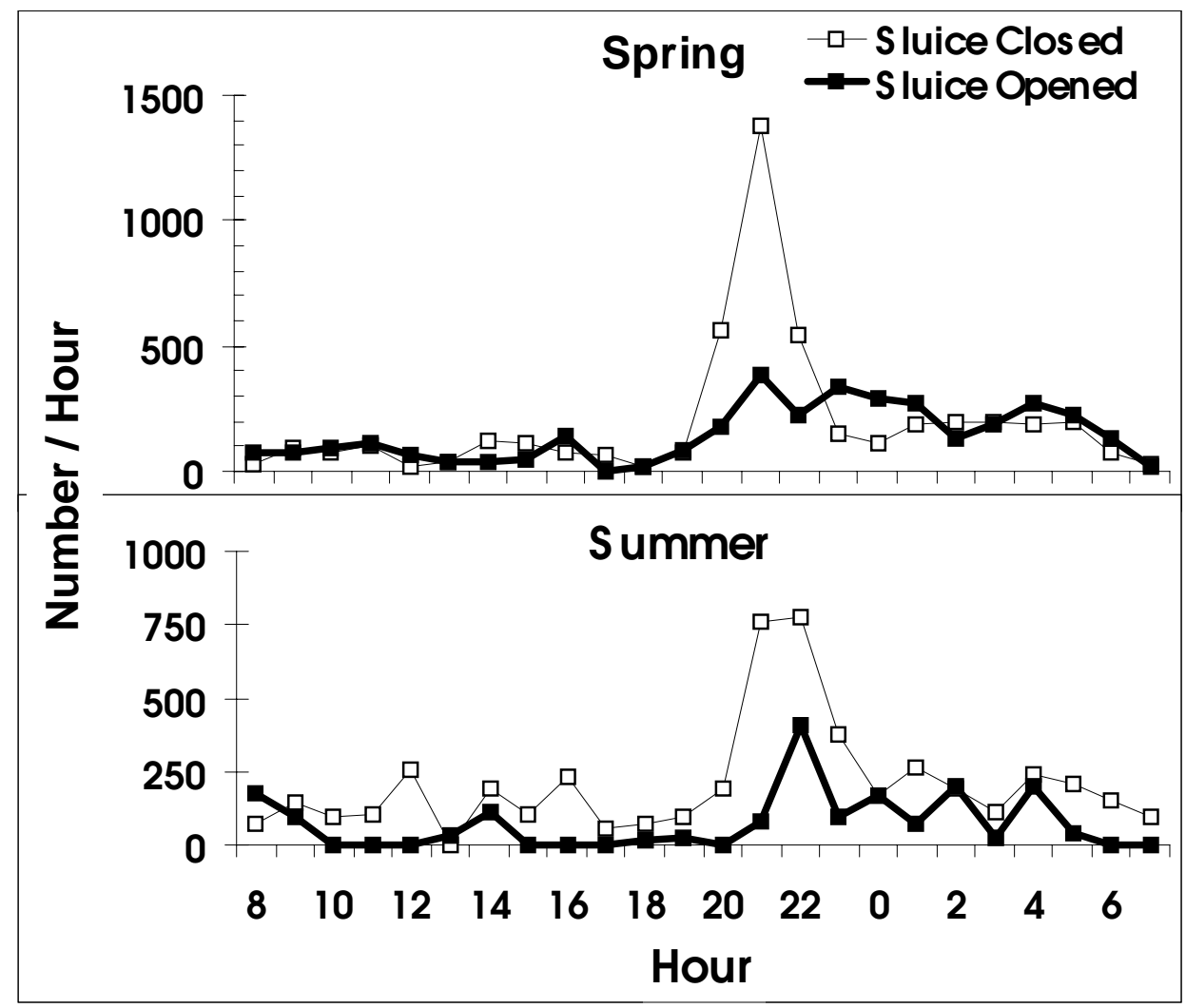

Figure 52. Diel trends in the hourly passage of fish below STS (unguided fish) in Intakes 11b, 12b, and 13b adjacent to the sluice chute. (The sluice chute was either opened or closed (see line references) on a daily basis.)

In turbine, the ranking of trackers by their counts changed slightly for the four trackers that found the most fish at PSC slots, but Tracker 1 still consistently produced the lowest count. We divided Tracker 1's counts for every file set and location (Figure 55) by the median of average counts of Trackers 2, 3, and 5 to obtain a correction factor of 0.45 . This fraction was used as a multiplier to reduce estimates of numbers of fish entering the PSC slots, as tracked by Trackers 2, 3, and 5 and compensate for intertracker bias in efficiency estimates. Unadjusted and bias-corrected efficiency estimates for the PSC based upon adjusted slot counts are shown in Figure 56. Correcting for relative bias reduced the average efficiency by about 5 percent for the 20 -ft slot and about 15 percent for the 5-ft slot.

\section{Comparing Sluice-Chute and Deep-Slot Passage and Effectiveness}

The sluice chute passed significantly more fish per day than the 5-ft-wide, deep slots in the PSC at Powerhouse 1 in spring and summer and more than the 20-ft-wide PSC slot in spring, although not in summer (Table 5). Significantly more fish passed the 20-ft-wide slot than passed through the 5-ft-wide slot in summer, but mean daily passage did not differ significantly in spring. 


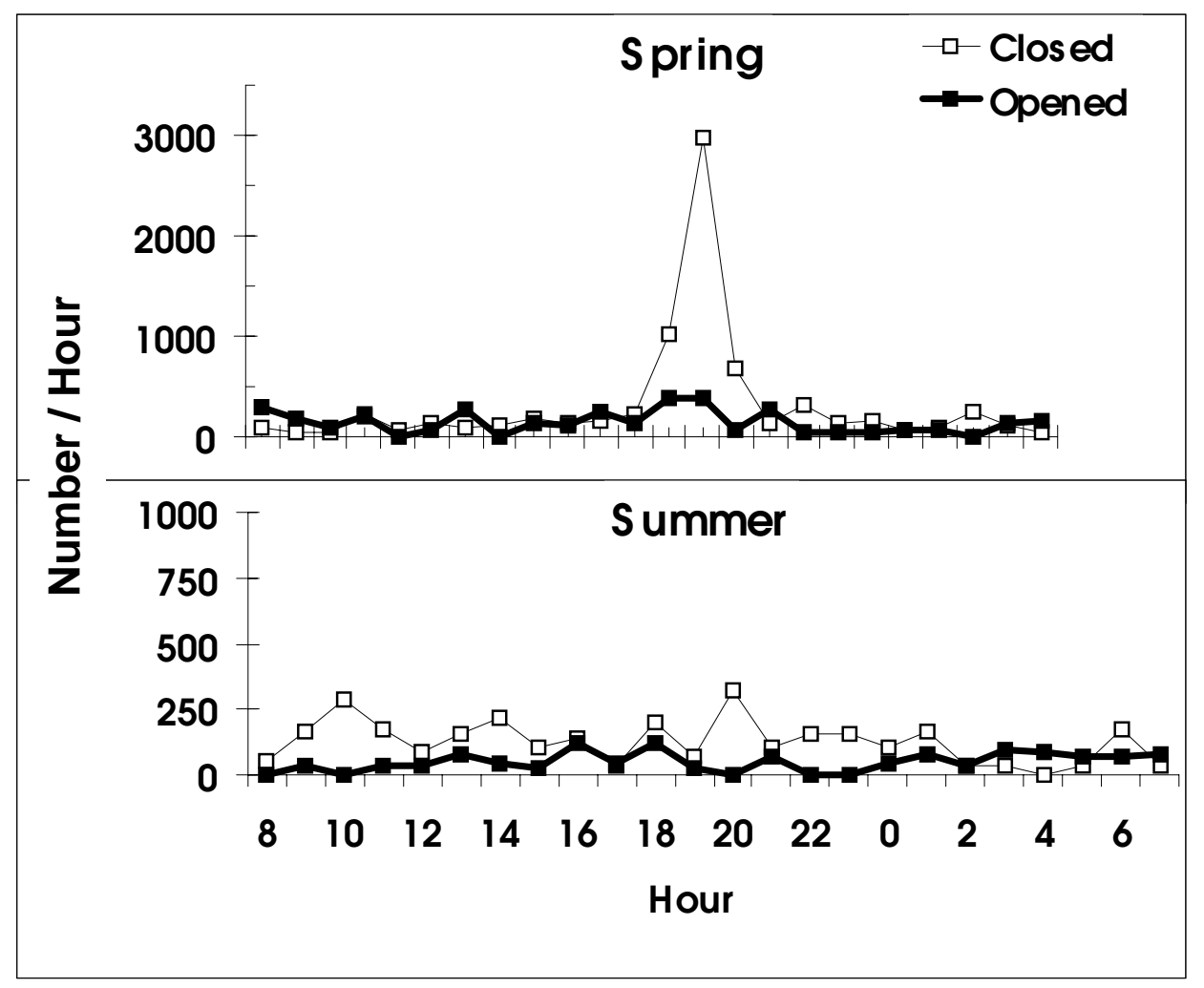

Figure 53. Diel trends in hourly passage of fish above STS in Intakes 11b, 12b, and $13 \mathrm{~b}$ adjacent to the sluice chute, which was either opened or closed (see line references) on a daily basis. (Note that the vertical scale for spring is three times greater in spring than in summer)

Effectiveness was inversely related to the width of the surface opening (Table 5). In both seasons, estimates of mean effectiveness (Table 5) for the 5-ftwide slot was significantly higher than for the sluice chute. The mean sluicechute effectiveness was higher than the mean for the 20-ft-wide slot.

\section{Diel Patterns of Fish Passage}

Diel patterns of passage at the sluice chute were different from those observed at the PSC and turbines. Most fish passed the 15-ft-wide, 13-ft-deep sluice chute during the daytime. In contrast, the 40-ft-deep slots passed significantly more fish at night in spring and about equal numbers during the day and night in summer (compare Figures 38 and 49). 


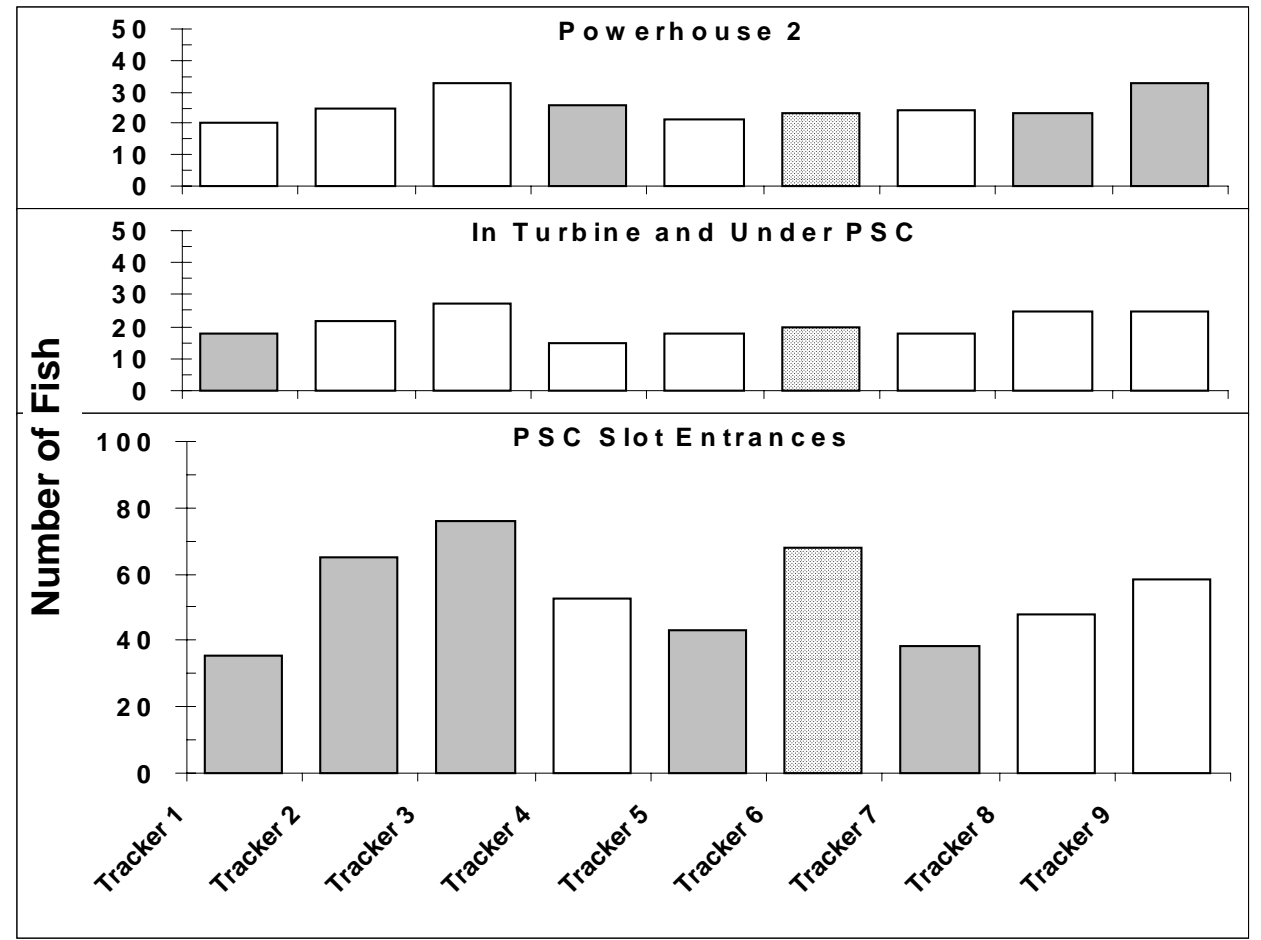

Figure 54. Fish counts made by trackers on thirty 12-min files collected at select locations where transducers were deployed at Bonneville Dam (Gray bars indicate trackers whose counts would be combined to estimate fish metrics. Tracker 4 processed the sluice-chute data whereas Trackers 8 and 9 processed data from Units 11-13. Tracker 1 processed data from turbine intakes downstream of the PSC including fish passing through and under the PSC. Trackers 2, 3, 5, and 7 processed data from PSC-slot entrances) 


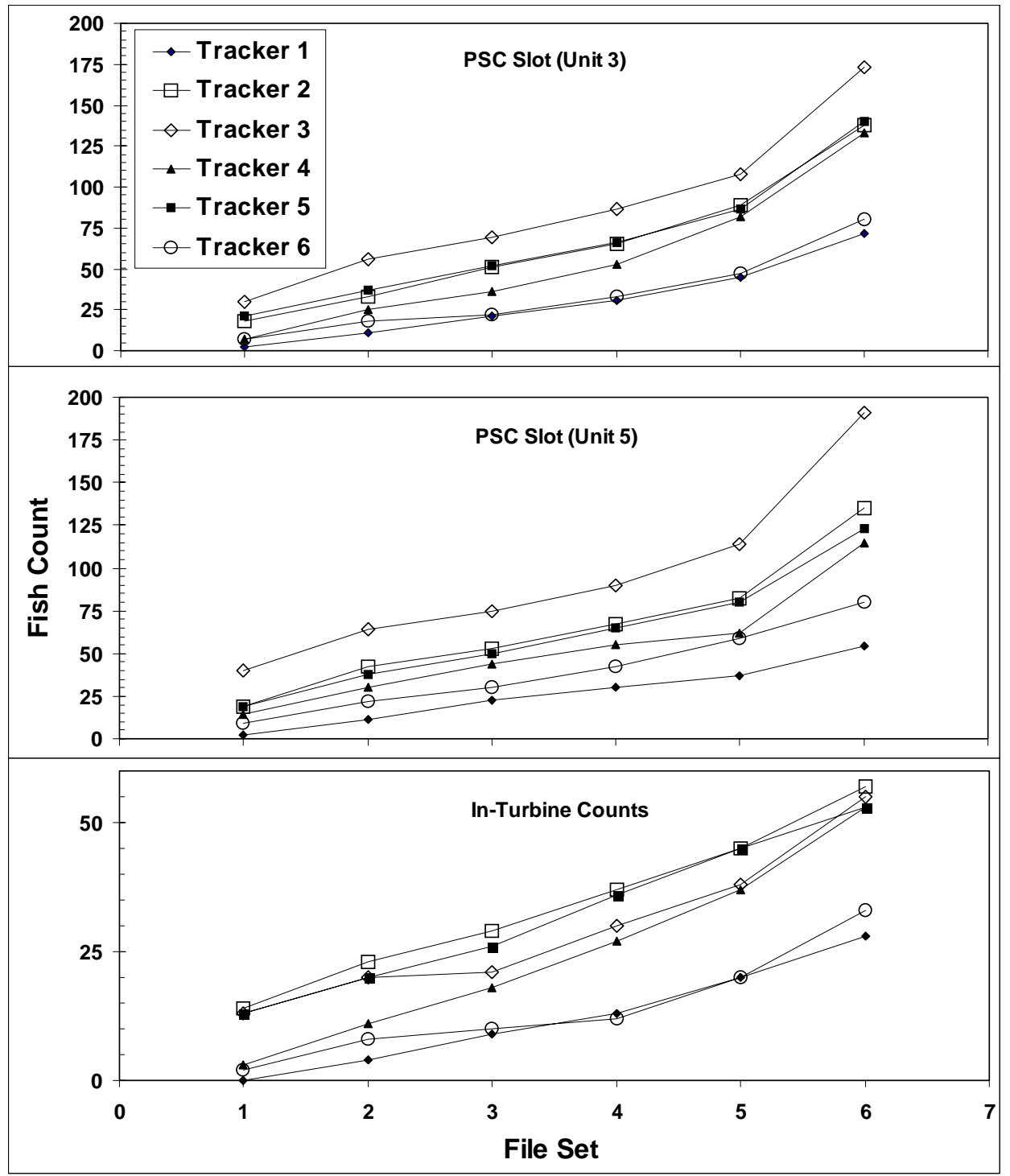

Figure 55. Fish counts from six sets of data files by trackers who processed data in summer 1998 (Sampling duration was about 120 min per file set for each of the sampling locations. In summer 1998, Trackers 2-5 processed all data from slot entrances of Units 3 or 5 ; Tracker 1 processed in-turbine samples; and Tracker 6 processed all samples from Units 1, 2, and 8) 


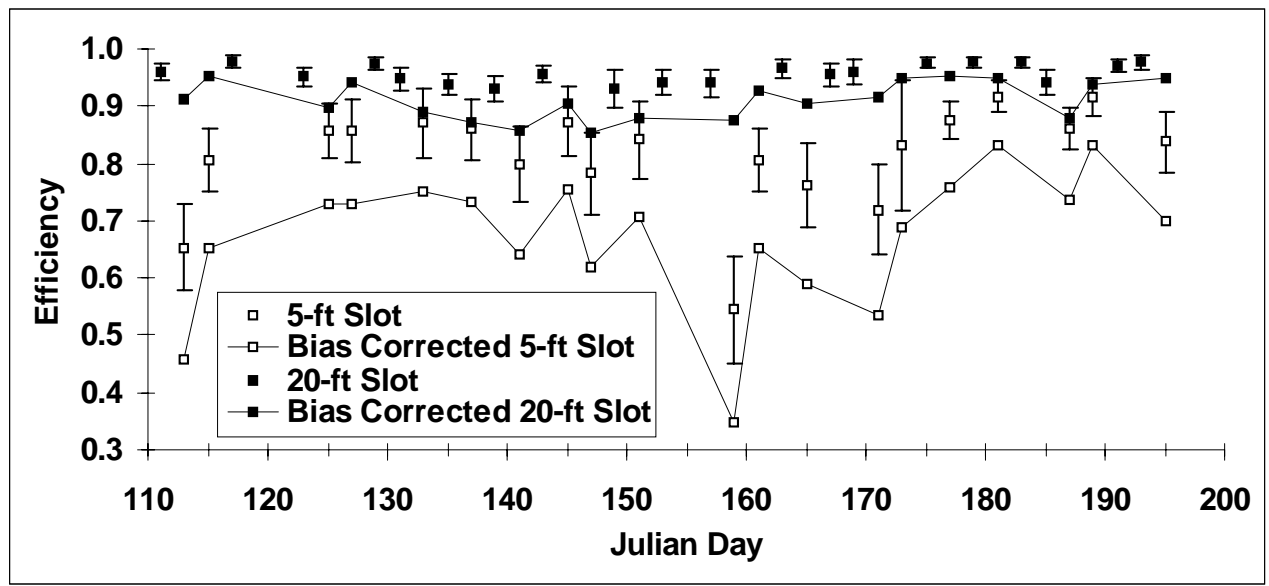

Figure 56. Efficiency of the PSC based upon unadjusted counts (means with 95-percent confidence intervals) and bias-corrected counts (means with connecting lines) of fish at PSC slot entrances (Error bars are 95-percent confidence intervals on estimates)

\begin{tabular}{l}
\hline \hline Table 5 \\
Comparison of Mean Fish Passage per Day and Effectiveness \\
Among the Two PSC Deep-Slot Treatments at Powerhouse 1 \\
Based upon In-Turbine Hydroacoustic Sampling and the Sluice \\
Chute at Powerhouse 2 Based upon Split-Beam Hydroacoustic \\
Sampling (Means that are underlined did not differ significantly at \\
$\alpha=\mathbf{0 . 0 5 )}$ \\
\begin{tabular}{|l|l|l|l||}
\hline \hline Hydroacoustic Metric & PSC-5-ft Slot & PSC-20-ft Slot & Sluice Chute \\
\hline \hline Spring & \multicolumn{3}{||}{} \\
\hline Mean number/day & 3802 & 2894 & 5889 \\
\hline Effectiveness & 9.5 & 3.1 & 5.8 \\
\hline Summer & & 3658 & 4782 \\
\hline Mean number/day & 2894 & 3.1 & 4.9 \\
\hline Effectiveness & 7.3 &
\end{tabular} \\
\hline \hline
\end{tabular}




\section{Discussion}

\section{Prototype Surface Collector and Adjacent Turbine Units}

Despite potential problems with estimating numbers of PSC-collected fish by sampling at slot entrances and inside intakes, 1998 results were encouraging and consistent. First, both slot and in-turbine sampling estimated PSC efficiencies $\geq 80$ percent in spring and summer, and effectiveness estimates by both methods were very similar and highly correlated (Figure 17). Correcting slot samples for potential intertracker bias reduced the mean efficiency of the $20-\mathrm{ft}$ slot from 95 to 90 percent and of the mean of the 5-ft slot from about 85 to 70 percent. However, the correction failed to change our conclusion that the PSC was highly efficient and effective. In-turbine sampling estimated efficiencies of 89-90 percent for spring and summer. Slot sampling showed that fish passage and PSC efficiency were significantly higher for the 20 - $\mathrm{ft}$ slot treatment than for the 5 - $\mathrm{ft}$ treatment in spring and summer. In-turbine sampling provided the same conclusion but with a smaller difference in summer. In-turbine estimates of efficiency for the 5- and 20-ft treatments in spring were within 4 percent of each other (92 versus 88, respectively), and while statistically higher for the 5-ft slot, the difference probably is not biologically meaningful. We found that significantly more fish passed under the 5 - $\mathrm{ft}$ slot than under the 20 - $\mathrm{ft}$ slot in summer $(\mathrm{P}=0.0079)$ but not in spring. This difference might be related to greater downward flows at the 5-ft slot and the relatively smaller size and reduced swimming capability of subyearling salmon in summer relative to that of yearling salmon sampled in spring.

Although in-turbine sampling was only intended to be a check on slot sampling, three problems with slot sampling inside the PSC made us rely heavily on in-turbine data. First, PSC slot samples were often contaminated with entrained air bubbles within 1-2 m of the water's surface, particularly for the 20 -ft opening. Fish traces embedded in noise were not trackable, resulting in underestimates of slot passage. The amount of the underestimate would depend upon the vertical distribution of fish passing through the slot. With a 12-m-deep slot, noise in the upper $2 \mathrm{~m}$, and a uniform vertical distribution of fish, passage could have been underestimated by 17 percent. If the vertical distribution were skewed toward the surface, which is likely, then the underestimate would be greater. Second, some of the flow entering the PSC in the middle module circulated laterally into the side modules and returned to the middle module as an 
eddy. This circulation pattern made it possible, if not likely, that some fish were counted multiple times, especially during sampling of sides of the 20 -ft slot. If multiple counts on side transducers caused the skewed distribution of fish passage toward the sides of the 20 -ft-wide slot (Figure 7), they could have resulted in overestimates of 44 percent in spring and 25 percent in summer. Third, systematic differences in numbers of fish counted by people tracking fish at slot entrances and another tracker counting fish passing under the collector could have inflated estimates of PSC passage by 11-45 percent. However, a 45 percent bias correction reduced PSC efficiency only by 5 percent for the $20-\mathrm{ft}$ slot and 15 percent for the 5-ft slot (Figure 56).

Evidence suggests that the skewed distribution at the 20-ft-wide PSC slot resulted from multiple counts rather than the way fish approached and entered the slot. Observation of water circulation patterns in the 100-to-1-scale model at the U.S. Army Engineer Research and Development Center, Vicksburg, MS, suggested that targets may pass through hydroacoustic beams more than once. Radiotelemetry data indicated that many fish entering the PSC did not pass into the turbine immediately but circulated for an average of 6 min. A few were there for hours. To evaluate the possibility that fish passed through hydroacoustic beams more than once, we sampled for several hours with a split-beam transducer in the PSC entrances. These data indicated that equal numbers of fish crossed the beam laterally as crossed moving directly downstream. The observed lateral skew in the fish distribution of passage (Figure 7) is possible without multiple counting, although that is unlikely. We observed a very similar distribution pattern with multiple cameras mounted on top of a 21-ft-wide sluice gate in 1996 (Ploskey et al. 1998).

In-turbine sampling had two important limitations that may have made it less sensitive to slot treatments than slot sampling. First, in-turbine transducers could not sample fish passing through the PSC and then the center sluice gate of the unit. The center sluice gate was opened 1-1.5 $\mathrm{m}$ to reduce turbulence in the PSC box. Turbulence in the PSC was a problem for sampling of slot entrances. Second, the single downlooking transducer in each of six intakes could not sample fish in the upper $3 \mathrm{~m}$ of the intake, presumably where most of the fish pass. Beams were too narrow within $3 \mathrm{~m}$ of the transducer and had limited ability to detect fish, i.e., return four consecutive echoes given rates of fish movement, transceiver ping rate, and beam diameter. This low detectability probably made in-turbine sampling less capable of detecting differences in 5-and 20 -ft slot treatments than slot sampling because larger spatial expansions were required for "collected" fish. Both limitations encountered in 1998 can be eliminated for future testing. The center sluice gate can be closed to force fish to pass through the intakes where they can be sampled with an uplooking hydroacoustic beam. Sampling of slot entrances cannot be justified given the many problems described in the next paragraph; therefore, the need to open the sluice gate to dampen noise in the collector no longer exists. A closed sluice may make the PSC noisier than an open sluice, but it also may better resemble flow in a PSC where water is channeled around intakes. The second limitation can be

\footnotetext{
${ }^{1}$ Personal Communication, Marvin Shutters, Fisheries Biologist, U.S. Army Engineer Distrist, Portland, Portland, OR.

${ }^{2}$ Personal Communication, Rip Shively, U.S. Geological Survey.
} 
eliminated in future tests by adding an additional uplooking beam that samples an adequate volume up to the intake ceiling. Aside from these limitations, inturbine samples were relatively noise free; fish could not be counted more than once; and a single tracker happened to provide all counts of fish passing through and under the PSC, so there was no intertracker bias. The distribution of slopes of thousands of fish trajectories in hydroacoustic beams indicated that all fish were moving downward and most within $10 \mathrm{~m}$ of the transducer had similar trajectories (Figure 12). Therefore, fish passing under the collector floor were very unlikely to dart upward closer to the transducer where they would be classified as "collected." In addition, analysis of the effect of cutoff range on PSC efficiency revealed that efficiency was not very sensitive to cutoff range within $\pm 0.5 \mathrm{~m}$ of the range used (Figure 13).

In-turbine sampling had two important limitations that may have made it less sensitive to effects of 5- and 20-ft slot treatments than sampling slot entrances. The distribution of slopes of thousands of fish trajectories in hydroacoustic beams indicated that all fish were moving downward and most within $10 \mathrm{~m}$ of the transducer had similar linear trajectories. Therefore, fish passing under the collector floor were very unlikely to dart upward closer to the transducer where they would be classified as "collected." In addition, analysis of the effect of cutoff range on PSC efficiency revealed that efficiency was not very sensitive to cutoff range within $\pm 0.5 \mathrm{~m}$ of the range used.

Slot and in-turbine sampling both showed that the 5-ft slot was significantly more effective than the 20 -ft slot in passing juvenile salmon per unit of flow. The 5-ft slot treatment passed over 6 times more fish than would be expected based upon the proportion of flow passing through the slot relative to flow passing into the turbine in spring and summer (Figure 11). The 20-ft slot treatment only passed 3.1 times more fish than would be expected from the proportion of flow entering the slot relative to the whole turbine. At 2,750 cfs, the 20 -ft-wide slot passes 2.81 times more water than the 5 -ft slot (980 cfs) and, therefore, usually passed more fish per unit of time in spite of differences in effectiveness. Since a limiting factor for future development of surface collection is how much water can be handled, the question of what size and how many slots is extremely important. Effectiveness data indicate that presenting many 5-ft slots might be better than presenting a few 20-ft slots, given equal volumes of water to be passed. We believe it is important not to equate slot width with the volume of water that can be passed but to select a slot width based upon its effectiveness. An analogy is to say that large lakes are more productive than small lakes because they have more fish. While large lakes usually have more fish than small lakes, they usually are much less productive per unit of area. The density of fish passing through PSC slots and intakes indicated that per unit volume, more fish pass through the 5- than through the 20 -ft slot.

Slot-entrance counts of fish at PSC Units 3 and 5 were significantly correlated, although on average the Unit 3 opening collected more fish than the Unit 5 opening (Figure 16), perhaps because of lateral flow patterns. For all treatments, Units 3 and 5 had the same slot opening ( 5 or $20 \mathrm{ft}$ ). The Unit 3 slot averaged 2.8 times more fish than the Unit 5 slot during 5 - $\mathrm{ft}$ slot treatments. The Unit 3 slot also averaged 1.4 times more fish than the Unit 5 slot during 20-ft slot 
treatments. In the lateral flow along the PSC, Unit 3 was located downstream of Unit 5, and fish may have had more time to get close to the upstream face of the PSC before encountering its opening. At Unit 5, the 20-ft slot passed more fish than the 5-ft slot, and this could account for lower among-unit differences during 20 -ft slot treatments.

Unlike the efficiency of the PSC, which was high in spring and summer, mean FGE of STS in intakes $1 b$ and $2 b$ both decreased seasonally. The FGE also was consistently higher at Intake $1 \mathrm{~b}$ (79 percent in spring and 62 percent in summer) than at Intake $2 b$ ( 46 percent in spring and 21 percent in summer), perhaps because of the hydraulic characteristics adjacent to each intake. The downward forces associated with this hydraulic phenomenon may have drawn fish deeper at intake $2 \mathrm{~b}$. Relative to lateral flow from north to south along the PSC and powerhouse, Intake $1 \mathrm{~b}$ is further downstream than intake $2 \mathrm{~b}$ where lateral flow is gradually slowing. Fish in this area may be distributed higher in the water column than at Unit 2 and therefore may be more readily guided by the STS. Additionally, Unit 1 may be passing more fish than Unit 2 because of its corner location, where fish moving south along the powerhouse or west along the old navigation-lock wall end up at Unit 1.

Slot-width treatments at the PSC had no effect on numbers of fish passing at Units 1 and 2, and mean passage there was lower than passage through the PSC in spring and similar to PSC passage in summer. Therefore, the efficiency of the PSC slots relative to Units 1, 2, 3, and 5 was about 60 percent in spring and 50 percent in summer if differences in the size of the passage routes are ignored. However, since the six intakes at Units 1 and 2 are 3.2 times wider than two 20ft-wide PSC slots and 12.6 times wider than two 5-ft PSC slots, a standardized efficiency would be 85 percent. This suggests that fish are more likely to enter the PSC slots than to enter the adjacent turbines, and that the only reason passage estimates were similar was due to the greater size of the turbine passage route.

\section{Extended-Submerged Bar Screen at Intake 8b}

Unlike the efficiency of the PSC slots or the sluice chute, the FGE of an ESBS declined significantly from spring through summer. Our hydroacoustic sampling and NMFS net sampling both showed that numbers of guided fish declined and numbers of unguided fish increased from spring through summer, although daily variability was high for both methods (Figures 25, 27, and 29). Summer FGE was lower than expected from sampling at The Dalles (Brege et al.1994; Absolson et al. 1995), John Day (Brege et al. 1997), and McNary (Brege et al. 1992; McComas et al. 1993) dams, where it ranged from 53-64 percent.

Counts of ESBS-guided fish by hydroacoustics and gatewell dipping both indicated a significant decline from spring through summer. Hydroacoustic estimates were lower than netting estimates in spring but similar to netting estimates in summer; nonetheless, they were correlated. Hydroacoustic counts of unguided fish gradually increased from spring through summer $(P=0.0142)$, and netting estimates showed a similar rate of change, although daily variability was high for both methods. On average, hydroacoustic estimates of unguided fish 
were about 33 percent of netting estimates in spring and 50 percent of netting estimates in summer.

High daily variation and poor correlations by the two methods (Figures 26 and 28) were not surprising given the 50-percent spatial coverage of most fyke netting and low temporal coverage of hydroacoustic sampling. If an objective of sampling is to obtain a high correlation between the two methods, more effort is required for both methods. With hydroacoustic sampling time split among Units 1,2 , and 8 , the effort was only sufficient to detect broad seasonal trends. The quarter-time sampling rate of hydroacoustics was minimal relative to the nearly continuous sampling with nets for 1-2 hours. Gatewell-dipping estimates of guided fish were on average 1.7 times higher than hydroacoustic estimates in spring, but estimates were similar in summer. We used a threshold of $-57 \mathrm{~dB}$ for on-axis targets in spring and $-60 \mathrm{~dB}$ in summer. If larger spring fish maintained a consistent horizontal aspect (i.e., orientation), some could have gone undetected by the hydroacoustic beam, which was aimed 46 deg downstream of vertical (Figure 4). Unfortunately, we do not know what orientation fish maintain, if any, while passing through a turbine intake. Even with the underestimate of guided fish in spring, mean hydroacoustic estimates of FGE were higher than mean netting estimates because the downlooking transducers consistently underestimated numbers of unguided fish (Figure 29) by an average factor of two. This error compensation in the FGE estimate shows the advantage of using a ratio estimate over a "quantitative" passage estimate from hydroacoustics.

\section{Sluice Chute and Adjacent Units at Powerhouse 2}

Turbine intake extensions (TIES) on the south end of Powerhouse 2 were removed in 1998. Consequently, relatively laminar bulk flows moved along the powerhouse toward the sluice chute, and water entering the sluice chute was less turbulent than in prior years. Removal of TIES provided a low noise environment for hydroacoustic sampling with three uplooking split-beam transducers. A pulse repetition rate of 37 pings per second provided uniform and adequate detectability despite high-water velocities and short-sampling ranges.

All metrics comparing the sluice chute to Units 11-13 remained high and relatively stable through summer (Figures 30-32), unlike the FGE of Units 11-13, which declined from spring to summer (Figure 33). Combined efficiency of the sluice chute and STS in Units 11-13 averaged 90 percent in spring and summer when the sluice chute was open, but STS efficiency alone (sluice closed) was only 55 percent in spring and 30 percent in summer. The efficiency of the sluice chute relative to total passage at Units $11-13$ plus passage at the sluice chute averaged 83 percent in spring and 81 percent in summer. The effectiveness metric indicated that about five times more fish were passed by the sluice chute than would be expected from the proportion of water passing through the chute relative to the total for the chute and Units 11-13. Even though the sluice chute had $<1.1$ percent of the combined cross-sectional area of adjacent units, it passed significantly greater numbers of fish (Figure 34). Fish passage through the sluiceway averaged 5,888 per day in spring. Passage averaged 4,246 fish per day 
in summer, excluding observations from the last 2 days when passage was dominated by American shad.

The proportion of fish relative to the proportion of water passing through the sluice chute relative to Units 11-13 and the sluice chute or "sluice-chute effectiveness" averaged 5.8 in spring and 4.6 in summer. In spring, the FGE of Units 11-13 was significantly lower when the sluice chute was opened (FGE = $0.45)$ than when the sluice-chute was closed (FGE $=0.59)$. Mean FGE did not differ among sluice treatments in summer.

When we compared sluice-chute passage to estimates of passage through the JBS for the entire powerhouse, we found similar seasonal trends and a mean sluice-chute efficiency of 20 percent in spring and 25 percent in summer. This is high considering that sluice-chute flow represents only about 2 percent of the flow from which fish are screened to the JBS. We could not estimate potential bias for sluice efficiency relative to the JBS because the two measures were very different. For example, hydroacoustic sampling of the sluice chute was continuous for 23 hours per day, while estimates from the JBS were expanded counts of fish screened from whatever turbines happened to be operating. Nevertheless, significant correlation of passage estimates by the two approaches was encouraging, because it indicated concordance in respective run-timing estimates.

\section{Comparing Sluice-Chute and In-turbine Estimates of PSC Passage and Effectiveness}

We strongly believe that differences in estimates of passage at the sluice chute and two deep slots in the PSC had more to do with opening location and orientation than with shape. The basis for this belief originates from differences

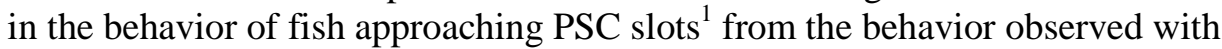
split-beam transducers at the sluice chute. Paths of fish approaching PSC slots became increasingly tortuous, whereas paths of fish approaching the sluice chute were linear. The sluice chute passed significantly more fish than the 5-ft-wide PSC slot in spring and summer and more than the 20-ft-wide slot in spring. The $20-\mathrm{ft}$ slot passed similar numbers of fish as the sluice chute in summer. The success of the sluice chute probably was due to its location in the corner of the south end of Powerhouse 2 and the removal of TIES from Intakes 11-14. Removal of TIES enhanced lateral flow along the south face of Powerhouse 2 toward the sluice chute. The orientation of the sluice chute to intercept some of the lateral flow also was fortuitous. In contrast, PSC openings were oriented oblique to flow. Perhaps an equally important difference was the presence of trash racks in front of PSC slots. There were no trash racks in front of the sluice chute. The PSC trash racks often accumulated trash before the end of the 2-day slot treatments in 1998. Future studies should carefully examine fish behaviors immediately upstream of PSC slots when trash racks are present and absent to see if behavior changes. Environmental variables including flow, acceleration, and sound also should be measured at the sluice chute and PSC slots during these

\footnotetext{
${ }^{1}$ Personal Communication, Bob Johnson, Battelle, Richland, WA.
} 
treatments. We believe fish could be responding to the presence of trash racks using a number of sensory mechanisms, including eyes (sight), inner ear (acceleration), and lateral line (distant touch). It is possible that trash racks were vibrating, especially under a hydraulic load, and providing stimuli to fish.

Data collected in 1998 showed that within the range of tested slot widths (5$20 \mathrm{ft}$ ), narrow surface openings were more effective than wide openings for passing fish. These data suggest that for equal volumes of water discharged for surface collection, more, narrower (down to $5 \mathrm{ft}$ ) surface openings would collect more fish than fewer, wider openings (up to $21 \mathrm{ft}$ ). The 5-ft-wide slot in the PSC passed 7.3-9.5 times more fish than would be expected based upon flow proportions at the PSC units. This rate was significantly higher than for the sluice chute (4.9-5.8 times more fish than flow), which in turn was higher than the rate for the 20 -ft-wide slot (3.1 times more fish) in the PSC.

\section{Diel Patterns of Fish Passage}

Differences in diel patterns of fish passage most likely are a function of the depth of the hydraulic structures passing fish. Most fish passed through the relatively shallow sluice chute during the day, while they passed through turbines or deep PSC slots in greater numbers at night, at least in spring. The PSC slots had no strong diel pattern in summer. This suggests that deep slots had diel passage patterns that were in between night-dominated patterns observed for turbines (Figures 42, 45, 52) and the diurnal pattern observed for the sluice chute (Figure 49). 


\section{References}

Absolon, R. F., Brege, D. A., Stanford, B. P., and Dey, D. B. (1995). "Studies to evaluate the effectiveness of extended-length screens at The Dalles Dam, 1994," Report to the U.S. Army Corps of Engineers, Delivery Order E96930030, Northwest Fisheries Science Center, Seattle, WA.

Biosonics, Incorporated. (1998). "Hydroacoustic evaluation and studies at Bonneville Dam, Spring/Summer 1997," Contract Report to the U.S. Army Engineer District, Portland, OR.

Brege, D. A., Grabowski, S. J., Muir, W. D., Hirtzel, S. R., Mazur, S. J., and Sanford, D. P. (1992). "Studies to determine the effectiveness of extended travelling screens and extended bar screens at McNary Dam, 1991," Report to the U.S. Army Corps of Engineers, Delivery Order E86910060, Northwest Fisheries Science Center, Seattle, WA.

Brege, D. A., Absolon, R. F., Sanford, B. P., and Dey, D. B. (1994). "Studies to evaluate the effectiveness of extended-length screens at The Dalles Dam, 1993," Report to the U.S. Army Corps of Engineers, Delivery Order E96930030, Northwest Fisheries Science Center, Seattle, WA.

. (1997). "Studies to evaluate the effectiveness of extended-length screens at John Day Dam, 1996," Report to U.S. Army Corps of Engineers, Delivery Order E969600028, Northwest Fisheries Science Center, Seattle, WA.

Gessel, M. H., Monk, B. H., and Williams, J. G. (1988). "Evaluation of the juvenile fish collection and bypass systems at Bonneville Dam, 1987," Annual Report by the U.S. Department of Commerce, NOAA, NMFS, Coastal Zone and Estuarine Studies Division to the U.S. Army Engineer District, Portland, OR.

Gessel, M. H., Monk, B. H., Brege, D. A., and Williams, J. G. (1989). "Fish guidance efficiency studies at Bonneville Dam First and Second Powerhouse, 1988," Annual Report by the U.S. Department of Commerce, NOAA, NMFS, Coastal Zone and Estuarine Studies Division to the U.S. Army Engineer District, Portland, OR. 
Gessel, M. H., Williams, J. G., Brege, D. A., Krcma, R. F., and Chambers, D. R. (1991). "Juvenile salmon guidance at the Bonneville Dam Second Powerhouse, Columbia River, 1983-1989," North American Journal of Fisheries Management 11. (3), 400-412.

Giorgi, A. E., and Stevenson, J. R. (1995). "A review of biological investigations describing smolt passage behavior at Portland District Corps of Engineer Projects: Implications in surface collection systems," Contract Report prepared by Don Chapman Consultants, Inc., for the U.S. Army Engineer District, Portland, OR.

Johnson, G. E., Johnson, R.L., Abernethy, C. S., Anglea, S. M., Blanton, S., Simmons, M., Kudera, E., A., Sullivan, C. M., and Skalski, J. R. (1998a). "Fixed-location hydroacoustic evaluation of the prototype surface bypass and collector, spill efficiency, and fish guidance efficiency at Lower Granite Dam in spring and summer 1997," Final Report to U.S. Army Engineer District, Walla Walla. Contract DACW68-96-D-0002, Delivery Order 004. Battelle Pacific Northwest Division, Richland, WA.

Johnson, G. E., Johnson, R. L., Anglea, S. M., Blanton, S. L., Simmons, M. A., Thorsten, S., Kudera, E. A., Skalski, J. R., and Thomas, J. (1998b). "Fixedlocation hydroacoustic evaluation of the prototype surface bypass structures at Lower Granite Dam in spring 1998," Preliminary Analysis Report to the U.S. Army Engineer District, Walla Walla, Contract DACW68-96-D-0002, Delivery Order 007, Battelle Pacific Northwest Division, Richland, WA.

Krcma, R. F., DeHart, D., Gessel, M., Long, C., and Sims, C. W. (1982). "Evaluation of submersible traveling screens, passage of juvenile salmonids through the ice-trash sluiceway, and cycling of gatewell-orifice operations at the Bonneville first powerhouse, 1981," Final Report by the U.S. Department of Commerce, NOAA, NMFS, Coastal Zone and Estuarine Studies Division to the U.S. Army Engineer District, Portland, OR.

Krcma, R. F., Brege, D. A., and Ledgerwood, R. D. (1986). "Evaluation of the rehabilitated juvenile salmonid collection and passage system at John Day Dam, 1985," Report to the U.S. Army Corps of Engineers, Contract DACW57-85-H-0001, Northwest Fisheries Science Center, Seattle, WA.

Magne, R. A., Rawling, D. J., and Nagy, W. T. (1986). "Hydroacoustic monitoring at the Bonneville Dam second powerhouse during 1986 fish guiding efficiency tests," Fishery Field Unit, U.S. Army Engineer District, Portland, OR.

Magne, R. A. (1987). "Hydroacoustic monitoring at the Bonneville Dam Project in 1987," Fishery Field Unit, U.S. Army Engineer District, Portland, OR.

Magne, R. A., Stansell, R. J., and Nagy, W. T. (1989). "A summary of hydroacoustic monitoring at the Bonneville Dam second powerhouse in 1988," Fishery Field Unit, U.S. Army Engineer District, Portland, OR. 
McComas, R. L., Brege, D. A., Muir, W. D., Sandford, B. P., and Dey, D. B. (1993). "Studies to determine the effectiveness of extended-length submersible bar screens at McNary Dam, 1992," Report to the U.S. Army Corps of Engineers, Delivery Order E86910060, Northwest Fisheries Science Center, Seattle, WA.

Muir, W. D., Giorgi, A. E., Zaugg, W. S., and Beckman, B. R. (1989). “An assessment of the relationship between smolt development and fish guidance efficiency at Bonneville Dam," Annual Report by the U.S. Department of Commerce, NOAA, NMFS, Coastal Zone and Estuarine Studies Division to the U.S. Army Engineer District, Portland, OR.

Nagy, W. T. and Magne, R. A.. (1986). "Hydroacoustic study of juvenile fish passage at the Bonneville Second Powerhouse in 1985," Fishery Field Unit, U.S. Army Engineer District, Portland, OR.

Ploskey, G. R., Johnson, P. N., and Carlson, T. J. (1996). "Evaluation of an array of low-frequency, sound-pressure transducers for guiding juvenile salmon away from turbines at Bonneville Dam, Columbia River," Report to the U.S. Army Engineer District, Portland, by the U.S. Army Engineer Waterways Experiment Station, Vicksburg, MS.

Ploskey, G. R., Johnson, P. N., Nagy, W. T., Burczynski, M. G., and Lawrence, L. R. (1998). "Hydroacoustic evaluations of juvenile salmonid passage at Bonneville Dam including surface-collection simulations," Technical Report EL-98-4, U.S. Army Engineer Waterways Experiment Station, Vicksburg, MS.

Stansell R. J., Magne, R. A., Nagy, W. T., and Beck, L. M. (1990). "Hydroacoustic monitoring of downstream migrant juvenile salmonids at Bonneville Dam, 1989," Fishery Field Unit, U.S. Army Engineer District, Portland, OR.

Thorne, R. E., and Kuehl, E. S. (1989). "Evaluation of hydroacoustics techniques for assessment of juvenile fish passage at Bonneville Powerhouse 1," Final Report by BioSonics, Inc., Seattle, WA, for the U.S. Army Engineer District, Portland, OR.

Uremovich, B. L., Cramer, S. P., Willis, C. F., and Junge, C. O. (1980). "Passage of juvenile salmonids through the ice-trash sluiceway and squawfish predation at Bonneville Dam, 1980," Oregon Department of Fish and Wildlife, Annual progress report prepared for the U.S. Army Engineer District, Portland, OR.

Willis, C. F., and Uremovich, B. L. (1981). "Evaluation of the ice and trash sluiceway at Bonneville Dam as a bypass system for juvenile salmonids, 1981," Oregon Department of Fish and Wildlife, Annual progress report prepared for the U.S. Army Engineer District, Portland, OR 


\section{Appendix A Detectability Modeling Results for All Transducers Deployed at Bonneville Dam in 1998}

Tables show model inputs, outputs, and logistic regression equations and coefficients fitted to effective beam angle. Maximum ranges were truncated in most cases when the effective beam angle was approaching an asymptote. Underlined ranges and effective beam angles were the minima at which fish were counted. 


\begin{tabular}{|c|c|c|c|c|c|c|c|c|c|c|c|c|}
\hline \multirow{2}{*}{$\begin{array}{l}\text { Detectibility Model Results for: } \\
\text { Model Inputs }\end{array}$} & \multicolumn{2}{|c|}{$\begin{array}{c}\text { PSC } \\
\text { uplooking } \\
\text { 5-ft slot }\end{array}$} & \multicolumn{2}{|c|}{$\begin{array}{c}\text { PSC } \\
\text { downlooking } \\
\text { 5-ft slot }\end{array}$} & \multicolumn{2}{|c|}{$\begin{array}{c}\text { PSC } \\
\text { uplooking } \\
20 \text {-ft slot } \\
\end{array}$} & \multicolumn{2}{|c|}{$\begin{array}{c}\text { PSC } \\
\text { downlooking } \\
\text { 20-ft slot }\end{array}$} & \multicolumn{2}{|c|}{$\begin{array}{c}\text { PSC } \\
\text { In-turbine } \\
\text { 5-ft slot }\end{array}$} & \multicolumn{2}{|c|}{$\begin{array}{c}\text { PSC } \\
\text { In-turbine } \\
20 \text {-ft slot }\end{array}$} \\
\hline & \\
\hline \multicolumn{2}{|l|}{ Fish Velocity (ft / sec) } & 6.8 & & 6 & & 4.5 & & 4.5 & & 5 & & 4 \\
\hline \multicolumn{2}{|l|}{ Pulse Repetition Rate (pings/sec) } & 15 & & 15 & & 15 & & 15 & & 15 & & 15 \\
\hline \multicolumn{2}{|l|}{ Minimum \# Echoes for Detection } & 4 & & 4 & & 4 & & 4 & & 4 & & 4 \\
\hline Beam Angle Along Direction of Trave & & 7 & & 7 & & 7 & & 7 & & 7 & & 7 \\
\hline Beam Angle Perpendicular to Travel & & 7 & & 7 & & 7 & & 7 & & 7 & & 7 \\
\hline Transducer Aiming Orientation & & up & & down & & up & & down & & down & & down \\
\hline Orientation from Vertical (degrees) & & 17 & & 5 & & 17 & & 5 & & 0 & & 0 \\
\hline Fish Trajectory (degrees from horiz.) & & 1 & & -1 & & 1 & & -1 & & 2 & & 2 \\
\hline Maximum Range Modeled (ft) & & 50 & & 50 & & 50 & & 50 & & 60 & & 60 \\
\hline Model Outputs & Range, m & Angle & Range, m & Angle & Range, $\mathrm{m}$ & Angle & Range, $\mathrm{m}$ & Angle & Range, $\mathrm{m}$ & Angle & Range, $\mathrm{m}$ & Angle \\
\hline & 4.3 & 0.0 & 4.0 & 0 & 2.7 & 0.0 & 2.9 & 0.0 & 3.3 & 0.0 & 2.6 & 0.0 \\
\hline & 4.4 & 1.6 & 4.1 & 1.74 & 2.9 & 1.3 & 3.0 & 1.4 & 3.5 & 2.0 & 2.7 & 1.7 \\
\hline & 4.6 & 2.4 & 4.3 & 2.5 & 3.0 & 2.5 & 3.2 & 2.5 & 3.7 & 2.9 & 2.9 & 2.9 \\
\hline & 4.7 & 2.9 & 4.4 & 3.02 & 3.2 & 3.2 & 3.4 & 3.2 & 3.8 & 3.5 & 3.1 & 3.6 \\
\hline & 4.9 & 3.3 & 4.6 & 3.43 & 3.4 & 3.7 & 3.5 & 3.7 & 4.0 & 3.9 & 3.3 & 4.1 \\
\hline & 5.0 & 3.6 & 4.7 & 3.76 & 3.5 & 4.1 & 3.7 & 4.0 & 4.2 & 4.3 & 3.5 & 4.5 \\
\hline & 5.2 & 3.9 & 4.9 & 4.03 & 3.7 & 4.4 & 3.8 & 4.4 & 4.4 & 4.6 & 3.7 & 4.8 \\
\hline & 5.3 & 4.1 & 5.0 & 4.27 & 3.8 & 4.7 & 4.0 & 4.6 & 4.6 & 4.8 & 3.8 & 5.1 \\
\hline & 5.5 & 4.3 & 5.2 & 4.47 & 4.0 & 4.9 & 4.1 & 4.8 & 4.8 & 5.0 & 4.0 & 5.3 \\
\hline & 5.6 & 4.5 & 5.3 & 4.65 & 4.1 & 5.1 & 4.3 & 5.0 & 4.9 & 5.2 & 4.2 & 5.4 \\
\hline & 5.8 & 4.7 & 5.5 & 4.81 & 4.3 & 5.2 & 4.4 & 5.2 & 5.1 & 5.3 & 4.4 & 5.6 \\
\hline & 5.9 & 4.8 & 5.6 & 4.95 & 4.4 & 5.4 & 4.6 & 5.3 & 5.3 & 5.5 & 4.6 & 5.7 \\
\hline & 6.1 & 5.0 & 5.8 & 5.08 & 4.6 & 5.5 & 4.7 & 5.4 & 5.5 & 5.6 & 4.8 & 5.8 \\
\hline & 6.2 & 5.1 & 5.9 & 5.19 & 4.7 & 5.6 & 4.9 & 5.5 & 5.7 & 5.7 & 4.9 & 5.9 \\
\hline & 6.4 & 5.2 & 6.1 & 5.3 & 4.9 & 5.7 & 5.0 & 5.6 & 5.9 & 5.8 & 5.1 & 6.0 \\
\hline & 6.6 & 5.3 & 6.2 & 5.39 & 5.0 & 5.8 & 5.2 & 5.7 & 6.0 & 5.8 & 5.3 & 6.1 \\
\hline & 6.7 & 5.4 & 6.4 & 5.48 & 5.2 & 5.9 & 5.3 & 5.8 & 6.2 & 5.9 & 5.5 & 6.1 \\
\hline & 6.9 & 5.5 & 6.6 & 5.56 & 5.3 & 5.9 & 5.5 & 5.9 & 6.4 & 6.0 & 5.7 & 6.2 \\
\hline & 7.0 & 5.5 & 6.7 & 5.63 & 5.5 & 6.0 & 5.6 & 5.9 & 6.6 & 6.0 & 5.9 & 6.2 \\
\hline & 7.2 & 5.6 & 6.9 & 5.7 & 5.6 & 6.0 & 5.8 & 6.0 & 6.8 & 6.1 & 6.0 & 6.3 \\
\hline & 7.3 & 5.7 & 7.0 & 5.76 & 5.8 & 6.1 & 5.9 & 6.1 & 6.9 & 6.2 & 6.2 & 6.3 \\
\hline & 7.5 & 5.7 & 7.2 & 5.82 & 5.9 & 6.1 & 6.1 & 6.1 & 7.1 & 6.2 & 6.4 & 6.4 \\
\hline & 7.6 & 5.8 & 7.3 & 5.87 & 6.1 & 6.2 & 6.2 & 6.2 & 7.3 & 6.2 & 6.6 & 6.4 \\
\hline & 7.8 & 5.8 & 7.5 & 5.92 & 6.2 & 6.2 & 6.4 & 6.2 & 7.5 & 6.3 & 6.8 & 6.4 \\
\hline & 7.9 & 5.9 & 7.6 & 5.97 & 6.4 & 6.3 & 6.6 & 6.2 & 7.7 & 6.3 & 6.9 & 6.5 \\
\hline & 8.1 & 5.9 & 7.8 & 6.01 & 6.6 & 6.3 & 6.7 & 6.3 & 7.9 & 6.3 & 7.1 & 6.5 \\
\hline & 8.2 & 6.0 & 7.9 & 6.05 & 6.7 & 6.3 & 6.9 & 6.3 & 8.0 & 6.4 & 7.3 & 6.5 \\
\hline & 8.4 & 6.0 & 8.1 & 6.09 & 6.9 & 6.4 & 7.0 & 6.3 & 8.2 & 6.4 & 7.5 & 6.5 \\
\hline & 8.5 & 6.1 & 8.2 & 6.12 & 7.0 & 6.4 & 7.2 & 6.4 & 8.4 & 6.4 & 7.7 & 6.6 \\
\hline & 8.7 & 6.1 & 8.4 & 6.16 & 7.2 & 6.4 & 7.3 & 6.4 & 8.6 & 6.5 & 7.9 & 6.6 \\
\hline & 8.8 & 6.1 & 8.5 & 6.19 & 7.3 & 6.5 & 7.5 & 6.4 & 8.8 & 6.5 & 8.0 & 6.6 \\
\hline & 9.0 & 6.2 & 8.7 & 6.22 & 7.5 & 6.5 & 7.6 & 6.4 & 9.0 & 6.5 & 8.2 & 6.6 \\
\hline & 9.1 & 6.2 & 8.8 & 6.25 & 7.6 & 6.5 & 7.8 & 6.5 & 9.1 & 6.5 & 8.4 & 6.6 \\
\hline & 9.3 & 6.2 & 9.0 & 6.27 & 7.8 & 6.5 & 7.9 & 6.5 & 9.3 & 6.5 & 8.6 & 6.7 \\
\hline & 9.4 & 6.2 & 9.1 & 6.3 & 7.9 & 6.5 & 8.1 & 6.5 & 9.5 & 6.6 & 8.8 & 6.7 \\
\hline & 9.6 & 6.3 & 9.3 & 6.32 & 8.1 & 6.6 & 8.2 & 6.5 & 9.7 & 6.6 & 9.0 & 6.7 \\
\hline & 9.8 & 6.3 & 9.4 & 6.35 & 8.2 & 6.6 & 8.4 & 6.5 & 9.9 & 6.6 & 9.1 & 6.7 \\
\hline & 9.9 & 6.3 & 9.6 & 6.37 & 8.4 & 6.6 & 8.5 & 6.6 & 10.1 & 6.6 & 9.3 & 6.7 \\
\hline & 10.1 & 6.3 & 9.8 & 6.39 & 8.5 & 6.6 & 8.7 & 6.6 & 10.2 & 6.6 & 9.5 & 6.7 \\
\hline & 10.2 & 6.4 & 9.9 & 6.41 & 8.7 & 6.6 & 8.8 & 6.6 & 10.4 & 6.6 & 9.7 & 6.7 \\
\hline & 10.4 & 6.4 & 10.1 & 6.43 & 8.8 & 6.6 & 9.0 & 6.6 & 10.6 & 6.7 & 9.9 & 6.7 \\
\hline & 10.5 & 6.4 & 10.2 & 6.44 & 9.0 & 6.6 & 9.1 & 6.6 & 10.8 & 6.7 & 10.1 & 6.8 \\
\hline & 10.7 & 6.4 & 10.4 & 6.46 & 9.1 & 6.7 & 9.3 & 6.6 & 11.0 & 6.7 & 10.2 & 6.8 \\
\hline & 10.8 & 6.4 & 10.5 & 6.48 & 9.3 & 6.7 & 9.4 & 6.6 & 11.2 & 6.7 & 10.4 & 6.8 \\
\hline & 11.0 & 6.4 & 10.7 & 6.49 & 9.4 & 6.7 & 9.6 & 6.7 & 11.3 & 6.7 & 10.6 & 6.8 \\
\hline & 11.1 & 6.5 & 10.8 & 6.51 & 9.6 & 6.7 & 9.8 & 6.7 & 11.5 & 6.7 & 10.8 & 6.8 \\
\hline Logistic Equation: $y=(a-d) /\left(1+(x / c)^{b}\right)+$ & $+d$ and Co & cients - & -1--- & 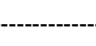 & -1--- & 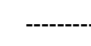 & & & & & & \\
\hline$a$ & & 6.663 & & 6.688 & & 6.838 & & 6.817 & & 6.818 & & 6.859 \\
\hline b & & -3.524 & & -3.525 & & -3.068 & & -3.146 & & -3.277 & & -3.249 \\
\hline$c$ & & 1.291 & & 1.384 & & 0.707 & & 0.753 & & 0.829 & & 0.824 \\
\hline d & & -392.2 & & -237.2 & & -396.4 & & -428.0 & & -557.5 & & -314.2 \\
\hline$r^{2}$ - Coefficient of Determination & & 0.987 & & 0.983 & & 0.993 & & 0.991 & & 0.984 & & 0.992 \\
\hline
\end{tabular}




\begin{tabular}{|c|c|c|c|c|c|c|c|c|c|c|c|c|c|c|}
\hline & \multicolumn{2}{|c|}{$\begin{array}{l}\text { Intakes } 1 \mathrm{~b} \\
\text { and } 2 \mathrm{~b} \\
\text { uplooking }\end{array}$} & \multicolumn{2}{|c|}{$\begin{array}{c}\text { Intakes } 1 \mathrm{~b} \\
\text { and } 2 \mathrm{~b} \\
\text { downlooking }\end{array}$} & \multicolumn{2}{|c|}{$\begin{array}{l}\text { Intake 8b } \\
\text { uplooking }\end{array}$} & \multicolumn{2}{|c|}{$\begin{array}{c}\text { Intake 8b } \\
\text { downlooking }\end{array}$} & \multicolumn{2}{|c|}{ Sluice Chute } & \multicolumn{2}{|c|}{$\begin{array}{l}\text { Intake } 11 b \text {, } \\
12 b, \& 13 b \\
\text { uplooking }\end{array}$} & \multicolumn{2}{|c|}{$\begin{array}{l}\text { Intake 11b, } \\
\text { 12b, \& 13b } \\
\text { downlooking }\end{array}$} \\
\hline \multicolumn{15}{|l|}{ Model Inputs } \\
\hline Fish Velocity (ft / sec) & & 3.0 & & 4.5 & & 4.0 & & 5.0 & & 6.0 & & 3 & & 4.5 \\
\hline Pulse Repetition Rate (pings/sec & & 25.0 & & 25.0 & & 25.0 & & 25.0 & & 40.0 & & 25 & & 25 \\
\hline Minimum \# Echoes for Detection & & 4.0 & & 4.0 & & 4.0 & & 4.0 & & 4.0 & & 4 & & 4 \\
\hline Beam Angle Along Direction of $T$ & Travel & 7.0 & & 7.0 & & 7.0 & & 7.0 & & 7.0 & & 7 & & 7 \\
\hline Beam Angle Perpendicular to $\mathrm{Tr}$ & Travel & 7.0 & & 7.0 & & 7.0 & & 7.0 & & 7.0 & & 7 & & 7 \\
\hline Transducer Aiming Orientation & & up & & down & & up & & down & & up & & up & & down \\
\hline Orientation from Vertical (degree & ees) & 35.0 & & 13.0 & & 41.0 & & 30.0 & & 10.0 & & 33 & & 4 \\
\hline Fish Trajectory (degrees from hc & horiz.) & -3.0 & & 20.0 & & 20.0 & & -10.0 & & -5.0 & & -30 & & 20 \\
\hline Maximum Range Modeled (ft) & & 50.0 & & 70.0 & & 45.0 & & 45.0 & & 25.0 & & 38 & & 60 \\
\hline \multirow[t]{47}{*}{ Model Outputs } & Range, m & Angle & Range, m & Angle & Range, m & Angle & Range, m & Angle & Range, $\mathrm{m}$ & Angle & Range, $\mathrm{m}$ & Angle & Range, m & Angle \\
\hline & 0.9 & 0.0 & 1.5 & 0.0 & 0.7 & 0.0 & 1.8 & 0.0 & 1.5 & 0.0 & 1.2 & 0.0 & 1.5 & 0.0 \\
\hline & 1.1 & 2.1 & 1.7 & 3.3 & 0.8 & 2.4 & 1.9 & 1.5 & 1.5 & 1.4 & 1.3 & 2.4 & 1.6 & 0.5 \\
\hline & 1.2 & 3.9 & 1.9 & 4.3 & 0.9 & 4.1 & 2.1 & 2.9 & 1.6 & 2.5 & 1.4 & 3.6 & 1.8 & 3.1 \\
\hline & 1.4 & 4.7 & 2.1 & 5.0 & 1.1 & 5.0 & 2.2 & 3.6 & 1.7 & 3.2 & 1.5 & 4.3 & 2.0 & 4.1 \\
\hline & 1.5 & 5.2 & 2.3 & 5.4 & 1.2 & 5.5 & 2.3 & 4.2 & 1.8 & 3.7 & 1.6 & 4.7 & 2.2 & 4.7 \\
\hline & 1.7 & 5.6 & 2.6 & 5.7 & 1.4 & 5.8 & 2.5 & 4.6 & 1.8 & 4.1 & 1.7 & 5.1 & 2.4 & 5.1 \\
\hline & 1.8 & 5.8 & 2.8 & 5.9 & 1.5 & 6.0 & 2.6 & 4.9 & 1.9 & 4.4 & 1.9 & 5.4 & 2.6 & 5.4 \\
\hline & 2.0 & 6.0 & 3.0 & 6.0 & 1.6 & 6.2 & 2.7 & 5.1 & 2.0 & 4.6 & 2.0 & 5.6 & 2.7 & 5.6 \\
\hline & 2.1 & 6.2 & 3.2 & 6.2 & 1.8 & 6.3 & 2.9 & 5.3 & 2.1 & 4.8 & 2.1 & 5.7 & 2.9 & 5.8 \\
\hline & 2.3 & 6.3 & 3.4 & 6.3 & 1.9 & 6.4 & 3.0 & 5.5 & 2.1 & 5.0 & 2.2 & 5.9 & 3.1 & 6.0 \\
\hline & 2.4 & 6.4 & 3.6 & 6.4 & 2.1 & 6.5 & 3.1 & 5.6 & 2.2 & 5.2 & 2.3 & 6.0 & 3.3 & 6.1 \\
\hline & 2.6 & 6.4 & 3.8 & 6.4 & 2.2 & 6.6 & 3.3 & 5.8 & 2.3 & 5.3 & 2.4 & 6.1 & 3.5 & 6.2 \\
\hline & 2.7 & 6.5 & 4.1 & 6.5 & 2.3 & 6.6 & 3.4 & 5.9 & 2.4 & 5.4 & 2.6 & 6.2 & 3.7 & 6.3 \\
\hline & 2.9 & 6.6 & 4.3 & 6.6 & 2.5 & 6.7 & 3.6 & 6.0 & 2.4 & 5.5 & 2.7 & 6.3 & 3.8 & 6.3 \\
\hline & 3.0 & 6.6 & 4.5 & 6.6 & 2.6 & 6.7 & 3.7 & 6.0 & 2.5 & 5.6 & 2.8 & 6.3 & 4.0 & 6.4 \\
\hline & 3.2 & 6.6 & 4.7 & 6.6 & 2.7 & 6.7 & 3.8 & 6.1 & 2.6 & 5.7 & 2.9 & 6.4 & 4.2 & 6.5 \\
\hline & 3.4 & 6.7 & 4.9 & 6.7 & 2.9 & 6.7 & 4.0 & 6.2 & 2.7 & 5.8 & 3.0 & 6.4 & 4.4 & 6.5 \\
\hline & 3.5 & 6.7 & 5.1 & 6.7 & 3.0 & 6.8 & 4.1 & 6.2 & 2.7 & 5.9 & 3.1 & 6.5 & 4.6 & 6.5 \\
\hline & 3.7 & 6.7 & 5.3 & 6.7 & 3.1 & 6.8 & 4.2 & 6.3 & 2.8 & 5.9 & 3.2 & 6.5 & 4.8 & 6.6 \\
\hline & 3.8 & 6.8 & 5.5 & 6.7 & 3.3 & 6.8 & 4.4 & 6.3 & 2.9 & 6.0 & 3.4 & 6.5 & 4.9 & 6.6 \\
\hline & 4.0 & 6.8 & 5.8 & 6.8 & 3.4 & 6.8 & 4.5 & 6.4 & 3.0 & 6.1 & 3.5 & 6.6 & 5.1 & 6.6 \\
\hline & 4.1 & 6.8 & 6.0 & 6.8 & 3.6 & 6.8 & 4.7 & 6.4 & 3.0 & 6.1 & 3.6 & 6.6 & 5.3 & 6.7 \\
\hline & 4.3 & 6.8 & 6.2 & 6.8 & 3.7 & 6.9 & 4.8 & 6.4 & 3.1 & 6.2 & 3.7 & 6.6 & 5.5 & 6.7 \\
\hline & 4.4 & 6.8 & 6.4 & 6.8 & 3.8 & 6.9 & 4.9 & 6.5 & 3.2 & 6.2 & 3.8 & 6.7 & 5.7 & 6.7 \\
\hline & 4.6 & 6.8 & 6.6 & 6.8 & 4.0 & 6.9 & 5.1 & 6.5 & 3.3 & 6.2 & 3.9 & 6.7 & 5.9 & 6.7 \\
\hline & 4.7 & 6.8 & 6.8 & 6.8 & 4.1 & 6.9 & 5.2 & 6.5 & 3.4 & 6.3 & 4.1 & 6.7 & 6.0 & 6.7 \\
\hline & 4.9 & 6.9 & 7.0 & 6.8 & 4.2 & 6.9 & 5.3 & 6.6 & 3.4 & 6.3 & 4.2 & 6.7 & 6.2 & 6.8 \\
\hline & 5.0 & 6.9 & 7.3 & 6.9 & 4.4 & 6.9 & 5.5 & 6.6 & 3.5 & 6.3 & 4.3 & 6.7 & 6.4 & 6.8 \\
\hline & 5.2 & 6.9 & 7.5 & 6.9 & 4.5 & 6.9 & 5.6 & 6.6 & 3.6 & 6.4 & 4.4 & 6.7 & 6.6 & 6.8 \\
\hline & 5.3 & 6.9 & 7.7 & 6.9 & 4.7 & 6.9 & 5.8 & 6.6 & 3.7 & 6.4 & 4.5 & 6.8 & 6.8 & 6.8 \\
\hline & 5.5 & 6.9 & 7.9 & 6.9 & 4.8 & 6.9 & 5.9 & 6.6 & 3.7 & 6.4 & 4.6 & 6.8 & 6.9 & 6.8 \\
\hline & 5.6 & 6.9 & 8.1 & 6.9 & 4.9 & 6.9 & 6.0 & 6.7 & 3.8 & 6.4 & 4.8 & 6.8 & 7.1 & 6.8 \\
\hline & 5.8 & 6.9 & 8.3 & 6.9 & 5.1 & 6.9 & 6.2 & 6.7 & 3.9 & 6.5 & 4.9 & 6.8 & 7.3 & 6.8 \\
\hline & 5.9 & 6.9 & 8.5 & 6.9 & 5.2 & 6.9 & 6.3 & 6.7 & 4.0 & 6.5 & 5.0 & 6.8 & 7.5 & 6.8 \\
\hline & 6.1 & 6.9 & 8.7 & 6.9 & 5.3 & 6.9 & 6.4 & 6.7 & 4.1 & 6.5 & 5.1 & 6.8 & 7.7 & 6.8 \\
\hline & 6.2 & 6.9 & 9.0 & 6.9 & 5.5 & 6.9 & 6.6 & 6.7 & 4.1 & 6.5 & 5.2 & 6.8 & 7.9 & 6.9 \\
\hline & 6.4 & 6.9 & 9.2 & 6.9 & 5.6 & 6.9 & 6.7 & 6.7 & 4.2 & 6.5 & 5.3 & 6.8 & 8.0 & 6.9 \\
\hline & 6.6 & 6.9 & 9.4 & 6.9 & 5.8 & 6.9 & 6.9 & 6.7 & 4.3 & 6.6 & 5.5 & 6.8 & 8.2 & 6.9 \\
\hline & 6.7 & 6.9 & 9.6 & 6.9 & 5.9 & 6.9 & 7.0 & 6.7 & 4.4 & 6.6 & 5.5 & 6.8 & 8.4 & 6.9 \\
\hline & 6.9 & 6.9 & 9.8 & 6.9 & 6.0 & 6.9 & 7.1 & 6.8 & 4.4 & 6.6 & 5.7 & 6.8 & 8.6 & 6.9 \\
\hline & 7.0 & 6.9 & 10.0 & 6.9 & 6.2 & 6.9 & 7.3 & 6.8 & 4.5 & 6.6 & 5.8 & 6.9 & 8.8 & 6.9 \\
\hline & 7.2 & 6.9 & 10.2 & 6.9 & 6.3 & 7.0 & 7.4 & 6.8 & 4.6 & 6.6 & 5.9 & 6.9 & 9.0 & 6.9 \\
\hline & 7.3 & 6.9 & 10.5 & 6.9 & 6.4 & 7.0 & 7.6 & 6.8 & 4.7 & 6.6 & 6.0 & 6.9 & 9.1 & 6.9 \\
\hline & 7.5 & 6.9 & 10.7 & 6.9 & 6.6 & 7.0 & 7.7 & 6.8 & 4.7 & 6.6 & 6.1 & 6.9 & 9.3 & 6.9 \\
\hline & 7.6 & 6.9 & 10.9 & 6.9 & 6.7 & 7.0 & 7.8 & 6.8 & 4.8 & 6.7 & 6.2 & 6.9 & 9.5 & 6.9 \\
\hline & 7.8 & 6.9 & 11.1 & 6.9 & 6.9 & 7.0 & 8.0 & 6.8 & 4.9 & 6.7 & 6.4 & 6.9 & 9.7 & 6.9 \\
\hline \multicolumn{15}{|c|}{ Logistic Equation: $y=(a-d) /\left(1+(x / c)^{b}\right)+d$ and Coefficients --.- } \\
\hline a & & 7.0 & & 6.9 & & 7.0 & & 6.9 & & 6.8 & & 6.896 & & 6.946 \\
\hline$b$ & & -2.6 & & -3.2 & & -2.7 & & -3.0 & & -3.3 & & -3.279 & & -2.822 \\
\hline c & & 0.2 & & 0.3 & & 0.1 & & 0.4 & & 0.5 & & 0.288 & & 0.375 \\
\hline$d$ & & -372.2 & & -692.5 & & -632.2 & & -666.8 & & -274.2 & & -670.2 & & -350.8 \\
\hline$r^{2}-$ Coefficient of Determination & & 1.0 & & 1.0 & & 1.0 & & 1.0 & & 1.0 & & 0.981 & & 0.992 \\
\hline
\end{tabular}

Appendix A Detectability Modeling Results 


\section{Appendix B Statistical Synopsis for Calculating Metrics and Testing}

This statistical synopsis was prepared before the study by Dr. John Skalski for the Statistical Oversight Committee.

\section{Introduction}

During spring and summer 1998, fixed-location hydroacoustic investigations will be conducted to evaluate smolt bypass measures at Bonneville Powerhouses 1 and 2. This synopsis summarizes key statistical analyses that will be performed during the 1998 investigations. This report covers the analyses for six work elements of the investigations as follows:

Estimating fish guidance efficiency (FGE) of an extended-length submersible bar screen (ESBS) at turbine Unit 8b, Powerhouse 1.

a. Estimating FGE at turbine Units 11-13, Powerhouse 2.

b. Estimating smolt passage at the sluice chute, Powerhouse 2.

c. Estimating smolt passage, effectiveness, and efficiency of the prototype surface collector (PSC) at Powerhouse 1.

d. Testing the effects of PSC entrance configurations on smolt passage performance at the PSC.

$e$. Testing the effects of the sluice chute on smolt passage at turbine Units 11-13 at Powerhouse 2.

These plans will be reviewed by the staff of the Army Corps of Engineers (ACOE), Pacific Northwest National Laboratory, and independent statistical reviewers employed by ACOE.

For many of the parameters of interest, their estimators are quotients of two or more independently measured values. Approximate variance estimators were 
derived using the Delta method ${ }^{1}$ The variances are based on finite sampling theory that takes into account the subsampling within the hour. Without the finite population correction (fpc), the variances have a positive bias. With the variances expressed as in the report with the fpc included, variance esitmators will be progressively more negatively biased as the fpc increases. A detailed discussion of the use of finite sampling theory in conjunction with fixed location hydroacoustic monitoring is offered by in Skalski et al. (1993).

\section{Estimating FGE}

The FGE of an ESBS will be evaluated at turbine Intake 8B at Powerhouse 1. Two transducers will be mounted on trash racks below the top of the bar screen and aimed upward to count guided smolt. Two downlooking transducers will be mounted high in the intake and aimed downward toward the intake floor to estimate unguided smolt (Figure B1). The four transducers will be sampled sequentially for 1 min each for a total of 15, 1-min periods per transducer per hour. The order of the sequencing will be changed daily.

The estimate of FGE will be calculated by the quotient:

$$
F \hat{G} E=\frac{\hat{G}}{\hat{G}+\hat{U}}
$$

where

$$
\begin{aligned}
& \hat{G}=\text { estimated number of smolt guided } \\
& \hat{U}=\text { estimated number of smolt unguided }
\end{aligned}
$$

with approximate variance

$$
\operatorname{Var}(F \hat{G} E) \doteq F \hat{G} E^{2}(1-F \hat{G} E)^{2}\left[\hat{C} V(\hat{G})^{2}+\hat{C} V(\hat{U})^{2}\right]
$$

and where $\hat{C} V$ is expressed as

$$
\hat{C} V(\hat{\theta})=\frac{\sqrt{\operatorname{Var}(\hat{\theta})}}{\hat{\theta}}
$$

for any estimate $\hat{\theta}$.

The estimator of FGE at a turbine unit and its associated variance estimator [i.e., $\operatorname{Va} r(F \hat{G} E)$ ] can be calculated for a period as short as 1 day (i.e., $\mathrm{D}=1$ ) or as long as the entire hydroacoustic study without a change in formula.

\footnotetext{
${ }^{1}$ Seber, G. A. F. (1982). The estimation of animal abundance and related parameters. MacMillan, New York.

2 Skalski, J. R., Hoffmann, A., Ransom, B. H., and Steig, T. W. (1993). "Fixed-location hydroacoustic monitoring design for estimating fish passage using stratified random and systematic sampling," Can. J. Fish. and Aquat. Sci. 50, 1208-1221.
} 
a. Side view

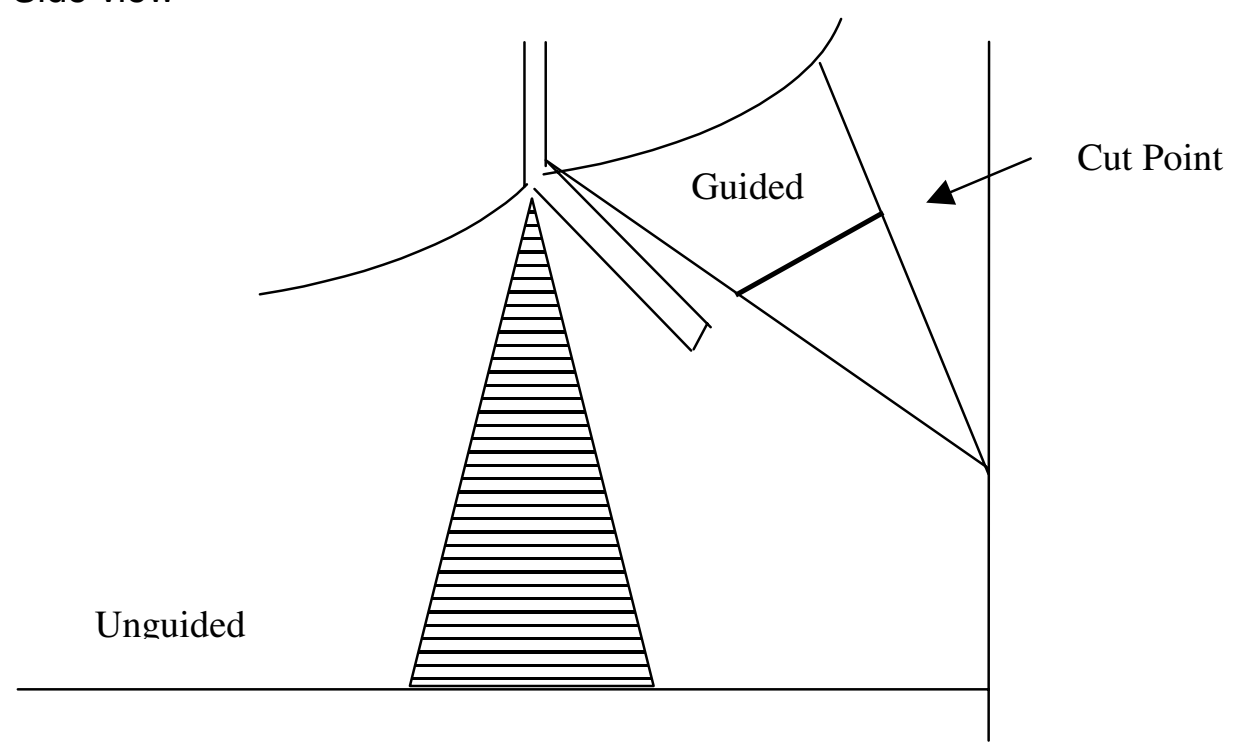

b. Frontal view of trash rack-mounted transducers

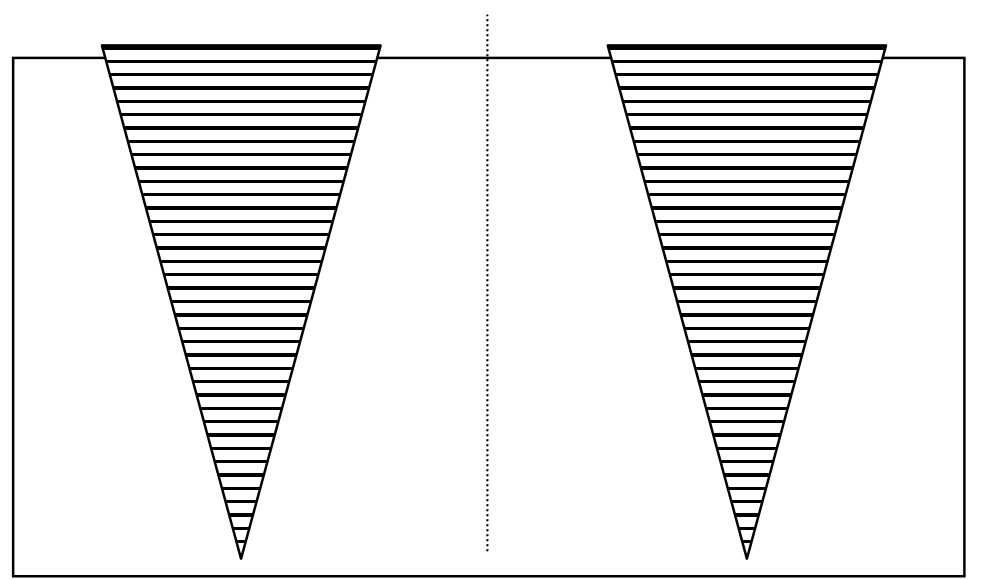

Figure B1. Schematic of transducer deployment within turbine intake, Unit 8B

\section{Estimating guided numbers}

The estimate of guided fish numbers $(\hat{G})$ will be calculated according to the equation

$$
\hat{\mathrm{G}}=\sum_{i=1}^{\mathrm{D}} \sum_{j=1}^{24} \sum_{k=1}^{2} \frac{H}{h} \sum_{l=1}^{h} v_{\mathrm{ijkl}}
$$


where

$$
\begin{aligned}
v_{i j k l}= & \text { weighted number of guided fish in the } l \text { th sampling interval } \\
& (l=1, \ldots, h) \text { at the } k \text { th transducer location }(k=1,2) \text { in the } j \text { th } \\
& \text { hour }(j=1, \ldots, 24) \text { of the } i \text { th day }(i=1, \ldots, D) \\
h= & \text { number of samples within-hour collected at the } k \text { th transducer } \\
& \text { location }(k=1,2) \\
H= & \text { total number of possible samples that could be drawn within the } \\
& \text { hour at a location. }
\end{aligned}
$$

Here, $v_{i j k l}$ is the expanded number of detections of smolt in a 1-min interval of time and to the one-half cross-sectional area of the intake of the $k$ th location. It should also be noted that the zone above which smolt are classified as guided (Figure B1) is somewhat arbitrary and may result in several calculations at different distances from the transducer.

The variance of $\hat{G}$ can be approximated by assuming that one can use the variance formula for simple random sampling to estimate the within-hour variance based on the samples collected per hour. The approximate variance for $\hat{G}$ can be written as

$$
\operatorname{Var}(\hat{G}) \doteq \sum_{i=1}^{D} \sum_{j=1}^{24} \sum_{k=1}^{2}\left[\frac{H^{2}\left(1-\frac{h}{H}\right) \hat{S}_{v_{j j k}}^{2}}{h}\right]
$$

and where

$$
\begin{aligned}
\hat{S}_{v_{i j k l}}^{2} & =\frac{\sum_{l=1}^{h}\left(v_{i j k l}-\bar{v}_{i j k}\right)^{2}}{(h-1)} \\
\bar{v}_{i j k} & =\frac{\sum_{l=1}^{h} v_{i j k l}}{h}
\end{aligned}
$$

Nominally, for a given transducer, $h$ is planned to be 15, 1-min samples with $H=60$.

\section{Estimating unguided numbers}

The estimate of unguided fish numbers $(\hat{U})$ will be calculated analogously to Equation (B1) where

$$
\hat{U}=\sum_{i=1}^{D} \sum_{j=1}^{24} \sum_{k=1}^{2} \frac{M}{m} \sum_{l=1}^{m} u_{i j k l}
$$


where

$$
\begin{aligned}
& \begin{array}{l}
u_{i j k l}=\text { weighted number of unguided fish in the } l \text { th sampling interval } \\
(l=1, \ldots, m) \text { at the } k \text { th transducer location }(k=1,2) \text { in the } j \text { th } \\
\text { hour }(j=1, \ldots, 24) \text { of the } i \text { th day }(i=1, \ldots, D)
\end{array} \\
& m=\text { number of samples within-hour collected at the } k \text { th transducer } \\
& \text { location }(k=1,2) \\
& M=\text { total number of possible samples that could be drawn within the } \\
& \text { hour }
\end{aligned}
$$

Once again, $u_{i j k l}$ is the expanded number of smolt detections in a 1-min interval and to the one-half cross-sectional area of the intake of the $k$ th location.

The variance of $\hat{U}$ will be estimated in a manner analogous to Equation (B2) where

$$
\operatorname{Var}(\hat{U}) \doteq \sum_{i=1}^{D} \sum_{j=1}^{24} \sum_{k=1}^{2}\left[\frac{M^{2}\left(1-\frac{m}{M}\right) \hat{S}_{u_{i j k l}^{2}}^{2}}{m}\right]
$$

and where

$$
\begin{aligned}
\hat{S}_{u_{i j k}}^{2} & =\frac{\sum_{l=1}^{m}\left(u_{i j k l}-\bar{u}_{i j k}\right)^{2}}{(m-1)} \\
\bar{u}_{i j k} & =\frac{\sum_{l=1}^{m} u_{i j k l}}{m}
\end{aligned}
$$

Nominally, $m$ for a given transducer is planned to be 15, 1-min samples with $M=60$.

At turbine Units 11B, 12B, and 13B, with submerged traveling screens, FGE will be estimated using a single uplooking and single downlooking pair of transducers at each unit. At each location, 10, 1-min samples will be collected per hour. The estimate of passage and associated variances for guided numbers will be calculated analogous to Equations (B1-B2) except $h=10$ samples will be collected at a single location per hour as follows:

$$
\hat{\mathrm{G}}=\sum_{i=1}^{\mathrm{D}} \sum_{j=1}^{24} \frac{H}{h} \sum_{l=1}^{h} v_{\mathrm{ijl}}
$$

and 


$$
\operatorname{Var}(\hat{G}) \doteq \sum_{i=1}^{D} \sum_{j=1}^{24}\left[\frac{H^{2}\left(1-\frac{h}{H}\right) \hat{S}_{v_{i j l}}^{2}}{h}\right]
$$

and where

$$
\begin{aligned}
\hat{S}_{v_{i j l}}^{2} & =\frac{\sum_{k=1}^{2} \sum_{l=1}^{h}\left(v_{i j l}-\bar{v}_{i j}\right)^{2}}{(h-1)} \\
\bar{v}_{i j} & =\frac{\sum_{l=1}^{h} v_{i j l}}{h} .
\end{aligned}
$$

The estimates of unguided smolt passage and associated variances will be calculated analogously to Equations (B3-B4) except $m=10$ samples will be collected at a single location per hour as follows:

$$
\hat{U}=\sum_{i=1}^{D} \sum_{j=1}^{24} \frac{M}{m} \sum_{l=1}^{m} u_{i j l}
$$

and

$$
\operatorname{Var}(\hat{U}) \doteq \sum_{i=1}^{D} \sum_{j=1}^{24}\left[\frac{M^{2}\left(1-\frac{m}{M}\right) \hat{S}_{u_{i j l}}^{2}}{m}\right]
$$

and where

$$
\begin{aligned}
\hat{S}_{u_{i j l}}^{2} & =\frac{\sum_{l=1}^{m}\left(u_{i j l}-\bar{u}_{i j}\right)^{2}}{(m-1)} \\
\bar{u}_{i j} & =\frac{\sum_{l=1}^{m} u_{i j l}}{m}
\end{aligned}
$$

\section{Combining FGE estimates}

There may be the desire to obtain an FGE estimate across two or more turbine units. In combining separate FGE estimates, the estimates should be weighted by the smolt passage through the respective units, such that 


$$
F \hat{G} E_{\bullet}=\frac{\sum_{h=1}^{H} \hat{N}_{h} F \hat{G} E_{h}}{\sum_{h=1}^{H} \hat{N}_{h}}
$$

where

$$
\begin{aligned}
\hat{N}_{h} & =\text { estimated smolt passage through the } h \text { th unit }(h=1, \ldots, H) \\
F \hat{G} E_{h} & =\text { estimated FGE at the } h \text { th unit }(h=1, \ldots, H)
\end{aligned}
$$

The estimate of smolt passage in turn is $\hat{N}_{h}=\hat{G}_{h}+\hat{U}_{h}$ leading to the estimator

$$
\begin{aligned}
F \hat{G} E_{\bullet}=\frac{\sum_{h=1}^{H}\left(\hat{G}_{h}+\hat{U}_{h}\right)\left[\frac{\hat{G}_{h}}{\left(\hat{G}_{h}+\hat{U}_{h}\right)}\right]}{\sum_{h=1}^{H}\left(\hat{G}_{h}+\hat{U}_{h}\right)} \\
=\frac{\sum_{h=1}^{H} \hat{G}_{h}}{\sum_{h=1}^{H}\left(\hat{G}_{h}+\hat{U}_{h}\right)} \\
=\frac{\hat{G}_{\bullet}}{\hat{G}_{\bullet}+\hat{U}_{\bullet}}
\end{aligned}
$$

where

$$
\begin{aligned}
& \hat{G}_{\bullet}=\sum_{h=1}^{H} \hat{G}_{h} \\
& \hat{U}_{\bullet}=\sum_{h=1}^{H} U_{h}
\end{aligned}
$$

The estimated variance of $F \hat{G} E_{\text {。 }}$ is then

$$
\hat{V}\left(F \hat{G} E_{\bullet}\right)=F \hat{G} E_{\bullet}^{2}\left(1-F \hat{G} E_{\bullet}\right)^{2}\left[\hat{C} V\left(\hat{G}_{\bullet}\right)^{2}+\hat{C} V\left(\hat{U}_{\bullet}\right)^{2}\right] .
$$

\section{Estimating Smolt Passage at Sluice Chute}

The sluice chute at Powerhouse 2 will be hydroacoustically sampled using three upward-looking transducers centrally located in the southern, middle, and northern thirds of the cross-sectional width of the chute (Figure B2). Each transducer will be sampled for 20, 1-min intervals per hour. The three transducers will be systematically sampled in consecutive 1-min intervals, 
20 times per hour. The estimate of total sluice-chute passage $(\hat{L})$ will be calculated as follows:

$$
\hat{L}=\sum_{i=1}^{D} \sum_{j=1}^{24} \sum_{k=1}^{3} \frac{C}{c} \sum_{l=1}^{c} w_{i j k l}
$$

where

$w_{i j k l}=$ weighted number of fish in the $l$ th sampling interval $(l=1, \ldots, c)$ at the $k$ th transducer location $(k=1, \ldots, 3)$ in the $j$ th hour $(j=1, \ldots, 24)$ of the $i$ th day $(i=1, \ldots, D)$

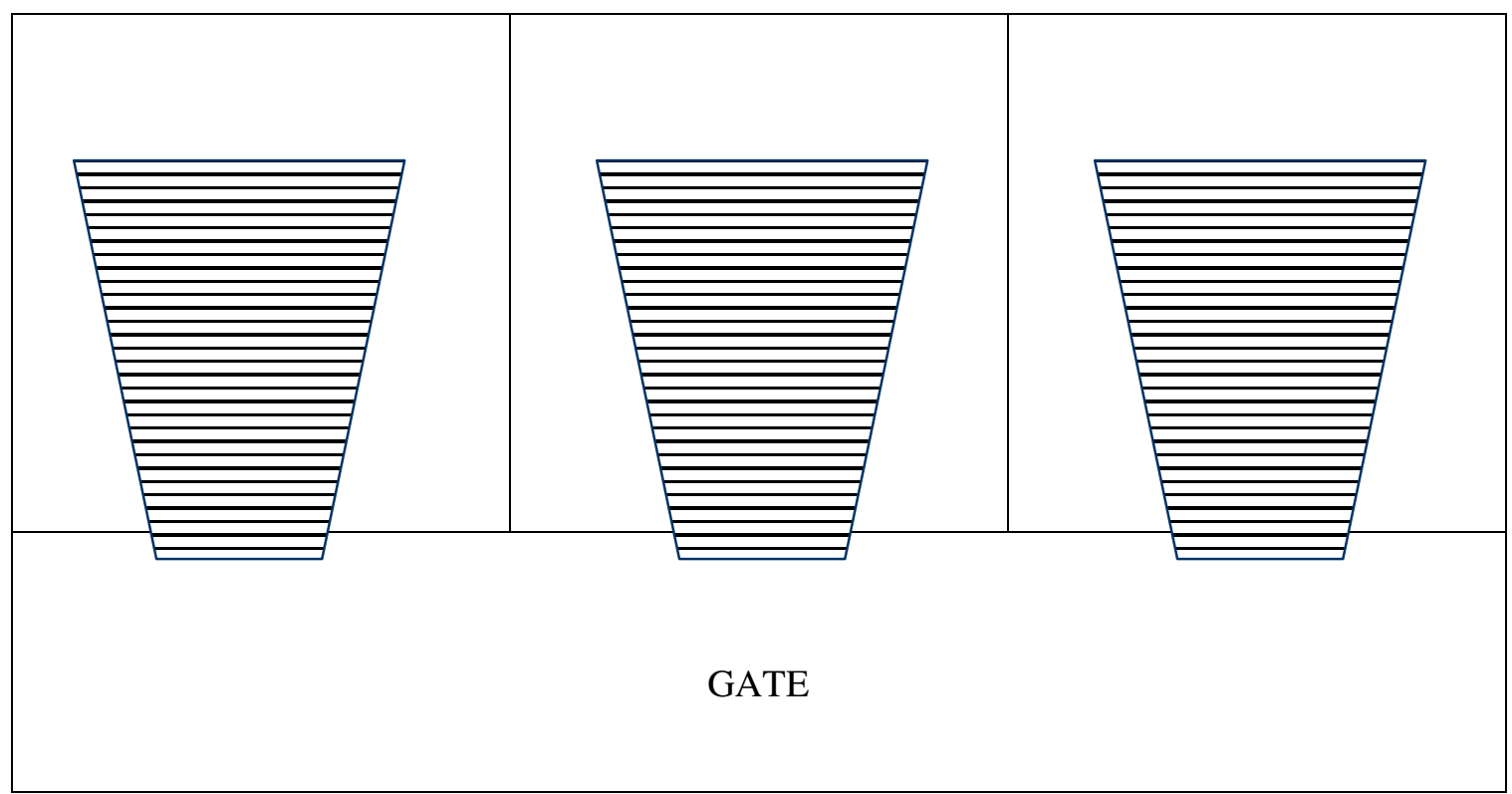

Figure B2. Schematic of transducer locations at the sluice chute, Powerhouse 2

Here, $w_{i j k l}$ is the expanded number of detections of smolt in a 1-min time interval and the one-third cross-sectional area of the sluice chute it is sampling. Nominally, $c=20$ sampling intervals per location per hour from among $C=60$.

Treating each third of the sluice chute as a separate spatial stratum, the variance of $\hat{L}$ can be computed as follows:

$$
\operatorname{Var}(\hat{L}) \doteq \sum_{i=1}^{D} \sum_{j=1}^{24} \sum_{k=1}^{3}\left[\frac{C^{2}\left(1-\frac{c}{C}\right) \hat{S}_{w_{i j k l}^{2}}}{c}\right]
$$

and where 


$$
\begin{aligned}
\hat{S}_{w_{i j k}} & =\frac{\sum_{l=1}^{c}\left(w_{i j k l}-\bar{w}_{i j k}\right)^{2}}{(c-1)} \\
\bar{w}_{i j k} & =\frac{\sum_{l=1}^{c} w_{i j k l}}{c}
\end{aligned}
$$

The effect of the sluice chute will be evaluated using various performance measures including the following:

a. Sluice-chute efficiency (SCE) defined as

$$
S \hat{C} E=\frac{\hat{L}}{\hat{L}+3\left(\hat{G}_{11-13}+\hat{U}_{11-13}\right)}
$$

where

$$
\begin{aligned}
& \hat{G}_{11-13}=\text { estimated total guided in B slots of turbine Units 11-13 } \\
& \hat{U}_{11-13}=\text { estimated total unguided in B slots of turbine Units 11-13 } \\
& \text { with estimated variance } \\
& \operatorname{Var} r(S \hat{C} E) \doteq\left(\frac{1}{\hat{L}+3 \hat{G}+3 \hat{U}}\right)^{2}\left[\operatorname{Var} r(\hat{L})(1-S \hat{C} E)^{2}+\operatorname{Vâr}(\hat{G}) \cdot\left(9 S \hat{C} E^{2}\right)+\operatorname{Vâ} r(\hat{U}) \cdot(9 S \hat{C} E)^{2}\right]
\end{aligned}
$$

Here, it is assumed that total turbine passage is three times the passage in the B slot. The estimate of SCE could also be calculated based on relative flow volume through the B slots.

In addition to calculating sluice-chute efficiency relative to turbine Units 1113, it will also be calculated on the basis of turbine Unit 11 alone and Units 1112. Prior to conducting the study, the spatial extent of the sluice chute in attracting and passing smolt is unknown. The multiple expressions for SCE will be used to look at the relative contribution of the sluice chute to localized smolt passage.

b. FGE at Units 11-13 defined as

$$
F \hat{G} E_{11-13}=\frac{\hat{G}_{11-13}}{\hat{G}_{11-13}+\hat{U}_{1113}}
$$

with approximate variance

$$
\operatorname{Var}\left(F \hat{G} E_{11-13}\right) \doteq\left(F \hat{G} E_{11-13}\right)^{2}\left(1-F \hat{G} E_{11-13}\right)^{2}\left[\hat{C} V\left(\hat{G}_{11-13}\right)^{2}+\hat{C} V\left(\hat{U}_{11-13}\right)^{2}\right]
$$

c. Spatial difference in FGE defined as 


$$
\begin{aligned}
\hat{\Delta}_{F G E} & =F \hat{G} E_{12}-F \hat{G} E_{11} \\
& =\left(\frac{\hat{G}_{12}}{\hat{G}_{12}+\hat{U}_{12}}\right)-\left(\frac{\hat{G}_{11}}{\hat{G}_{11}+\hat{U}_{11}}\right)
\end{aligned}
$$

with variance

$$
\operatorname{Var}\left(\hat{\Delta}_{F G E}\right)=\operatorname{Var} r\left(F \hat{G} E_{12}\right)+\operatorname{Var}\left(F \hat{G} E_{11}\right)
$$

d. Sluice-chute passage $\hat{L}$ with estimator (9) and approximate variance estimator (10).

e. Sluice-chute combined efficiency (SCCE) defined as

$$
S \hat{C} C E=\frac{\hat{L}+3 \hat{G}_{11-13}}{\hat{L}+3\left(\hat{G}_{11-13}+\hat{U}_{11-13}\right)}
$$

with approximate variance

$$
\begin{aligned}
\operatorname{Var}(S \hat{C} C E) & =\operatorname{Var}\left(\hat{L}\left(\frac{\left(3 \hat{U}_{11-13}\right)^{2}}{\left(\hat{L}+3 \hat{G}_{11-13}+3 \hat{U}_{11-13}\right)^{4}}\right)+\operatorname{Varr}\left(\hat{G}_{11-13}\left(\frac{\left(9 \hat{U}_{11-13}\right)^{2}}{\left(\hat{L}+3 \hat{G}_{11-13}+3 \hat{U}_{11-13}\right)^{4}}\right)\right.\right. \\
& +\operatorname{Var} r\left(\hat{U}_{11-13}\left(\frac{9\left(\hat{L}_{11-13}+3 \hat{G}_{11-13}\right)^{2}}{\left(\hat{L}+3 \hat{G}_{11-13}+3 \hat{U}_{11-13}\right)^{4}}\right)\right.
\end{aligned}
$$

The estimate of SCCE could be based on relative flow volume through the B slots instead of assuming equal passage through each slot. The value of SCCE could also be expressed in terms of turbine Unit 11 and turbine Units 11-12. Alternative expressions for SCCE will investigate the relative contribution of the sluice chute to localized smolt passage in its vicinity.

f. $\quad$ Sluice-chute effectiveness $\left(\hat{S} C_{F}\right)$ defined as

$$
\hat{S} C_{F}=\frac{S \hat{C} E}{\left(\frac{f}{F}\right)}=\frac{F}{f} \cdot S \hat{C} E
$$

with associated variance

$$
\operatorname{Var} r\left(\hat{S} C_{F}\right)=\left(\frac{F}{f}\right)^{2} \cdot \operatorname{Var}(S \hat{C} E)
$$


where

$f=$ total flow discharge through sluice chute

$F=$ total flow discharge through sluice chute and turbine Units 11-13

g. Sluice-chute relative passage $(\hat{S} C R P)$ defined as

$$
\hat{S} C R P=\frac{\hat{L}}{\hat{L}+F P C}
$$

where

$$
\begin{gathered}
F P C=\text { unadjusted fish passage center count of smolts entering } \\
\text { the bypass system at Powerhouse } 2 .
\end{gathered}
$$

The FPC unadjusted count is adjusted by the sampling fraction through time but is not adjusted for spill. In so doing, it is an estimate of the total smolt entering the bypass system at Powerhouse 2. The value of $\hat{S} C R P$ estimates the relative contribution of the sluice chute to smolt passage at Powerhouse 2.

\section{Estimating PSC Efficiency and Effectiveness}

In 1998, a PSC will be installed in front of turbine Units 3-6. During the PSC testing, turbine Units 4 and 6 will be off-line. Above each of turbine Units 3 and 5, the PSC will have a vertical slot for smolt passage. Each PSC slot will be equipped with three downlooking and three uplooking transducers (Figure B3). Passage into a slot will be estimated from the sums of weighted fish counts in the distall half of the range of each pair of transducers (Figure B3). These six areas within an entrance (i.e., 2 vertical by 3 horizontal partitions) will serve a spatial strata in the estimation of total slot passage. Each transducer location in the PSC will be sampled for 10, 1-min intervals per hour.

Below the PSC at turbine Units 3 and 5, a single downlooking transducer will be estimating fish passage in each of the six turbine intakes. At each turbine intake, smolt passage will be sampled using 10, 1-min intervals per hour.

The monitoring at the PSC will be used to estimate various performance measures for test evaluation. These performance measures include the following:

a. PSC efficiency defined as

$$
\begin{aligned}
P \hat{S C E} & =\frac{\hat{P}_{3}+\hat{P}_{5}}{\hat{P}_{3}+\hat{P}_{5}+\hat{T}_{3}+\hat{T}_{5}} \\
& =\frac{\hat{P}}{\hat{P}+\hat{T}}
\end{aligned}
$$




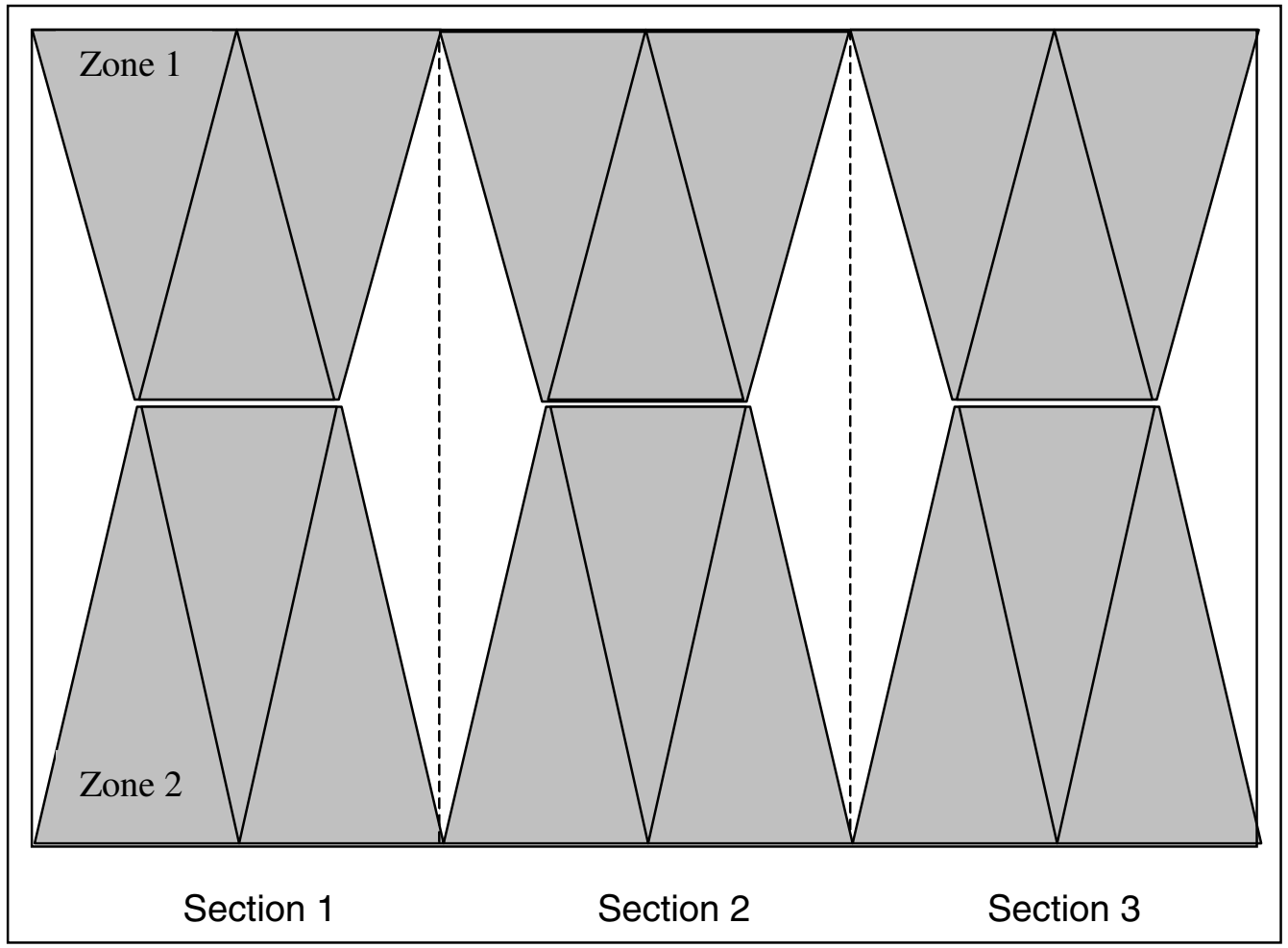

Figure B3. Schematic of a pair of uplooking and downlooking transducers in a PSC slot (Shaded area denotes the zones of insonification where estimation will occur)

where $P_{i}$ and $T_{i}$ are estimates of total smolt passage through the $i$ th PSC slot or turbine unit, respectively. The variance of $P \hat{S} C E$ can be approximately by

$$
\operatorname{Var}(P \hat{S} C E) \doteq(P \hat{S} C E)^{2}(1-P \hat{S} C E)^{2}\left[\hat{C} V(\hat{P})^{2}+\hat{C} V(\hat{T})^{2}\right]
$$

b. PSC passage defined as

$$
\hat{P}=\hat{P}_{3}+\hat{P}_{5}
$$

c. PSC effectiveness defined as

$$
P \hat{S} C_{F}=\frac{\left(\frac{\hat{P}}{\hat{P}+\hat{T}}\right)}{\left(\frac{f}{F}\right)}=\frac{F}{f} \cdot P \hat{S} C E
$$


with variance

$$
\operatorname{Varr}\left(P \hat{S} C_{F}\right) \doteq\left(\frac{F}{f}\right)^{2} \cdot \operatorname{Vâr}(P \hat{S} C E)
$$

where

$f=$ total flow discharge through the PSC

$F=$ total flow discharge through the PSC and turbine Units 3 and 5

d. PSC smolt density defined as

$$
\hat{D}=\frac{\hat{P}}{f}
$$

with variance

$$
\operatorname{Vâ}(\hat{D})=\frac{\operatorname{Vâr}(\hat{P})}{f^{2}}
$$

\section{Estimating PSC passage}

Passage at a given PSC entrance will be estimated according to the formula

$$
\hat{P}_{i}=\sum_{i=1}^{D} \sum_{j=1}^{24} \sum_{k=1}^{3} \sum_{l=1}^{2} \frac{B}{b} \sum_{m=1}^{b} x_{i j k l m}
$$

where

$x_{i j k l m}=$ weighted number of fish in the $m$ th sampling interval

$(m=1, \ldots, b)$ of the $l$ th zone $(l=1,2$, see Fig. B3) of the $k$ th vertical section $(k=1, \ldots, 3$, see Fig. B3) in the $j$ th hour $(j=1, \ldots, 24)$ for the $i$ th day $(i=1, \ldots, D)$

and where

$$
\begin{aligned}
& b=\text { number of time intervals sampled per hour } \\
& B=\text { total number of possible time intervals in an hour }
\end{aligned}
$$

Here, the $x_{i j k l m}$ is the expanded fish count in a 1-min interval to the cross section of the upper or lower half of a vertical section. In this estimation scheme, each of the six (i.e., 2 vertical by 3 horizontal partitions) subdivisions of the entrance are treated as separate strata. Nominally, $B=60$ and $b=10$ intervals per hour. The variance of $\hat{P}_{i}$ can be approximated by 


$$
\operatorname{Var}\left(\hat{P}_{i}\right) \doteq \sum_{i=1}^{D} \sum_{j=1}^{24} \sum_{k=1}^{3} \sum_{l=1}^{2}\left[\frac{B^{2}\left(1-\frac{b}{B}\right) \hat{S}_{x_{i k l k m}}^{2}}{b}\right]
$$

where

$$
\hat{S}_{x_{i j k l}}=\frac{\sum_{i=1}^{b}\left(x_{i j k l m}-\bar{x}_{i j k l}\right)^{2}}{(b-1)}
$$

and

$$
\bar{x}_{i j k l}=\frac{\sum_{m=1}^{b} x_{i j k l m}}{m}
$$

For the total PSC passage $\hat{P}=\hat{P}_{3}+\hat{P}_{5}$, the variance of the estimate would be

$$
\operatorname{Var}(\hat{P})=\operatorname{Varr}\left(\hat{P}_{3}\right)+\operatorname{Var}\left(\hat{P}_{5}\right)
$$

\section{Estimating turbine passage}

For one of the turbine units (e.g., 11, 12, 13), the estimate of smolt passage would be calculated as

$$
\hat{T}_{i}=\sum_{i=1}^{D} \sum_{j=1}^{24} \frac{A}{a} \sum_{k=1}^{a} y_{i j k}
$$

where

$$
\begin{aligned}
& y_{i j k}=\text { weighted fish count in the } k \text { th sampling interval }(k=1, \ldots, a) \text { for } \\
& \text { the } j \text { th hour }(j=1, \ldots, 24) \text { in the } i \text { th day }(i=1, \ldots, 24) \\
& a=\text { number of time intervals sampled per hour } \\
& A=\text { total number of possible time intervals in an hour }
\end{aligned}
$$

Nominally, $A=60$ with $a=10$, 1-min samples per hour

The variance of $\hat{T}_{i}$ can be estimated by

$$
\operatorname{Var}\left(\hat{T}_{i}\right) \doteq \sum_{i=1}^{D} \sum_{j=1}^{24}\left[\frac{A^{2}\left(1-\frac{a}{A}\right) \hat{S}_{y_{i j k}}^{2}}{a}\right]
$$


where

$$
\begin{aligned}
\hat{S}_{y_{i j k}}^{2} & =\frac{\sum_{k=1}^{a}\left(y_{i j k}-\bar{y}_{i j}\right)^{2}}{(a-1)} \\
\bar{y}_{i j} & =\frac{\sum_{k=1}^{a} y_{i j k}}{a}
\end{aligned}
$$

\section{Testing PSC Effects}

A randomized block experimental design will be used to test two different slot widths, 5 and $20 \mathrm{ft}$. The experimental unit in the test will be a 2-day consecutive period minus $1 \mathrm{hr}$ for configuration change. In spring, 10 blocks are scheduled as are 10 blocks during the summer test. This test design can be analyzed as a two-way analysis of variance (ANOVA) or as a two-sample paired t-test of equal means. The test of slot configurations will be analyzed with the following metrics:

a. PSC efficiency $(P \hat{S} C E)$

b. PSC passage $(\hat{P})$

c. PSC effectiveness $\left(P \hat{S} C_{F}\right)$

$d$. PSC smolt density $(\hat{D})$

The analysis will test the null hypothesis

$$
H_{o}: \mu_{1}=\mu_{2}
$$

against

$$
H_{a}: \mu_{1} \neq \mu_{2}
$$

at a significance level of $\alpha=0.10$ two-tailed. Analyses will be conducted for daytime, nighttime, and full-day periods of time.

Within a block, if data are missing for few to several hours during a treatment, the corresponding time will also be trimmed from the other treatment as well. This process of trimming will be used to eliminate any diel effect that might otherwise confound treatment comparisons. With unequal sample durations, weighted ANOVA might be performed weighting inversely proportional to the estimated sampling variances. Determination of whether a weighted ANOVA is necessary will be made after inspection of the study results. 


\section{Testing Sluice-Chute Effects}

A randomized block experimental design will be used to test two sluice-chute operating levels, open and closed. The experimental units in the tests will be 1day periods of testing. In both spring and summer, 20 test blocks are scheduled. The test design can be analyzed as a two-way ANOVA or as a two-sample paired t-test of

$$
H_{o}: \mu_{1}=\mu_{2}
$$

against

$$
H_{a}: \mu_{1} \neq \mu_{2}
$$

at a significance level of $\alpha=0.10$ two-tailed. The tasks of treatment effects will be based on the following metrics:

a. $F \hat{G} E_{11-13}$.

b. $F \hat{G} E_{12}-F \hat{G} E_{11}$.

c. Sluice-chute combined efficiency $(S \hat{C} C E)$.

Analyses will be performed for daytime, nighttime, and full-day periods of time. Other measures such as sluice-chute passage $(\hat{L})$, sluice-chute efficiency $(S \hat{C} E)$, and sluice chute effectiveness $\left(S \hat{C}_{F}\right)$ will be used to characterize sluicechute performance but are not meaningful in tests of hypotheses.

Within a block, if data are missing for few to several hours during a treatment, the corresponding time will also be trimmed from the other treatment as well. This process of trimming will be used to eliminate any diel effect that might otherwise confound treatment comparisons. With unequal sample durations, weighted ANOVA might be performed weighting inversely proportional to the estimated sampling variances. Determination of whether a weighted ANOVA is necessary will be made after inspection of the study results. 


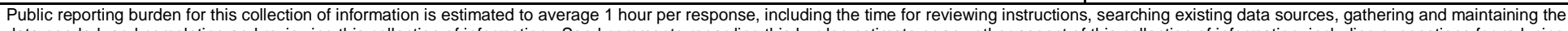

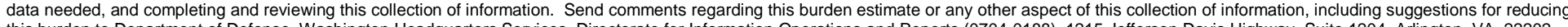

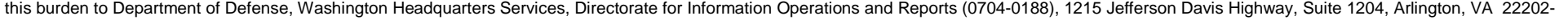

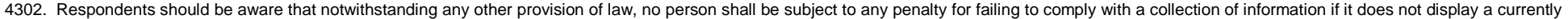
valid OMB control number. PLEASE DO NOT RETURN YOUR FORM TO THE ABOVE ADDRESS.

\begin{tabular}{l|l|l} 
1. REPORT DATE (DD-MM-YYYY) & 2. REPORT TYPE & 3. DATES COVERED (FrOm - TO)
\end{tabular}

January 2001

4. TITLE AND SUBTITLE

Final Report

Hydroacoustic Evaluation of Juvenile Salmonid Passage Through Experimental Routes at Bonneville Dam in 1998

5a. CONTRACT NUMBER

5b. GRANT NUMBER

5c. PROGRAM ELEMENT NUMBER

6. AUTHOR(S)

5d. PROJECT NUMBER

Gene R. Ploskey, William T. Nagy, Larry R. Lawrence, Deborah S. Patterson, Carl R. Schilt, Peter N. Johnson, John R. Skalski

\section{5e. TASK NUMBER}

5f. WORK UNIT NUMBER

\section{PERFORMING ORGANIZATION NAME(S) AND ADDRESS(ES)} AND ADDRESS(ES)

U.S. Army Engineer Research and Development Center

Environmental Laboratory

3909 Halls Ferry Road

Vicksburg, MS 39180-6199;

DynTel Corporation

3530 Manor Drive, Suite 4

Vicksburg, MS 39180;

\section{SPONSORING / MONITORING AGENCY NAME(S) AND ADDRESS(ES)}

AScI Corporation 1365 Beverly Road McLean, VA 22101;

University of Washington Columbia Basin Branch, School of Fisheries 1325 Fourth Avenue, Suite 1820

Seattle, WA 98101-2509
U.S. Army Engineer District, Portland

P.O. Box 2946

Portland, OR 97208-2946

8. PERFORMING ORGANIZATION REPORT NUMBER

ERDC/EL TR-01-2

10. SPONSOR/MONITOR'S ACRONYM(S)

11. SPONSOR/MONITOR'S REPORT $\operatorname{NUMBER}(\mathbf{S})$

\section{DISTRIBUTION / AVAILABILITY STATEMENT}

Approved for public release; distribution is unlimited.

\section{SUPPLEMENTARY NOTES}

\section{ABSTRACT}

This technical report describes results of studies conducted by the U.S. Army Engineer District, Portland, and the U.S. Army Engineer Research and Development Center, Vicksburg, MS, to evaluate prototype fish bypass systems at Bonneville Dam, Washington and Oregon. The bypass systems included a prototype surface collector at Powerhouse 1, an extended submersible bar screen at Turbine Unit 8 , and the ice-trash sluice chute at Powerhouse 2. The performance of each route for passing juvenile salmon was evaluated using fixed-aspect hydroacoustics. Surface passage routes proved to be highly effective in bypassing young salmon.

\section{SUBJECT TERMS}

Bonneville Dam

Fish guidance efficiency

16. SECURITY CLASSIFICATION OF:

a. REPORT

UNCLASSIFIED b. ABSTRACT UNCLASSIFIED
Fish passage efficiency

Fixed-aspect hydroacoustics
Juvenile salmon

Sluiceway passage
17. LIMITATION OF ABSTRACT
Surface collection

\begin{tabular}{|c|c|}
\hline 18. NUMBER & 19a. NAME OF RESPONSIBLE PERSON \\
\hline 108 & $\begin{array}{l}\text { 19b. TELEPHONE NUMBER (include area } \\
\text { code) }\end{array}$ \\
\hline
\end{tabular}

